\title{
A Historical Review of Portable Health Physics Instruments and Their Use in Radiation Protection Programs at Hanford, 1944 Through 1988
}
W. P. Howell
J. L. Kenoyer
C. D. Corbit
M. L. Kress
L. V. Zuerner
K. L. Swinth
D. M. Fleming
H. W. DeHaven

September 1989

Prepared for the U.S. Department of Energy under Contract DE-AC06-76RLO 1830

Pacific Northwest Laboratory Operated for the U.S. Department of Energy by Battelle Memorial Institute 


\title{
DISCLAIMER
}

This program was prepared as an account of work sponsored by an agency of the United States Government. Neither the United States Government nor any agency thereof, nor Battelle Memorial Institute, nor any or their employees, makes any warranty, expressed or implied, or assumes any legal liability or responsibility for the accuracy, completeness, or usefulness of any information, apparatus, product, or process disclosed, or represents that its use would not infringe privately owned rights. Reference herein to any specific commercial product, process, or service by trade name, trademark, manufacturer, or otherwise, does not necessarily constitute or imply its endorsement, recommendation, or favoring by the United States Government of any agency thereof, or Battelle Memorial Institute. The views and opinions of authors expressed herein do not necessarily state or reflect those of the United States Government or any agency thereof.

\section{PACIFIC NORTHWEST LABORATORY operated by \\ BATTELLE MEMORIAL INSTITUTE for the \\ UNITED STATES DEPARTMENT OF ENERGY under Contract DE-ACO6-76RLO 1830}

\author{
Printed in the United States of America
}

Available to DOE and DOE contractors from the Office of Scientific and Technical Information, P.O. Box 62, Oak Ridge, TN 37831; prices available from (615) 576-8401. FTS 626-8401.

Available to the public from the National Technical Information Service, U.S. Department of Commerce, 5285 Port Royal Rd., Springfield, VA 22161.

NTIS Price Codes, Microfiche A01

\begin{tabular}{|c|c|}
\hline \multicolumn{2}{|c|}{ Printed Copy } \\
\hline Pages & $\begin{array}{l}\text { Price } \\
\text { Codes }\end{array}$ \\
\hline$\overline{001-025}$ & $\mathrm{A02}$ \\
\hline $026-050$ & $\mathrm{~A} 03$ \\
\hline 051-075 & $\mathrm{A} 04$ \\
\hline $076-100$ & A05 \\
\hline $101-125$ & $\mathrm{~A} 06$ \\
\hline $126-150$ & $\mathrm{~A} 07$ \\
\hline $151-175$ & A08 \\
\hline $176-200$ & $\mathrm{~A} 09$ \\
\hline $201-225$ & A10 \\
\hline $226-250$ & A11 \\
\hline $251-275$ & A12 \\
\hline $276-300$ & A13 \\
\hline
\end{tabular}


A HISTORICAL REVIEW OF PORTABLE HEALTH PHYSICS INSTRUMENTS AND THEIR USE IN RADIATION PROTECTION PROGRAMS AT HANFORD, 1944 THROUGH 1988
W. P. Howel1
J. L. Kenoyer
C. D. Corbit
M. L. Kress
L. V. Zuerner
K. L. Swinth
D. H. Fleming
H. W. DeHaven

September 1989

Prepared for

the U.S. Department of Energy

under Contract DE-AC06-76RLO 1830 


\section{PREFACE}

For the past 45 years (1944-1988), portable health physics instruments have been used at Hanford to detect and measure radiation emissions from radioactive materials. These instruments are used daily by specially trained health physics technicians to make radiation surveys, which are an integral, indispensable part of every radiation control program. Such a program is designed to control the amount of interaction that workers have with radioactive material, and to prevent unmeasured releases from occurring in the work locations and to the environment.

To understand the importance of portable health physics instruments at Hanford, it is necessary to have a general idea of the elements that make up a radiation control program. The following paragraphs provide a simplified synopsis of the major elements of a radiation control program, with instrumentation explained within the context of that program.

A radiation control program is required whenever one or more radioactive materials are going to be used or generated in a Hanford facility. Once the types of radionuclides, and how they will be generated or used, have been determined, studies are conducted to establish a balanced mix of engineering and administrative safeguards. Engineering safeguards include consideration of such needs as

- shielding of radiation emissions

- remote handling of radioactive materials

- locked access doors

- glove box enclosures

- air ventilation and filtration systems

- air sampling systems

- fixed health physics instruments with alarms

- decontamination facilities

- storage of protective clothing and worker change rooms 
- office space for health physics technicians and storage for supplies.

Administrative safeguards include consideration of such needs as

- we11-defined radiation zones

- definition and procurement of the required type of health physics instruments

- documented radiation work procedures

- documented radiation survey procedures

- protective apparel and equipment supplies

- established frequencies for dosimeter exchanges, whole body counts, and bioanalysis

- health physics equipment and supplies

- the numbers of health physicists and technicians needed

- training programs on radiation control and emergency preparedness

- radiation protection records.

Radiation emissions can be detected by radiation measurement dosimeters, whole body counters, bioanalysis counters, and health physics surveillance instruments. There are four broadly defined classes of health physics surveillance instruments: 1) fixed radiation detection and measurement instruments that are most often equipped with audio and/or visual alarms to warn workers to leave the work area should dose rates or breathing air concentrations of radionuclides exceed preset levels; 2) semiportable radiation monitoring devices, such as portal monitors, that are used to check all workers before they leave a facility; 3) analytical instruments that quantify radionuclides generally or specifically, as found on air samples or collected in vacuum chambers; and 4) portable health physics instruments. All four of these classes of health physics instruments are sometimes required for a quality radiation control program. However, portable health physics instruments are always required; without such instruments, adequate control of work 
with radioactive materials cannot be maintained. Portable health physics instruments are therefore the indispensable foundation of every radiation control program at Hanford. 
$\therefore$ 


\section{SUMMARY}

This historical review covers portable health physics instruments at Hanford from an applications viewpoint. The review provides information on specific instruments and on the general kinds of facility work environments in which the instruments have been and are being used. It provides a short, modestly technical explanation of the types of nuclear radiations, the way radiation units are quantified, and the types of detection media used in portable health physics instruments. This document does not, however, cover the history of the entire Hanford program that was required to develop and/or modify the subject instruments.

The two functional types of portable health physics instruments addressed are 1) those specifically designed to monitor radioactive contamination and 2) those specifically designed to measure the exposure rates from radiation photons and neutrons and, when applicable, beta particles. Both types of instruments are used in the radiation surveillance portion of a radiation control program. Such surveys have been performed routinely over the past 45 years at Hanford with a variety of instruments.

This review describes the instruments, what they were used for, and how they were maintained and calibrated. Training programs, the impact of regulations on instrument uses, and record-keeping practices are also discussed. Technological improvements have made contemporary models lighter and easier to use. However, testimony from early Hanford technicians who used the portable health physics instruments, and readings from two earlier dose rate instruments compared with a new instrument, showed that instrument readouts were just as precise in the past as they are today. Portable health physics instruments have always been at the forefront of maintaining radiation control programs at Hanford. 


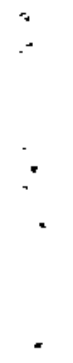




\section{ACKNOWLEDGMENTS}

The authors wish to express their appreciation to R. L. Kathren and F. E. Owen for their reviews and helpful comments; to D. K. Hilliard and P. L. Gurwell for editorial assistance; and to S. J. Ortiz, K. K. Chase, and J. D. Stephan for word processing efforts. Thanks are also extended to M. J. Haney of the Hanford Science Center for the loan of historical instruments that were used for testing and to J. C. McDonald for information on some of the radiation exposure systems. 


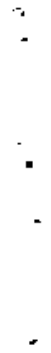

: 


\section{CONTENTS}

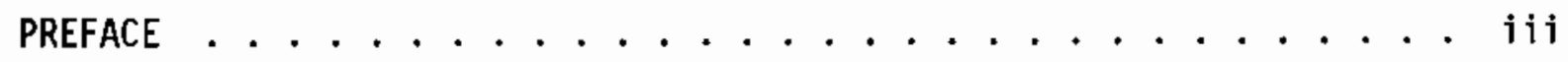

SUMMARY ................................ vi

ACKNOWLEDGMENTS ......................... ix

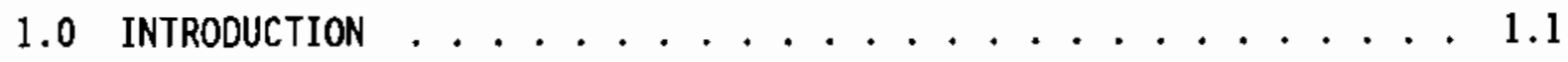

1.1 SCOPE OF DOCUMENT . . . . . . . . . . . 1.1

1.2 RADIATIONS TYPES, UNITS, AND DETECTION MEDIA . . . . . 1.2

1.2.1 Types of Nuclear Radiation . . . . . . . . 1.2

1.2.2 Quantifying Radiation Units ......... 1.3

1.2.3 Detection Media . . . . . . . . . . 1.5

1.3 HISTORY OF PORTABLE INSTRUMENTS . . . . . . . 1.7

1.3.1 Need for Instruments . . . . . . . . . 1.8

1.3.2 Types of Instruments Initially Available . . . . 1.8

1.3.3 Instrument Changes and Modifications ...... 1.9

1.3.4 Major Breakthroughs in Technology ........ . 1.9

1.3.5 Improvements in Calibrations ........ 1.10

1.3.6 National Standards on Instruments ........ 1.10

1.4 EVOLVING INSTRUMENT APPLICATIONS . . . . . . . 1.11

1.4.1 Programmatic Requirements . . . . . . . . 1.11

1.4.2 Timekeeping Practices and Dosimetry. . . . . . 1.12

1.4.3 Other Instrument Practices . . . . . . . . 1.12

1.4.4 Source Functional Tests ............. . 1.13

1.4.5 Instrument Maintenance . . . . . . . . 1.13

1.4.6 Quality Control ............... 1.14 
2.0 SUMMARY OF CONCLUSIONS . . . . . . . . . . . . . 2.1

3.0 DESCRIPTIONS OF PORTABLE INSTRUMENTS . . . . . . . . . . . 3.1

3.1 INSTRUMENTS USED AT HANFORD . . . . . . . . . . . 3.1

3.1.1 Period from 1944 through $1949 \ldots \ldots . . . . .3 .2$

3.1 .2 Period from 1950 through $1959 \ldots \ldots . . . \ldots 3.8$

3.1.3 Period from 1960 through $1969 \ldots . . . . .3 .14$

3.1.4 Period from 1970 through 1979 . . . . . . . 3.17

3.1.5 Period from 1980 through $1988 \ldots . . . . .3 .20$

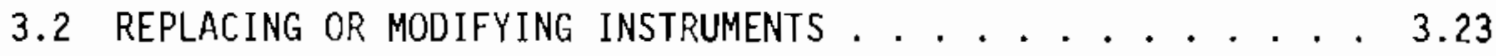

3.2.1 Procurement Control ............. 3.23

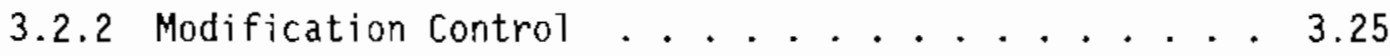

3.3 COMPARATIVE INSTRUMENT CALIBRATION RESULTS . . . . . . 3.25

4.0 INSTRUMENT APPLICATIONS . . . . . . . . . . . . . . . . 4.1

4.1 RADIATION MONITORING FIELD APPLICATIONS . . . . . . 4.1

4.1 .1 Fuers Fabrication ............. 4.1

4.1 .2 Reactor 0perations ........... . . 4.3

4.1.3 Chemical Separations ........... . . 4.4

4.1 .4 Laboratories . . . . . . . . . . 4.5

4.1 .5 Waste Management . . . . . . . . . 4.7

4.1 .6 Radioactive Shipments . . . . . . . . . 4.8

4.2 TECHNIQUES AND TRAINING . . . . . . . . . . 4.8

4.2.1 Initial Techniques ............... 4.9

4.2.2 Technique Changes and Bases......... 4.10

4.2.3 Records Generation ............ 4.11

4.2.4 Applications to Radiation Control ........ 4.11

4.2.5 Training Programs .......... 4.15 
5.0 CALIBRATION EQUIPMENT AND TECHNIQUES ............ 5.1

5.1 InItIAL EqUIPMENT AND TECHNIQUES . . . . . . . . 5.1

5.1 .1 Cal ibration Equipment .......... 5.2

5.1 .2 Calibration Practices . . . . . . . . 5.3

5.1 .3 Instrument Control . . . . . . . 5.6

5.1.4 Calibration Records . . . . . . . . . . 5.7

5.1 .5 Instrument Maintenance . . . . . . . 5.7

5.1.6 Site-Wide Delivery and Pickup . . . . . . . 5.7

5.1 .7 Calibration Frequencies . . . . . . . 5.8

5.2 SIGNIFICANT CHANGES IN THE CALIBRATION LABORATORY $\ldots \ldots .5 .8$

5.2.1 Changes in Facilities .......... 5.8

5.2.2 Changes in Equipment ........... 5.10

5.3 CURRENT EQUIPMENT AND TECHNIQUES . . . . . . . . . 5.13

5.3.1 Calibration Equipment .......... 5.15

5.3.2 Calibration Practices........... 5.19

5.3 .3 Instrument Control .......... 5.20

5.3.4 Calibration Records ............ 5.21

5.3.5 Instrument Maintenance .......... 5.21

5.3.6 Site-Wide De]ivery and Pickup .......... . 5.21

5.3.7 Calibration Frequencies . . . . . . . 5.21

6.0 PORTABLE INSTRUMENT RECORDS . . . . . . . . . . . . 6.1

6.1 CALIBRATIDN RECORDS .......................... 6.1

6.1 .1 Initial Filing System ............ 6.1

6.1 .2 Computerized Records . . . . . . . . . . 6.2

6.1.3 Initial Computer System Cancelled . . . . . 6.3

6.1 .4 Enhanced Computerization . . . . . . . . 6.3 
6.2 ISSUANCE/RECEIPT RECORDS . . . . . . . . . . 6.4

6.3 FIELD PROBLEM IDENTIFICATION/RESPONSE . . . . . . . 6.5

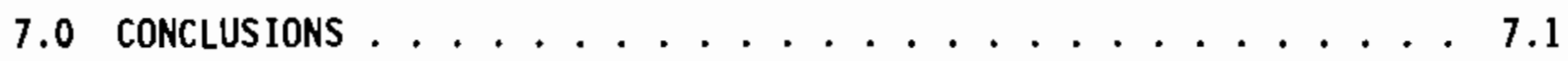

8.0 REFERENCES .................... 8.1 


\section{FIGURES}

3.1 Victoreen GM Survey Meter . . . . . . . . . . 3.3

3.2 Eltronics GM Survey Meter . . . . . . . . . . . . 3.3

3.3 Victoreen Thyac GM Survey Meter ............. . 3.4

3.4 Juno Electronics . . . . . . . . . . . . . . . . 3.6

3.5 Nuclear Chicago GM Survey Meter . . . . . . . . . . . . 3.9

3.6 Scintillation Portable Póppy . . . . . . . . . . . 3.9

3.7 Alpha Meter ............... . . 3.10

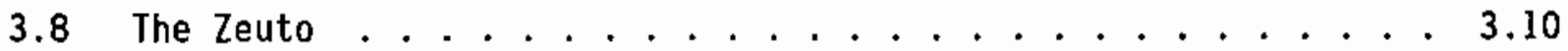

3.9 Hanford-Designed Cutie Pie . . . . . . . . . . . 3.12

3.10 Hanford-Designed Juno . . . . . . . . . . . . . 3.12

3.11 Hanford-Designed Totem Pole . . . . . . . . . . . 3.13

3.12 Hanford TPC . . . . . . . . . . . . . 3.14

3.13 Double-Moderated $\mathrm{BFQ} \ldots \ldots . \ldots . \ldots . \ldots$

3.14 Snoopy Neutron Meter . . . . . . . . . . . . . . . 3.17

3.15 Eberline PAC-6 with an Air Proportional Probe . . . . . . 3.18

3.16 Eberline R0-3B .................. . . . . . . . . . . .

3.17 Bumblebee .................... . . 3.20

3.18 Black Widow . . . . . . . . . . . . . 3.21

3.19 Victoreen Model 325 . . . . . . . . . . . . . . . . . 3.22

5.13745 Calibrations Building . . . . . . . . . . 5.2

5.2 Trolley System . . . . . . . . . . . . . . . 5.3

5.3 Sigma Pile..................... . . . 5.4

5.4 GM Calibration Jig with a Hanford GM . . . . . . . . . 5.5

5.5 Instrument Survey and Decontamination Booth in the 
5.63745 A Calibrations Building . . . . . . . . . . 5.9

5.7 Van de Graff Electrostatic Accelerator Console and Related Equipment . . . . . . . . . . . . . 5.9

5.8 Gamma Wells with Cutie Pie in Position . . . . . . . . . 5.11

5.9 Paraffin-Filled Tank with BFQ Instrument Being Calibrated . . 5.12

5.10 Picker X-Ray Machine . . . . . . . . . . . . . . 5.14

5.11318 Calibrations Building . . . . . . . . . . . 5.14

5.12 Neutron Calibrations Well in the 318 Building . . . . . . . 5.16

5.13 High-Leve1 Exposure System Control Pane1 . . . . . . . . . . 5.17

5.14 High-Level Exposure System . . . . . . . . . . . . 5.17

5.15 Low-Scatter Room in the 318 Building . . . . . . . . . 5.19

\section{$\underline{\text { TABLES }}$}

1.1 Nuclear Radiation Penetration Capabilities . . . . . . . . 1.3

3.1 Comparative Calibration Results ........... 3.26 


\subsection{INTRODUCTION}

As the need for production of special nuclear materials for defense purposes diminished and long-time Hanford workers began to retire, the decision was made to document Hanford's experience with portable health physics instruments while the resources to do so were still available. In 1989 , only a few health physics instrument specialists, radiation technicians and health physicists who worked at Hanford in the late 1940s still live in the vicinity. of these, even fewer were available to assist in developing and reviewing this document. From those few, a team was selected and the document was developed. Most of the information about the instruments and their use and maintenance was obtained from the files of people who participated in the instrument program, and from the team of authors, who have a combined Hanford experience of over 200 man-years. To the degree possible, this review is presented chronologically to relate the changes in development and in practices for use in routine Hanford operations.

\subsection{SCOPE OF DOCUMENT}

Section 2.0 of this document summarizes the conclusions made concerning Hanford's portable health physics instruments and the users over a period of 45 years. Section 3.0 describes most of the instruments used during the past 45 years and provides some insight on how they work and how changes evolved. Section 4.0 discusses 1) typical instrument operation and maintenance in various types of facilities and 2) training and requirements for control of radioactive materials. Section 5.0 focuses on calibration and maintenance of health physics instruments over the past 45 years. It also provides some comparative instrument calibration data between older and newer instruments. Section 6.0 discusses the records that are generated for portable health physics instruments. Section 7.0 provides the conclusions reached by the authors of this document, and Section 8.0 provides the references. The remainder of this section discusses the types of radiations measured, the units that quantify them and the media needed to detect or measure them with electronic instruments, and summarizes the history of portable instruments and the evolution of instrument usage. 


\subsection{RADIATIONS TYPES, UNITS, AND DETECTION MEDIA}

To understand how instruments detect radiation, it is necessary to generally understand the penetrating capabilities of nuclear radiations, the units that quantify them, and the media needed to detect or measure them with electronic instruments. This section provides simplified explanations of these factors.

\subsubsection{Types of Nuclear Radiation}

There are four common types of nuclear radiation: alpha and beta particles, gamma rays, and neutrons.

Alpha particles, composed of two protons and two neutrons, are released from an atom's nucleus during radioactive decay. Because no electrons are associated with them, they have a positive electrical charge. The heaviest of the nuclear radiations, alpha particles travel at speeds up to 7 million miles per hour. They can be stopped by an ordinary sheet of writing paper.

Beta particles are high-speed electrons ejected from an atom's nucleus when neutrons break apart to form protons and electrons. They can travel at speeds approaching 500 million miles per hour; most can be stopped by 1 in. of wood.

Gamma rays are electromagnetic waves, similar to visible light or radio waves, and can reach speeds of 670 million miles per hour. They differ from light rays only because they have more energy and because there are no substances that are realiy transparent to them. Several feet of concrete may be needed to stop energetic gamma rays. X-rays, like gamma rays, are electromagnetic waves. They are generated from atoms or by special machines and have the same penetration capabilities as gamma rays.

Neutrons, which are ejected from a nucleus, travel about 70 million miles per hour. Because of their high speed and 1ack of an electrical charge, 4 or 5 feet of concrete can be required to stop them.

Table 1.1 summarizes nuclear radiation penetration capabilities for five common materials at four or five energy levels. 
TABLE 1.1 Nuclear Radiation Penetration Capabilities

Type of

Radiation

\begin{tabular}{|c|c|c|c|c|c|c|}
\hline \multirow{2}{*}{$\begin{array}{c}\text { Type of } \\
\text { Radiation }\end{array}$} & \multirow[b]{2}{*}{ Energy } & \multicolumn{5}{|c|}{ Range in Material (a) } \\
\hline & & Air & Water & Earth & Wood & Lead \\
\hline Alpha & $\begin{array}{l}0.5 \mathrm{MeV} \\
1.0 \mathrm{MeV} \\
2.0 \mathrm{MeV} \\
4.0 \mathrm{MeV} \\
5.0 \mathrm{MeV}\end{array}$ & $\begin{array}{l}0.25 \mathrm{~cm} \\
0.50 \mathrm{~cm} \\
0.90 \mathrm{~cm} \\
2.40 \mathrm{~cm} \\
3.50 \mathrm{~cm}\end{array}$ & $\begin{array}{r}2.9 \mu \mathrm{m} \\
5.4 \mathrm{\mu m} \\
11.6 \mu \mathrm{m} \\
29.0 \mu \mathrm{m} \\
40.0 \mathrm{~mm}\end{array}$ & $\begin{array}{r}1.6 \mu \mathrm{m} \\
3.2 \mu \mathrm{m} \\
5.8 \mu \mathrm{m} \\
15.0 \mu \mathrm{m} \\
22.0 \mu \mathrm{m}\end{array}$ & $\begin{array}{r}4.5 \mathrm{\mu m} \\
9.2 \mathrm{\mu m} \\
17.0 \mathrm{~mm} \\
44.0 \mathrm{~mm} \\
65.0 \mathrm{~mm}\end{array}$ & $\begin{array}{r}1.0 \mathrm{\mu m} \\
1.3 \mathrm{~m} \\
3.6 \mathrm{~mm} \\
9.6 \mathrm{~mm} \\
14.0 \mathrm{~mm}\end{array}$ \\
\hline Beta & $\begin{array}{l}0.5 \mathrm{Mev} \\
1.0 \mathrm{MeV} \\
2.0 \mathrm{MeV} \\
4.0 \mathrm{MeV}\end{array}$ & $\begin{array}{r}155 \mathrm{~cm} \\
381 \mathrm{~cm} \\
837 \mathrm{~cm} \\
1710 \mathrm{~cm}\end{array}$ & $\begin{array}{l}.174 \mathrm{~cm} \\
.430 \mathrm{~cm} \\
.961 \mathrm{~cm} \\
2.40 \mathrm{~cm}\end{array}$ & $\begin{array}{l}.077 \mathrm{~cm} \\
.195 \mathrm{~cm} \\
.432 \mathrm{~cm} \\
.905 \mathrm{~cm}\end{array}$ & $\begin{array}{l}.174 \mathrm{~cm} \\
.430 \mathrm{~cm} \\
.961 \mathrm{~cm} \\
2.00 \mathrm{~cm}\end{array}$ & $\begin{array}{l}.029 \mathrm{~cm} \\
.068 \mathrm{~cm} \\
.139 \mathrm{~cm} \\
.259 \mathrm{~cm}\end{array}$ \\
\hline Gamma & $\begin{array}{l}0.5 \mathrm{MeV} \\
1.0 \mathrm{MeV} \\
2.0 \mathrm{MeV} \\
4.0 \mathrm{MeV} \\
5.0 \mathrm{MeV}\end{array}$ & $\begin{array}{r}89 \mathrm{~m} \\
122 \mathrm{~m} \\
174 \mathrm{~m} \\
252 \mathrm{~m} \\
282 \mathrm{~m}\end{array}$ & $\begin{array}{l}10.3 \mathrm{~cm} \\
14.1 \mathrm{~cm} \\
20.2 \mathrm{~cm} \\
29.4 \mathrm{~cm} \\
33.0 \mathrm{~cm}\end{array}$ & $\begin{array}{r}5.20 \mathrm{~cm} \\
7.15 \mathrm{~cm} \\
10.20 \mathrm{~cm} \\
14.30 \mathrm{~cm} \\
15.80 \mathrm{~cm}\end{array}$ & $\begin{array}{l}10.3 \mathrm{~cm} \\
14.1 \mathrm{~cm} \\
20.2 \mathrm{~cm} \\
29.4 \mathrm{~cm} \\
33.0 \mathrm{~cm}\end{array}$ & $\begin{array}{l}0.55 \mathrm{~cm} \\
1.25 \mathrm{~cm} \\
1.94 \mathrm{~cm} \\
2.13 \mathrm{~cm} \\
2.09 \mathrm{~cm}\end{array}$ \\
\hline Neutron & $\begin{array}{l}0.5 \mathrm{MeV} \\
1.0 \mathrm{MeV} \\
2.0 \mathrm{MeV} \\
4.0 \mathrm{MeV} \\
5.0 \mathrm{MeV}\end{array}$ & $\begin{array}{l}230 \mathrm{~m} \\
290 \mathrm{~m} \\
480 \mathrm{~m} \\
360 \mathrm{~m} \\
590 \mathrm{~m}\end{array}$ & $\begin{array}{r}5.9 \mathrm{~cm} \\
7.7 \mathrm{~cm} \\
12.0 \mathrm{~cm} \\
14.0 \mathrm{~cm} \\
25.0 \mathrm{~cm}\end{array}$ & $\begin{array}{r}6.3 \mathrm{~cm} \\
6.7 \mathrm{~cm} \\
13.0 \mathrm{~cm} \\
13.0 \mathrm{~cm} \\
17.0 \mathrm{~cm}\end{array}$ & $\begin{array}{r}6.3 \mathrm{~cm} \\
7.1 \mathrm{~cm} \\
14.0 \mathrm{~cm} \\
14.0 \mathrm{~cm} \\
20.0 \mathrm{~cm}\end{array}$ & $\begin{array}{l}5.6 \mathrm{~cm} \\
6.7 \mathrm{~cm} \\
5.0 \mathrm{~cm} \\
4.0 \mathrm{~cm} \\
6.3 \mathrm{~cm}\end{array}$ \\
\hline
\end{tabular}

Range in Materia) (a)

\footnotetext{
(a) Hughes 1958; Evans 1955; Radiological Health Handbook 1970. Gamma and neutron distances represent one median-free path.

This means that $\sim 50 \%$ of the gamma rays and neutrons are stopped by the ranges listed.
}

\subsubsection{Quantifying Radiation Units}

In order to develop a meaningful radiation surveillance program, units must be established for accurate and repeatable measurement. Furthermore, the established units must relate to acceptable levels of exposure risk. To establish acceptable levels of radiation risk, both for workers and the general population, the agencies of the United States government have used the recommendations promulgated by national and international radiation protection organizations. 
The Department of Energy (DOE) and the Nuclear Regulatory Commission (NRC) use a common set of radiation exposure units; the units most often used are the rad, the rem, and the roentgen. The relationships between these three units are discussed below.

The $\underline{\mathrm{rad}}$ is the unit of absorbed dose as measured in any exposed material and is energy dependent in human tissue. The rem is the unit of dose equivalent that relates radiation to damage in human tissue. It is the common biological denominator for particle and photon radiation. The rem is the product of absorbed dose in rads in tissue, a quality factor, and other modifying factors. (a)

The roentgen $(R)$ is the unit of exposure as measured in air. It refers only to electromagnetic radiation (i.e., gamma and x-rays). The roentgen is defined as the amount of ionization produced in a unit mass of standard air: $1 \mathrm{R} / \mathrm{h}=2.58 \times 10^{-4}$ coulombs per kilogram of air. When the radiation emissions are only photons above $200 \mathrm{keV}$, roentgens convert to rads on a onefor-one basis, and then to rems for estimation of both stochastic and nonstochastic effects.

High-level beta-gamma contamination surveys, conducted with portable health physics instruments, are measured in milliroentgen $(m R) / h$ or $R / h$. However, for low-level surveys the instruments used read out in counts per minute $(\mathrm{cpm})$. The $\mathrm{cpm}$ readings can be changed to disintegrations per minute (dpm) or disintegrations per second (dps) when the types and amounts of radionuclides and the instrument's counting efficiency in a specific counting geometry are known. Once this conversion is made, the activity in curies (Ci) can be calculated. The $\mathrm{C} i$ is a unit of radioactivity equal to $2.2 \times$ $10^{12} \mathrm{dpm}$.

(a) Based upon the amount of energy that is transferred to tissue by the radiation, quality factors have been designated. The dose equivalent, $H$, is the product of the absorbed dose (D), a quality factor (Q), and the product of other modifying factors (N). Thus, $H=D Q N$. When $D$ is expressed in rads, $\mathrm{H}$ is in rems (ICRU 1980). 
Contamination surveys are also made to ensure that people, materials, and equipment are not contaminated when they come out of, or are taken out of radiation areas. These surveys are normally read out on alpha or beta-gamma instruments that use the cpm units.

Although the International System (SI) units for radiation protection are currently replacing rem, rad, $\mathrm{Ci}$, and $\mathrm{dpm}$, the new units are not referenced in this document; only one of the Hanford instruments employs the new SI units, and the SI units are not currently in general use.

Portable health physics instruments are not chiefly used to establish worker dose in rem; however, they can serve that role in cases where the assigned personnel dosimeter is either damaged or lost. Should such an event occur, the health physics technician would take the following steps to estimate the individual's dose in rem. First, the recorded dose rate that was established for the job would be reviewed. Then, the length of time that the person worked in the radiation field would be defined. Next, the dose rate would be multiplied by the time in hours or portions thereof. Finaliy, the result would be given to the responsible health physicist to review and to evaluate the need for quality or other modifying factors before assigning the official dose estimate in rem.

\subsubsection{Detection Media}

Detection or measurement of radioactive particles or photons with portable health physics instruments takes place in a detector. The detector relies on the "energy imparted by ionizing radiation to the matter in a volume" (ICRU 1980). The idea is to measure the energy deposited by radiation in a very small volume that would be representative of human tissue. Since human tissue would not be a practical detection medium, media are selected that can be mathematically related to human tissue.

Portable health physics instruments at Hanford use one of two media (i.e., gas or scintillating materials) to detect and quantify ionizing radiation. Three major kinds of gas-medium detectors used are ionization chambers, Geiger-Mueller (GM) tubes, and proportional counters. Some of 
these instruments are used to estimate dose rates in locations having radioactive materials or radiation-generating machines, while others are read out in cpm and are used to detect and measure radioactive contamination levels.

Ionization Chambers. Historically, the need to quantify photons led to developing portable health physics instruments that used air as a medium. When photons pass through the air, they impart a charge to molecules, including both positive and negative charges within the instrument. Positively and negatively charged electrodes within an enclosed volume of air collect the ionized molecules. As the collection occurs, a small, measurable current is produced. This current is then related electronically to the radiation exposure rate in air, expressed in $\mathrm{mR} / \mathrm{h}$ to $\mathrm{R} / \mathrm{h}$.

To obtain representative exposure rate measurements, it is necessary to manufacture a chamber for the gas (air). The chamber is constructed of material thick enough to produce radiation equilibrium, but not so thick that it would stop other photons from entering the chamber. Although the ionization chambers are primarily designed for photon measurements, they can also be used to measure beta particles by using a very thin ( $\approx 0.015$ in.) "front window." By covering the thin window with a thicker movable shield, measurements can be made of photons only, or of photons plus beta particles with the shield removed. However, the use of ionization chambers for measurements smaller than $1 / 1000$ of an $R / h$ (i.e., l $\mathrm{mR} / \mathrm{h}$ ) is not generally practicable due to sensitivity limitations.

Geiger-Muller Tubes. For low-level radiation detection, another type of detector, the GM tube, is normally used. The GM instruments are pulseproducing ionization detectors that normally are designed to read out in cpm. They can be designed, however, with appropriate shielded electronic components and calibrated to read out in $\mathrm{mR} / \mathrm{h}$. At Hanford, however, all GMs read out in cpm and are used to detect and measure radioactive contamination.

Proportional Counters. A third type of portable health physics instrument, which uses gas as a medium, is the proportional counter. Proportional counters also use two electrodes and slightly pressurized gas. The chamber may either be incorporated into the instrument or be a probe attached to the instrument, similar to the approach used in the GMs. When probes are used, 
the electronic circuit is connected to the probes with cables. Ionization of the gas by the radiation produces a pulse amplified by secondary ionization that is proportional to the original ionization. The pulse is then fed into a count-rate meter that reads out in either $\mathrm{mrem} / \mathrm{h}$ or $\mathrm{cpm}$. Absorbers can be used to prevent beta particles from entering the chamber.

Neutron instruments are proportional counters that use a gas-filled tube as a detector. Since neutrons have no electrical charge and do not produce ionization of the gas directly, the tube is filled with a gas that will emit charged particles when it absorbs a neutron. Depending upon the energy (speed) of the neutrons, the probe can be placed into different levels of a hydrogenous substance (e.g., polyethylene) so that fast neutrons will be slowed by the material. The slower neutrons then can interact with the gas to produce charged particles that causes ionization. Boron-10 (in the form of boron trifluoride gas) is used to absorb slow or thermal neutrons. Alpha and lithium charged particles produced during the interaction cause the ionization of the gas. At Hanford, the neutron proportional counter used is called a Snoopy; it reads out in $\mathrm{mrem} / \mathrm{h}$.

In addition to the gas-medium instruments described above, scintillator materials are used in probes for detection of alpha particles. When hit by an alpha particle, scintillating materials emit small flashes of 1 ight. These light flashes are detected by a photomultiplier tube and the light energy is transformed into an electrical current that is then relayed to the meter read by the health physics technician. Because alpha particles cannot even penetrate the dead layer of the skin, it would not be worthwhile to attempt to calibrate alpha scintillation counters for measurements of dose rates so that they read out in mrad or mrem per hour.

\subsection{HISTORY OF PORTABLE INSTRUMENTS}

During the past 45 years, many changes to instruments have occurred: standards for portable health physics instruments have changed; breakthroughs in instrumentation technology have been made; and calibration facilities have improved. However, the need for instruments has not changed. This section summarizes the developments in instrument technology. 


\subsubsection{Need for Instruments}

The human senses cannot detect radiation. Consequently, electromechanical instruments are required to detect or measure radiation in qualitative and quantitative ways. The primary purpose of portable health physics instruments is to estimate personnel radiation exposure rates and/or quantities of radioactive contamination within work locations designated as radiation areas.

\subsubsection{Iypes of Instruments Initially Available}

The first portable instruments for measuring beta-gamma count rates that were available for use were the Victoreen GM and the Eltronics GM. In 1948, the Victoreen Thyac GM was introduced. The Thyac model was lighter in weight and used very thin-walled metal GM tubes. The Zeus, introduced in 1947, was equipped with movable a metal shield that would stop beta particles when it was closed. This feature allowed differentiation between beta and gamma radioactivity.

The first portable alpha survey instrument was the Sandy. It was similar in shape to the Zeus. In 1949, a smaller alpha detection instrument, called a Portable Poppy, was introduced. This instrument used a set of headphones to allow the health physics technicians to hear the "pop" rate of background radiation, and record the rate change while surveying an item or facility surface. A sensitivity control excluded the pops from beta radiation.

The first portable instrument used at Hanford to measure exposure (dose) rate was the Beckman. It was a bulky, heavy instrument about the size of the smallest microwave oven. It had a movable shield to differentiate between beta and gamma radiation. During the latter part of the 1940s, the Hanfordbuilt Cutie Pie (CP) was pressed into service to measure exposure (dose) rates. It could differentiate between beta and gamma radiations and measure exposure (dose) rates 2-1/2 times higher than the Beckman. 
The Hanford Juno, introduced in 1945, had two sliding shields to allow differentiation among alpha, beta, and gamma radiation. In 1949, the Espey Junos were introduced. These instruments were modified somewhat to function like the Hanford Junos.

Two portab]e neutron measurement instruments were introduced in 1948; the Boron Tri-Fluoride Probe (BFP) and the Neut. The BFP could detect slow neutrons and higher energy neutrons when a moderator was added. It was used to detect $\mathrm{cpm}$ per neutron per square centimeter per second $\left(\mathrm{cpm} / \mathrm{n} / \mathrm{cm}^{2} / \mathrm{s}\right)$. The Neut, a fast neutron instrument, also read out in $\mathrm{cpm} / \mathrm{n} / \mathrm{cm}^{2} / \mathrm{s}$.

\subsubsection{Instrument Changes and Modifications}

Advances in the field of electronics made possible many advances in portable health physics instruments. Improved switches, better batteries, tougher Mylar films for detector windows, and miniature high-voltage power supplies evolved over the ensuing years. Larger vacuum tubes gave way to low-powered, tiny vacuum tubes that in turn gave way to transistors. The number and variety of instruments increased, especially the number procured offsite. The Hanford-designed instruments were more and more frequently fabricated by vendors. Neutron instruments were improved and could be read out in $\mathrm{mrem} / \mathrm{h}$ to $\mathrm{rem} / \mathrm{h}$ values. Contamination monitoring instruments were designed so that they could be calibrated for use with several different types of detector probes.

\subsubsection{Major Breakthroughs in Technology}

The combined evolution of transistors, longer-lived batteries, and superior and smaller power supplies has, over the past 45 years, allowed much lighter instruments to be fabricated. While the measured readings provided by older instruments are essentialiy as accurate as those provided by the newer instruments, the newer instruments are easier to use and, in many cases, are both more reliable and more rugged. Thanks to improved electronics packaging and greater versatility, the health physics technician has better tools to accomplish a wider variety of tasks.

- Mylar is a registered trademark of E. I. du Pont de Nemours and Co., Inc., Wilmington, Delaware. 


\subsubsection{Improvements in Calibrations}

Major improvements in calibrations have included the design, fabrication, and use of shielded calibration wells and the use of computerized, automated control systems for the radiation sources. These improvements have increased the speed and efficiency of instrument calibration significantly and reduced technician exposure to radiation. The increase in speed is due largely to the ability to work close to the radiation source and to be able to make adjustments during the exposures. Early calibrations work required readings and adjustments to be made remotely because the dose rates close to the unshielded sources were too high for personnel. The remotely taken readings were made by the use of a small telescope. Similarly, the use of several facilities to calibrate instruments also reduced operational efficiency.

\subsubsection{National Standards on Instruments}

Initially, both the qualification of portable health physics instruments and the calibration of radioactive sources were based upon National Bureau of Standards (NBS) (a) standards. Most radioactive sources were certified by the NBS. The radiation values of the few sources not certified were qualified with an NBS-calibrated Victoreen R Meter. Thus, the calibrated instrument readings of dose rate instruments could be compared with readings recorded from the Victoreen $R$ Meter.

NBS sources were also used to calibrate contamination detection instruments. The NBS sources contained specified fractions of a curie of radioactive material. Since the number of disintegrations per second (dps) from a curie of radioactivity are the same for all radionuclides, it was easy to empirically establish the number of disintegrations per minute (dpm) for each source. Then measurements of the source taken by a GM, for example, would read out in cpm. An efficiency factor would then be determined for conversion to $\mathrm{dpm}$, and the results compared with the NBS standard.

The only national standards published on portable health physics instruments for the first 26 years were the NBS performance standards for sources

(a) Now the National Institute of Standards and Technology. 
and the " $R$ " meter. These were, in a sense, quality standards that allowed field instrument performance to be tested against known standards.

The International Electrotechnical Commission (IEC) in 1970 issued Pub1 ication 325 that covered contamination monitors (IEC 1970). In 1974, the IEC issued Publication 395 , covering $x$ and gamma radiation dose rate instruments (IEC 1974). The American National Standards Institute (ANSI) published a standard on radiation protection instrumentation test and calibration (ANSI N323) in 1978.

Currently the ANSI is preparing ANSI N42.17A, "Performance Specifications for Health Physics Instrumentation - Portable Instrumentation for Use in Normal Environmental Conditions." This document will be a comprehensive standard with regard to instrument performance testing.

\subsection{EVOLVING INSTRUMENT APPLICATIONS}

The initial operations at Hanford involved the construction and startup of a large number of new facilities; these included laboratories, fuel fabrication plants, nuclear reactors, and chemical separations facilities. During the early operations, each application of portable health physics instruments brought with it increased knowledge and competence to the health physics technicians. This section summarizes these applications.

\subsubsection{Programmatic Requirements}

Programmatic requirements drive the need for health physics portable instruments. The initial Hanford program requirements were for the production of special nuclear materials. Consequently, nuclear fuel fabrication facilities, reactors, chemical separations facilities, support facjlities, and laboratories were constructed and operated. Many of the facilities handled, generated, or processed radioactive materials. The broad spectrum of radionuclides introduced by the facilities required measurement capabilities for alpha and beta particles, neutrons, $x$ rays, and gamma rays. Furthermore, people had to be trained to make the measurements and to repair the instruments. 
As new and unique types of research or other programs arose at Hanford, special instruments or procedures to use existing instruments were developed. Some instruments, for example, had long cables between the probe or detector and the electronics so that remote readings could be taken.

\subsubsection{Timekeeping Practices and Dosimetry}

From the start of Hanford operations, personnel dosimeters have been the official method to measure the radiation exposure received by workers. However, to control the radiation exposure received, especialiy when elevated radiation dose rates are present, workers must rely on other methods, because dosimeters must be processed before the received dose can be determined.

Until the 1970s, the major method used to control the radiation dose received from high dose rates was timekeeping. Under this approach, the health physics technician would go into the high-dose-rate locations and measure the dose rates that a worker would be exposed to. Using the highest of the dose rates measured, the technician would calculate the amount of exposure that a worker would receive during a specific time period. Comparing this to allowable exposure levels, the technician would establish the maximum length of time for which a worker could remain in that area. Then, whenever a worker entered the radiation area, the technician would start a stop watch. When the specified time was up, the worker would leave the area. Because the exposure estimates were so conservative, the processed dosimeters aiways showed less radiation than had been estimated. The timekeeping method was not used as much after pocket electronic dose integrators with alarms became available in the 1970s. Nonetheless, the timekeeping method may be used occasionally to set a dose rate using portable health physics instruments.

\subsubsection{0ther Instrument Practices}

Routine surveillance is maintained in and around all facilities containing radioactive materials. Portable health physics instruments are used by technicians to check for radioactive contamination and dose rates. Facilities that do not contain radioactive materials but are close to those that do are also checked, but less frequently. For contamination control, smears with special paper or other materials are taken by the technician and counted 
loss of measurement capability. When that occurs, the instruments are returned for breakdown maintenance. During the first years of Hanford operations, instrument engineers and specialists worked together to train technicians on how to maintain portable health physics instruments. Later, the senior technicians took over training junior technicians for that work. The system for maintenance is discussed in Section 5.0.

\subsubsection{Quality Control}

The quality control factors involving a need for control of procured health physics instruments include 1) properly trained technicians, 2) functional tests of instruments prior to use, 3) precise calibrations in the laboratory, 4) quality maintenance, and 5) concise records that can be traced to each instrument. This kind of quality control system has always been in place at Hanford, although improvements in the effectiveness of the system have been made continuously. Details of this quality control system are found in Section 5.0. 
with a portable instrument. If any counts above background are found outside of a radiation area, corrective actions are immediately initiated. If such counts are found in the radiation area, they are recorded on a survey form and reported to management. Protective systems are in place to prevent loss of control in these areas.

ATl radiation areas containing radioactive materials that emit measurable dose rates are surveyed routinely with portable dose rate instruments. The results are posted on radiation signs and recorded on radiation surveys that are maintained as radiation protection records. Dose rate surveys are made before people operate or maintain equipment within the radiation areas.

Radiation exposure rates are estimated for both radiation-generating machines and radioactive materials. Unless radioactive samples that could be spilled are being used in the generating machines, contamination surveys are not needed for such machines.

Portable health physics instruments have also been designed for use in case emergency-level dose rates result from an accident. Generally, however, fixed instrumentation with alarms would be used for such postulated events.

\subsubsection{Source Functional Tests}

In addition to knowing how to use portable health physics instruments in radiation fields, Hanford health physics technicians have always had to be sure each instrument was properly working before taking surveys. Consequently, instrument check sources were designed and fabricated. The sources were placed either in or on the instrument electronic housing box (for contamination monitors) or else placed in the location where the technicians picked up their instruments before using them to make surveys (both dose rate and contamination monitors). By checking the instrument for proper functioning before making surveys, the health physics technician adds an important degree of quality control to the survey program.

\subsubsection{Instrument Maintenance}

There are two kinds of maintenance; preventive and breakdown. Most instruments undergo preventive maintenance before recalibration. However, some instruments may malfunction, be dropped and damaged, or otherwise suffer 


\subsection{SUMMARY OF CONCLUSIONS}

Since Hanford commenced operations in 1944, radioactive materials have been fabricated, irradiated, processed, handled, tested, shipped, contained, and buried. All of these programmatic actions have required the use of portable health physics instruments. These instruments have historically been carefully calibrated with radioactive sources that are traceable to the NBS-certified sources using an NBS Victoreen R Meter or other reference instruments. One group has always been responsible for procuring, controlling, and calibrating the Hanford portable health physics instruments. The people who use the instruments have always been given training on use of the instruments for contamination and dose rate monitoring of radionuclides. The people who maintain and calibrate the instruments have always been given training on how to maintain and/or calibrate the instruments.

Since 1944, there have been many significant improvements in portable health physics instruments. Modern instruments are lighter and easier to use. These improvements were made possible by technological breakthroughs involving transistors, longer-lived batteries, superior and smaller power supplies, and improved electronics packaging and probe design. When three earlier-procured instruments that were borrowed back from the Hanford Science Center were calibrated and compared against newer instruments, however, dose rate and contamination level readings from the first instruments were found to be essentially as accurate as those of today's instruments.

Calibrations facilities have also significantly improved since 1944. The improvements have increased the efficiency of calibrations operations and reduced technician exposure to ionizing radiation. Although fewer calibration sources were available for use in the early Hanford years, they too were all calibrated to NBS sources.

Portable health physics instruments have been successfully used at Hanford for 45 years in the surveillance of radioactive materials, equipment, facilities, and people. Indeed, these instruments have always been a major part of Hanford's radiation control programs. 


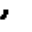




\subsection{DESCRIPTIONS OF PORTABLE INSTRUMENTS}

The generation or use of radioactive materials or the use of radiationgenerating machines mandates the use of portable health physics instruments for surveillance of radiation emissions. At Hanford, surveys of both materials and machines have historically been required. The key to good radiation surveillance is to match the type of radiation emission--either particles, neutrons, or photons--to the type of medium used to detect radiation (for example, gas or scintillating materials) and the thickness of the probe's shielding. This section identifies which instrument types are used at Hanford, and provides the bases that have been used for procurements or making changes to improve radiation surveillance.

\subsection{INSTRUMENTS USED AT HANFORD}

This section identifies the types of instruments used for initial surveillance operations in the 1940s and each of the decades thereafter. The written descriptions, pictures, and specifications are provided on a decadeby-decade basis.

It should be clearly understood that during the 45 years of experience with portable health physics instruments, there have been many technological advances. These advances have greatly reduced the weight and relative cost of the instruments, made them easier to read, increased their versatility in the field, lengthened the time of use following issuance from the calibrations/repair center, and, in some cases, reduced the instrument response time to changing radiation emission rates. However, the accuracy of both early and current instrument readings to traceable radioactive calibration sources has been shown to be essentially equal (see Section 5.3). Furthermore, discussions with health physics technicians and engineers who have worked at Hanford since the mid- to iate 1940 s revealed that early instruments had accuracies as good as those from instruments used in the mid- to late 1980s. (a)

(a) W. P. Howe 11, 3/17/88; H. W. DeHaven, 3/17/88; L. V. Zuerner, 4/15/88; and J. B. Levine, $3 / 17 / 88$. 
Hanford has historically used many different radiation detection and measuring instruments. The portable health physics instruments have generally been as functional and lightweight as the technology of the various periods allowed. Many of the instruments were box-shaped; some had the radiation detector mounted inside the case, and others had the detector mounted in a separate small case on the end of a cable attached to the main instrument case. The detector assembly at the end of the cable was usually called a "probe." Although there have been many developments in electronics over this period, the fundamental radiation detection methods have changed very little, and most of the original types of radiation detectors are still used. Most of the significant changes in portable health physics instruments have been in electronic components, with modest but significant changes in fabrication techniques and in the detector's structural materials.

\subsubsection{Period from 1944 through 1949}

The initial supply of portable instruments at Hanford was obtained either from the Metaliurgical Laboratory of the University of Chicago or from a few small electronic instrument manufacturers. Some of these manufacturers formed companies for the sole purpose of making instruments for the Manhattan Project. Those instruments were state-of-the-art for that time, but were usually bulky, heavy, and often fragile.

\subsubsection{Contamination Monitoring Instruments}

The first portable beta-gamma count-rate meters (CRMs) in regular use were the Victoreen GM (see Figure 3.1) and the Eltronics GM (see Figure 3.2). Both were large and heavy, and used glass-walled GM tubes as their detectors. The tube was enclosed in a metal case (probe) on the end of a cable attached to the main instrument case. The probe had a rotating outer shield that would admit beta radiation when open. When closed, the probe would only detect gamma radiation.

These count-rate instruments had three counting ranges, selected by a rotary switch. The units were in $\mathrm{cpm}$. The ranges were $X-1(1000 \mathrm{cpm}), x-10$ $(10,000 \mathrm{cpm})$, and $X-100(100,000 \mathrm{cpm})$. The $\mathrm{cpm}$ were displayed on a sma11 meter. The instrument controls consisted of an on-off switch and a range switch. 


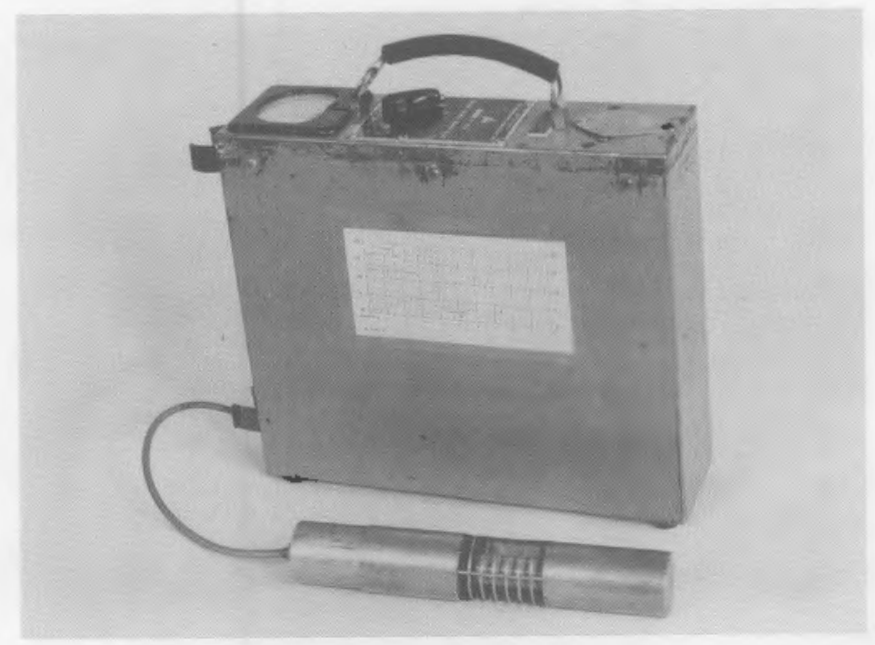

FIGURE 3.1. Victoreen GM Survey Meter

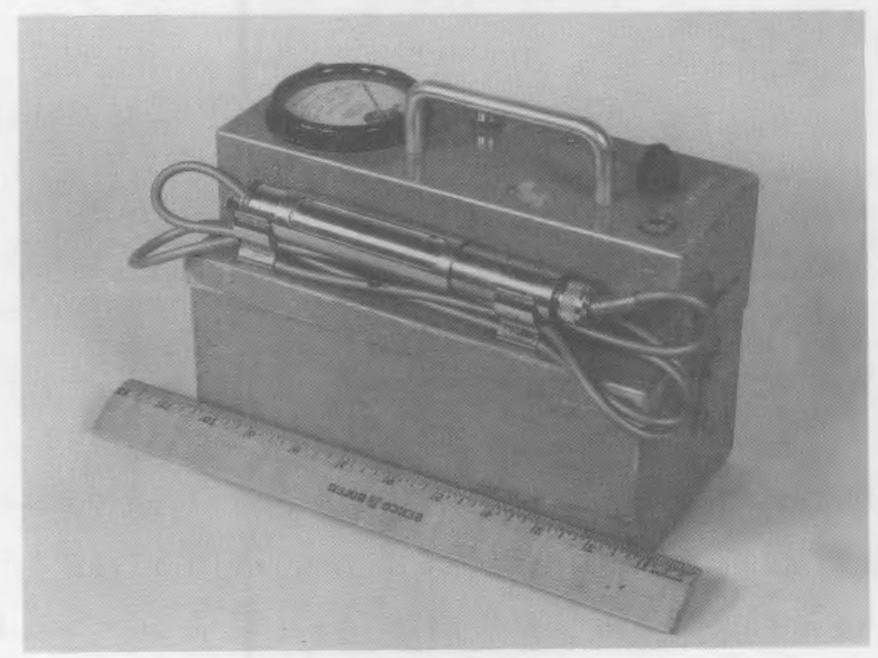

\section{FIGURE 3.2. Eltronics GM Survey Meter}

A later Victoreen GM, Model 389-C (Thyac) (see Figure 3.3), was introduced in 1948. It was much smaller and lighter in weight, but used the same probe case. It also had three ranges, but they were siightly different: $X-1$ $(800 \mathrm{cpm}), X-10(8,000 \mathrm{cpm})$, and $X-100(80,000 \mathrm{cpm}$.$) This model used a metal$ GM tube with very thin wa11s. Some Victoreen GMs were modified at Hanford; a mica-window GM tube was installed to permit detection of low-energy beta radiation. 


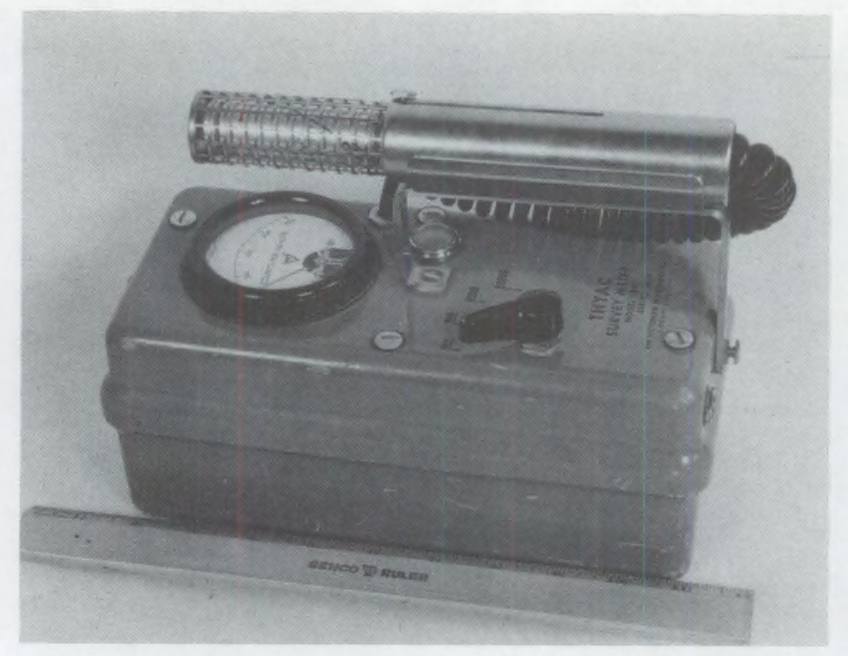

FIGURE 3.3. Victoreen Thyac GM Survey Meter

Near the middle of this period (early 1947), a higher range survey instrument called the "Zeus" was introduced. It was about the size and shape of a common shoebox, and had a small, square, and flat ion chamber on the bottom. On the detector face, there was a thin plastic window to admit beta radiation. It also had a metal shield that could slide over the window to exclude beta radiation, permitting only gamma to be detected. Although it detected gamma radiation, it was intended primarily as a sensitive beta measuring instrument. The shield was to permit determination of gamma response, so that it could be subtracted from the combined beta-gamma readings obtained when the window was open. The Zeus had controls similar to the GM instruments, but only two ranges: $X-1(50 \mathrm{mrep} / \mathrm{h})$ and $X-10(500 \mathrm{mrep} / \mathrm{h})$. [The rep was an exposure unit developed at Hanford that later became the rad (Parker 1950).]

The first portable alpha survey instrument was introduced in January 1944. Called the "Sandy," it was similar in shape to the Zeus. Like the Zeus it had a flat ion chamber on the bottom, with an open window and a fine mesh screen that would admit alpha radiation. The Sandy had three ranges: $X-1(1000 \mathrm{cpm}), X-10(10,000 \mathrm{cpm})$, and $X-100(100,000 \mathrm{cpm})$. It had an on-off switch and a three-position range switch similar to the early GM instruments. 
Near the end of this period, May 1949, a smaller alpha detection instrument was introduced. It was called the "Portable Poppy." It had a rectangular air proportional probe, with a flat face covered with very thin rubber hydrochloride, and was much more sensitive to alpha particles than the Sandy. However, it had no meter for indicating the counting rate. Instead, it used a set of headphones to detect "popping" noises. The health physics technicians 1 istened to the pop rate due to background, and noted the difference in the rate when an item or surface was being surveyed. Any increase in pop rate was attributed to the presence of alpha radiation. It had three controls: an on-off switch and two high-voltage controls, one to raise and the other to lower the voltage. These controls prevented possible response to beta radiation that might be present while maintaining correct alpha response.

\subsubsection{Exposure (Dose) Rate Monitoring Instruments}

The first portable beta-gamma exposure (dose) rate instrument was the Beckman, introduced in January 1944. It continued to be the dominant betagamma exposure (dose) rate instrument until near the end of this period. It was a bulky, heavy instrument, about $4 \times 12 \times 12 \mathrm{in.}$, and weighed about 15 pounds. It used a relatively large ( 4 in. diameter) upright cylindrical ion chamber, which was mounted in the front of the instrument. It had a thin plastic window on the front, with a rotating shield to close the window. With the window open, it would admit both beta and gamma radiation, but with the shield closed, it would admit only gamma radiation.

The Beckman had three ranges, $X-1(20 \mathrm{mR} / \mathrm{h}), X-10(200 \mathrm{mR} / \mathrm{h})$, and $X-100$ $(2 \mathrm{R} / \mathrm{h})$. Since it would detect beta radiation, it had a calibration chart attached to the case for typical fission product betas, with corresponding dose rate ranges about 2-1/2 times greater than those for gamma radiation. The instrument readings were displayed on a meter mounted in the top of the instrument. The meter scale was in $m R / h$. The instrument controls included an on-off switch, a zero control, and a range switch. The zero control was to set the meter to zero to compensate for meter drift when the instrument was in use. The instrument response time was fast and provided a stable reading. 
The first Hanford Cutie Pie (CP) instruments were designed and constructed in early 1944, but were not assigned to field service until the latter part of this period $(-1948)$. The instrument was shaped like a large pistol, with the cylindrical ion chamber in the position of the pistol barrel. Due to instrument stability problems, these instruments were not used extensively until they were modified late in this period.

The CP was much lighter than the Beckman, and the shape permitted the making of measurements closer to the source in some cases. It had a thin window on the front end of the chamber, with a plastic shield that could be moved to one side to permit beta radiation to enter the front of the chamber. The window was rubber hydrochloride, as were other thin windows mentioned earlier, but its thickness did not permit the entrance of alpha particles.

The CP had three ranges: $X-1(50 \mathrm{mR} / \mathrm{h}), X-10(500 \mathrm{mR} / \mathrm{h})$, and $X-100$ $(5 \mathrm{R} / \mathrm{h})$. A calibration chart was placed on the side of the instrument for beta particles with beta dose rate ranges about 3-1/2 times greater than those for gamma radiation. It had a small meter on the back, with an $\mathrm{mR} / \mathrm{h}$ scale. The controls were on top, similar to those on the Beckman.

The Juno, a shoebox-shaped instrument with an electronic circuit (see Figure 3.4) modeled after the one in the CP was introduced in January 1945. It had a sma11, flat ion chamber on the bottom, and a very thin rubber

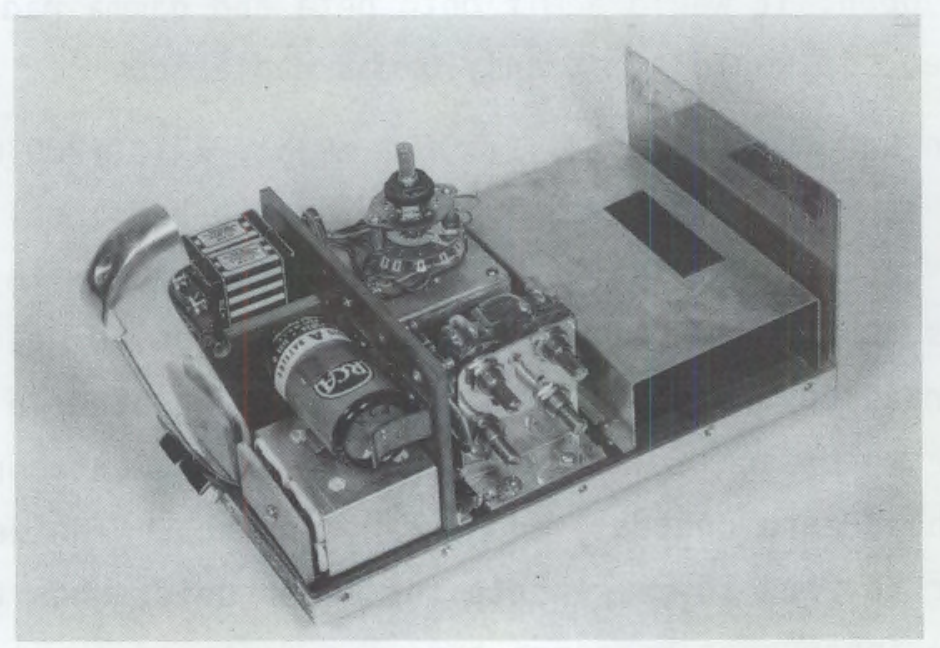

FIGURE 3.4. Juno Electronics 
hydrochloride window to permit measurement of alpha radiation. Two sliding shields could cover the window. A plastic shield stopped alpha particles, but permitted the measurement of beta and gamma radiation, and a metal shield permitted only gamma radiation to enter the chamber. The Juno had the same three ranges for gamma radiation as the $\mathrm{CP}$. It al so had calibration charts for beta and alpha radiation. On the $X-1$ range, it would measure up to $150 \mathrm{mrad} / \mathrm{h}$ of beta radiation and $50,000 \mathrm{dpm}$ of alpha. On the $\mathrm{X}-10$ range, it would measure up to $1.5 \mathrm{rad} / \mathrm{h}$ of beta and $500,000 \mathrm{dpm}$ of alpha; and on the $\mathrm{X}-100$ range, it would measure up to $15 \mathrm{rad} / \mathrm{h}$ of beta and $5 \mathrm{million} \mathrm{dpm}$ of alpha. The controls were the same as those on a CP while the meter for readout was similar. The beta reading was a calibrated surface dose rate. It was so noted on the calibration chart and by 1965 was given in mrad/h. Earlier it had been given in $\mathrm{mrep} / \mathrm{h}$.

Late in the period (1949), a number of Espey Junos were introduced. These instruments had been manufactured for civil defense purposes, and were released for use at various government facilities, including Hanford. The instruments were slightly modified to function to the same specifications as the existing Junos.

Two portable neutron instruments were introduced late in this period, the BFP instrument and the Neut. The BFP was introduced in June 1948. It used a boron trifluoride $\left(\mathrm{BF}_{3}\right)$ proportional counter detector with a paraffin moderator. It was used mainly for the detection of scattered neutrons. With the bare $\mathrm{BF}_{3}$ tube, it would detect only slow neutrons; but with the tube enclosed in the moderator, it would detect higher energy neutrons. No attempt was made to give it a dose rate calibration, but it was calibrated in terms of cpm per neutron per square centimeter per second $\left(\mathrm{cpm} / \mathrm{n} / \mathrm{cm}^{2} / \mathrm{s}\right)$. For slow neutrons, this was $1 \mathrm{cpm} / \mathrm{n} / \mathrm{cm}^{2} / \mathrm{s}$. The instrument readings could be compared with the neutron radiation tables in the National Council on Radiation Protection (NCRP) handbook on neutron radiation published by the NBS to produce approximate dose rates. The BFP had three ranges: $X-1\left(1000 \mathrm{n} / \mathrm{cm}^{2} / \mathrm{s}\right)$, $X-10\left(10,000 \mathrm{n} / \mathrm{cm}^{2} / \mathrm{s}\right)$, and $X-100\left(100,000 \mathrm{n} / \mathrm{cm}^{2} / \mathrm{s}\right)$. The instrument readings were displayed on a small meter similar to the other instruments, with the scale calibrated in $\mathrm{n} / \mathrm{cm}^{2} / \mathrm{s}$. 
The Neut, a fast neutron measuring instrument, was introduced in January 1948. It was a sma11, box-shaped instrument with two interchangeable chambers that could be mounted on the front. One chamber was filled with carbon dioxide $\left(\mathrm{CO}_{2}\right)$ gas, and would respond only to gamma radiation. The other was filled with methane gas, and would respond to both gamma and neutron radiation. The $\mathrm{CO}_{2}$ chamber was used first, and its response was cancelled, using the instrument meter together with a zero control. The $\mathrm{CO}_{2}$ chamber was then replaced with the methane chamber, and the net response was read on the meter, which was calibrated in $\mathrm{n} / \mathrm{cm}^{2} / \mathrm{s}$. The Neut had three ranges, $X-1$ $\left(160 \mathrm{n} / \mathrm{cm}^{2} / \mathrm{s}\right), X-10\left(1600 \mathrm{n} / \mathrm{cm}^{2} / \mathrm{s}\right)$, and $X-100\left(16,000 \mathrm{n} / \mathrm{cm}^{2} / \mathrm{s}\right)$. Like the BFP, the instrument readings were compared with the tables in the NCRP neutron handbook to produce approximate dose rates.

\subsubsection{Miscellaneous Instruments}

Smal1 numbers of a variety of other detection and dose rate instruments were evaluated for use at Hanford but were rejected for various reasons, including inability to perform the necessary functions, fragility, difficulty or awkwardness in use, and high cost compared with other available instruments fabricated onsite.

\subsubsection{Period from 1950 through 1959}

Many new developments in electronics occurred during the 1950 s, making possible significant advances in the portable health physics instruments. Items that contributed especially to these improvements were better switches, tiny, low-powered vacuum tubes, transistors, better batteries, tough Mylar film for detector windows, miniature high-voltage power supplies, and other related developments. This was a period of major expansion at Hanford, so the number and variety of radiation detection and measuring instruments procured also increased.

\subsubsection{Contamination Monitoring Instruments}

Three improved beta-gamma CRM instruments were introduced during this period: the Nuclear Chicago GM in June 1950, the Victoreen Model 389 CD GM in 1953, and the Hanford-designed Hanford Atomic Products Operation (HAPO) GM 
in March 1956. All were similar in size, shape, and functions, and had the same basic features as earlier GM instruments.

The Nuclear Chicago GM (see Figure 3.5) used a glass-walled GM tube, and had three ranges: $X-1(600 \mathrm{cpm}), X-10(6000 \mathrm{cpm})$, and $X-1000(60,000 \mathrm{cpm})$. Unlike the other two, it did not have provision for interchangeable probes.

The Victoreen Model 389 CD (improved Thyac) and the HAPO GM both used metal-walled GM tubes and had the same three ranges: $X-1$ (1000 cpm), X-10 $(10,000 \mathrm{cpm})$, and $X-100(100,000 \mathrm{cpm})$. They both also had a provision for interchangeable probes. A new model mica window GM tube became available and could be used with these instruments, permitting field measurements of very low energy beta radiation such as that from carbon-14.

The Scintillation Portable Poppy (SPP) (see Figure 3.6) was introduced in August 1955. It used a ZnS scintillation alpha detector coupled to a photomultiplier tube. The detector surface was rectangular, flat, and somewhat smaller than that of the original Portable Poppy, which used an air proportional alpha detector. Like the Portable Poppy, it had no meter and used earphones for detection of alpha radiation. It had only an on-off switch because of non-varying high voltage and the use of a photomultiplier tube. It was somewhat easier to use than the Poppy because it was more stable and the popping noises could be interpreted more quickly.

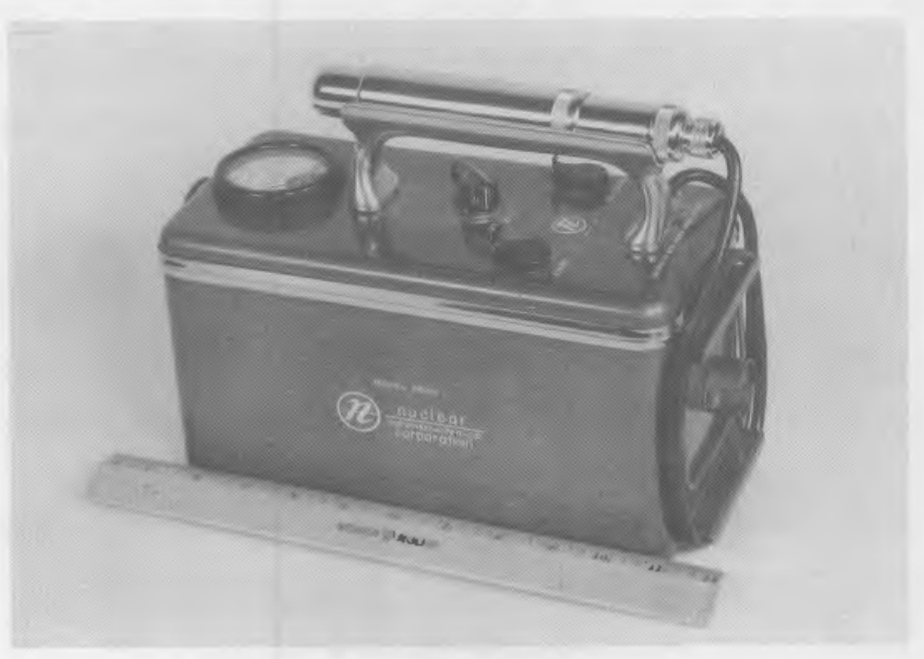

FIGURE 3.5. Nuclear Chicago GM Survey Meter 


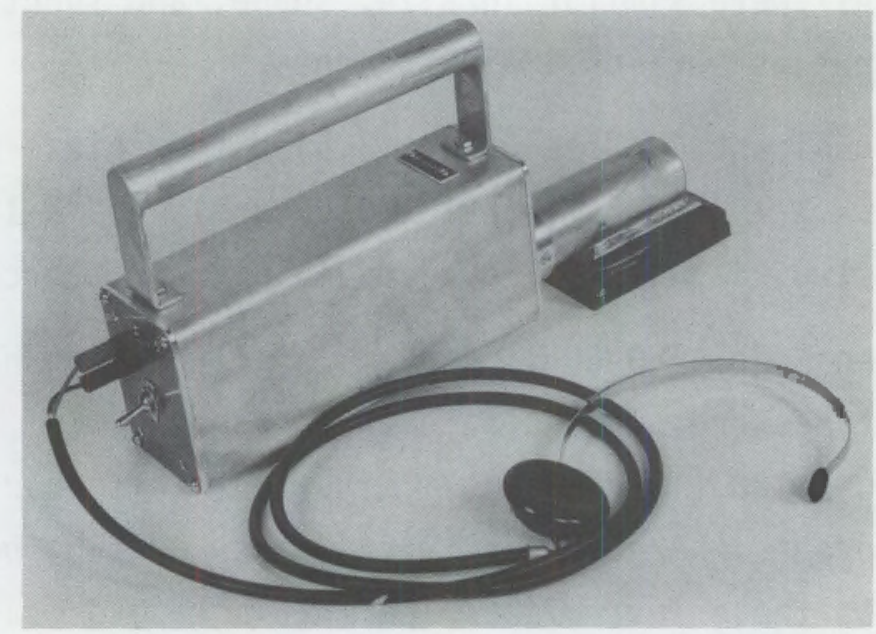

FIGURE 3.6. Scintillation Portable Poppy

Three instruments similar to the Sandy were introduced during this period. They were the Victoreen Alpha Meter, the Zeuto from the Metallurgical Laboratory of the University of Chicago, and the Nuclear Chicago Samson. All were similar shoebox-shaped instruments with a thin, flat ion chamber on the bottom. All had a thin window on the bottom (detection) side of the chamber and were designed to measure moderate levels of alpha and beta radiation.

The Alpha Meter (see Figure 3.7) and the Zeuto (see Figure 3.8) were similar instruments introduced in 1950 . Each had two ranges and was calibrated for both alpha and beta radiation on each range. On the $X-1$ range, the Alpha Meter could measure up to $5000 \mathrm{dpm}$ of alpha radiation, and $20 \mathrm{mrep} / \mathrm{h}$ of beta radiation. On the $\mathrm{X}-10 \mathrm{range}$, it could measure up to $50,000 \mathrm{dpm}$ of alpha radiation, and $200 \mathrm{mrep} / \mathrm{h}$ of beta radiation. On the $\mathrm{X}-1$ range, the Zeuto could measure up to $4000 \mathrm{dpm}$ of alpha and $10 \mathrm{mrep} / \mathrm{h}$ of beta radiation. On the $X-10$ range, it could measure up to $40,000 \mathrm{dpm}$ of alpha and $100 \mathrm{mrep} / \mathrm{h}$ of beta radiation.

The Samson was introduced in November 1955. It was somewhat more sensitive than the other two instruments, and had three ranges. It was calibrated for alpha, beta, and gamma radiations on all three ranges. On the $X-1$ range, it could measure up to $1000 \mathrm{dpm}$ of alpha, $4 \mathrm{mrad} / \mathrm{h}$ of beta, and $0.7 \mathrm{mR} / \mathrm{h}$ of 


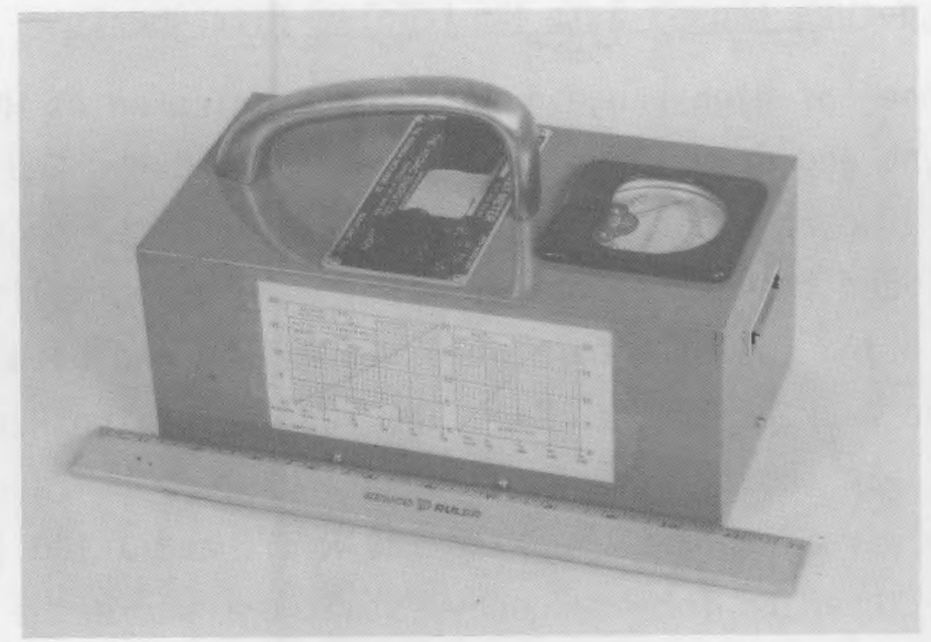

FIGURE 3.7. Alpha Meter

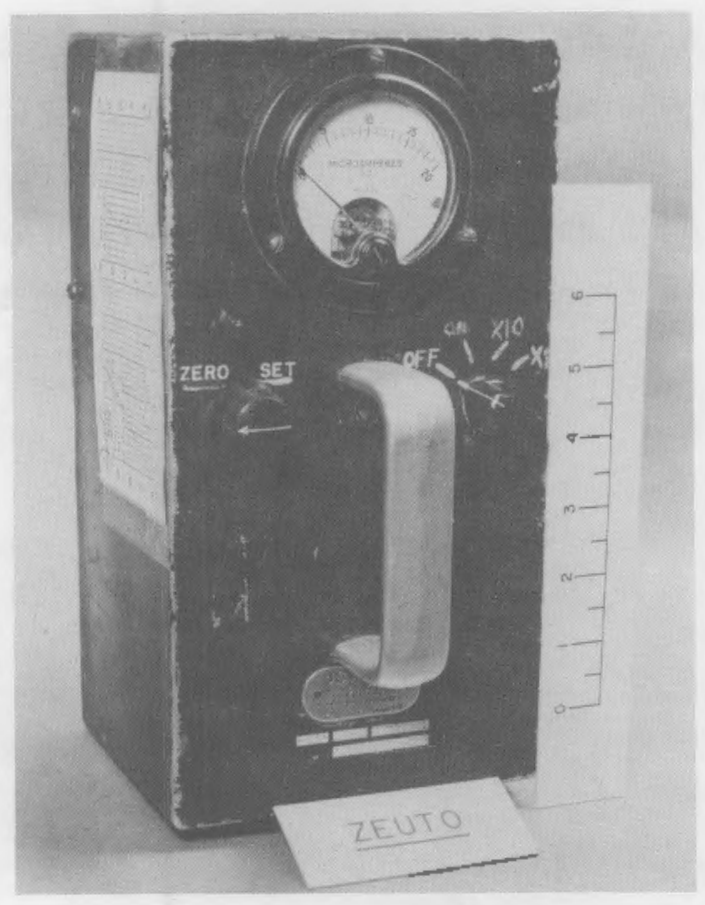

FIGURE 3.8. The Zeuto

gamma radiation. On the $X-5$ range, it could measure up to $5000 \mathrm{dpm}$ of alpha, $20 \mathrm{mrad} / \mathrm{h}$ of beta, and $3.5 \mathrm{mR} / \mathrm{h}$ of gamma radiation. On the highest range, $\mathrm{X}-25$, it could measure up to $25,000 \mathrm{dpm}$ of alpha, $100 \mathrm{mrad} / \mathrm{h}$ of beta, and $17.5 \mathrm{mR} / \mathrm{h}$ of gamma radiation. 


\subsubsection{Exposure (Dose) Rate Monitoring Instruments}

A small number of high-range Junos were fabricated at Hanford and placed in service in June and July 1950. These were called the Red Face Juno and the Yellow Face Juno according to the color of the meter face. Except for the meter faces, and the higher ranges, they were essentially identical to the other Junos using two sliding shields for alpha and beta radiations operated from the back of the handle. The ranges for the Red Face Juno were $X-1(250 \mathrm{mR} / \mathrm{h}), X-10(2.5 \mathrm{R} / \mathrm{h})$, and $X-100(25 \mathrm{R} / \mathrm{h})$. The ranges for the Yellow Face Juno were $X-1(2 \mathrm{R} / \mathrm{h}), X-10(20 \mathrm{R} / \mathrm{h})$, and $X-100(200 \mathrm{R} / \mathrm{h})$. These instruments were intended for emergency situations where the radiation levels could not be measured with the standard instruments.

Improved Hanford-designed CPs (see Figure 3.9) and Junos (see Figure 3.10) were introduced in 1954. They were substantially more rugged and stable than the earlier models, and less expensive to build. All of these were built offsite to Hanford specifications and had the same controls and ranges as earlier CPS and Junos. Some of the CPS were modified to place the chamber on an extension tube, permitting the health physics technicians to make measurements while standing a few feet away from the source of the radiation.

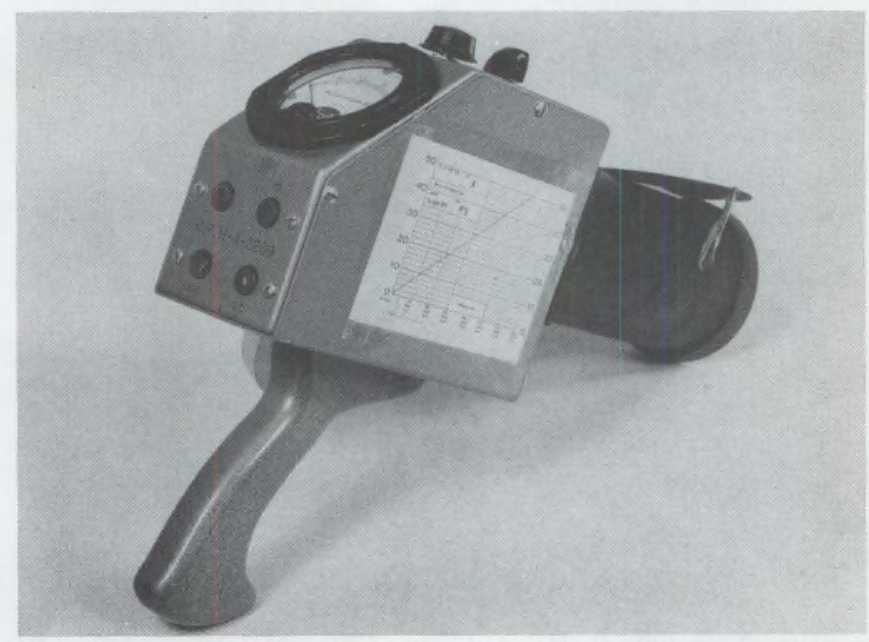

FIGURE 3.9. Hanford-Designed Cutie Pie 


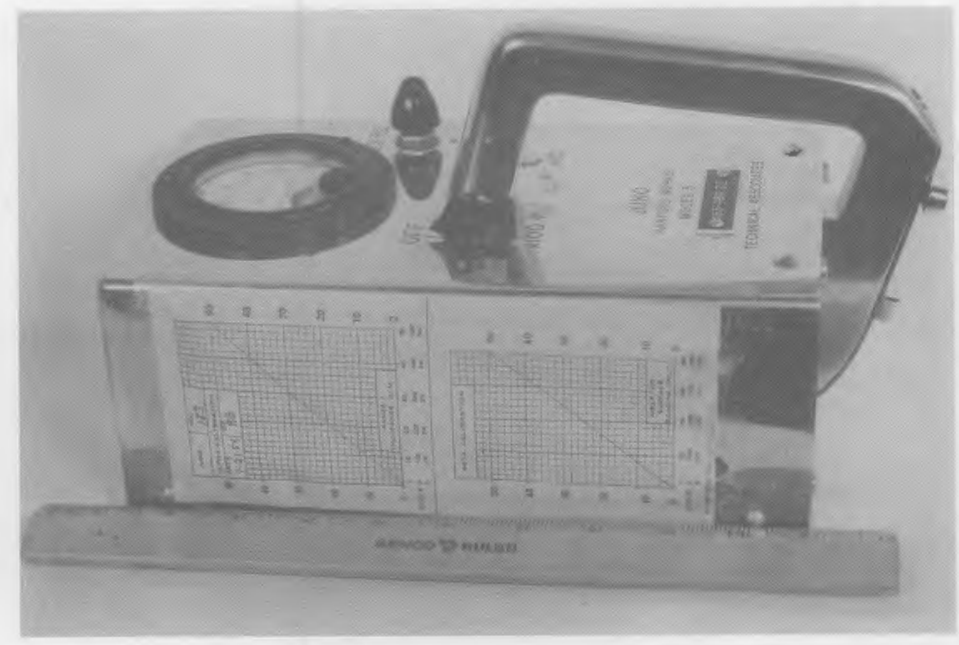

FIGURE 3.10. Hanford-Designed Juno

Another high-range ion chamber instrument was designed at Hanford and fabricated offsite. This was the "Totem Pole" (TP) (see Figure 3.11) instrument, so called because the ion chamber could be placed on an extension up to $10 \mathrm{ft}$ long in front of the instrument. There was also provision for a 50-ft-long extension cable for the probe. Though it was based upon the CP electronic circuit and had the same controls and meter, this instrument was physically quite different from the CP. The main TP electronics were enclosed in a small, nearly square metal box with a sliding cylindrical handle passing through the middle of the box from front to back. The chamber was on an extension attached to the front of the case, above the handle. The chamber was cylindrical and much smaller than the CP ion chamber. It also had thin walls all around, permitting both beta and gamma radiation to enter. Cylindrical metal and polyethylene shields, which slipped over the chamber, were provided to exclude beta radiation and permit measuring gamma radiation separately. The cylindrical extension for the chamber was about $1 \mathrm{ft}$ long and contained part of the electronics necessary to operate the small ion chamber.

Later the TP was changed to resemble the CP with the chamber attached to a standard CP case or else separated from the case by extension rod or cable. 


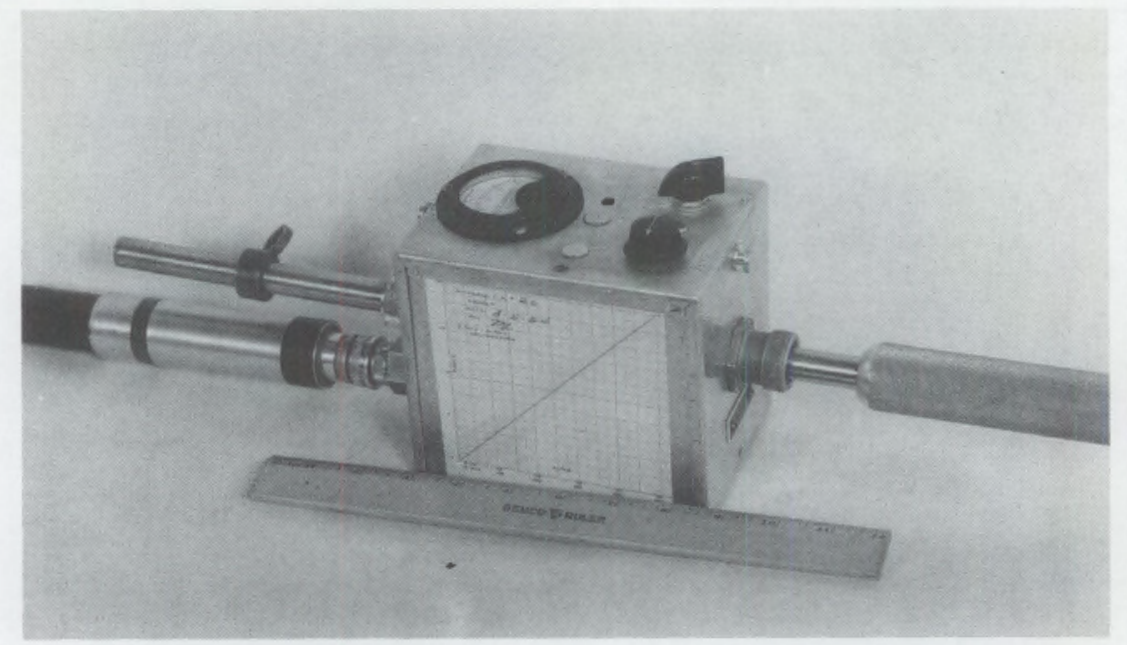

FIGURE 3.11. Hanford-Designed Totem Pole

A similar instrument was introduced with different ranges. The two instruments are physically identical, except for the ranges, and are designated the TPC (see Figure 3.12) and the LPC. The TPC ranges are $X-1(5 R / h), X-10$ $(50 \mathrm{R} / \mathrm{h})$, and $X-100(500 \mathrm{R} / \mathrm{h})$. The LPC ranges are $X-1(500 \mathrm{mR} / \mathrm{h}), X-10$ $(5 \mathrm{R} / \mathrm{h})$, and $\mathrm{X}-100(50 \mathrm{R} / \mathrm{h})$.

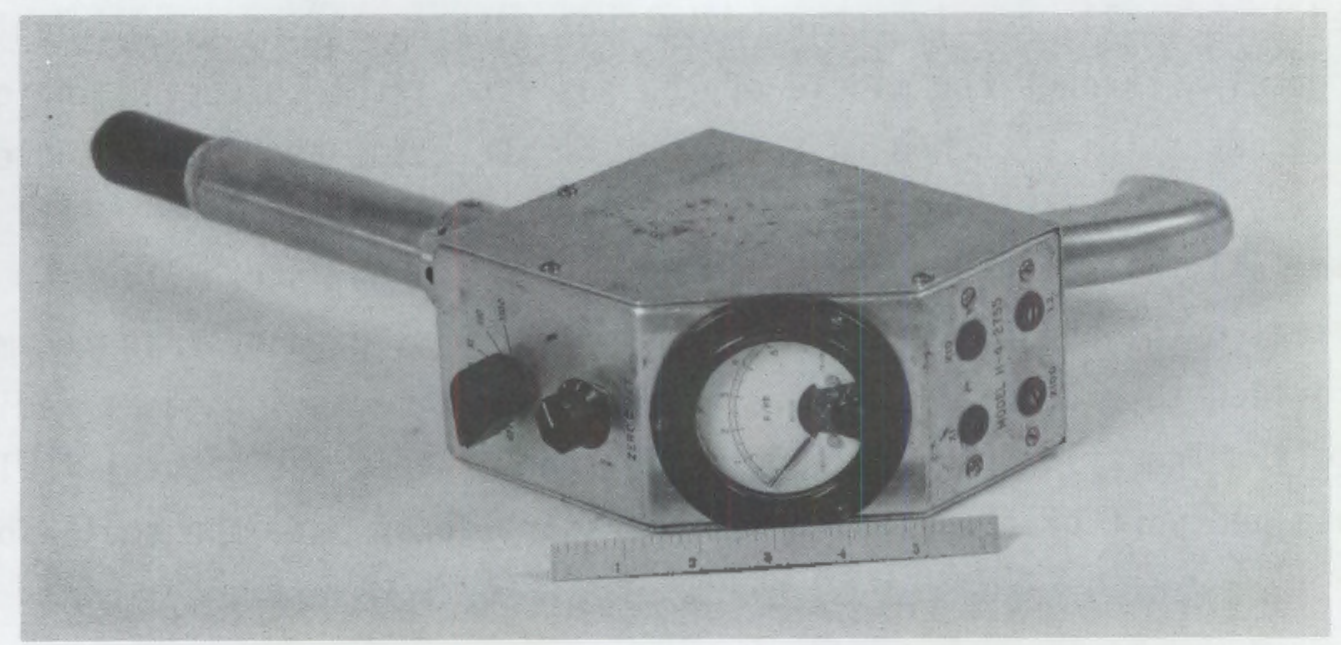

FIGURE 3.12. Hanford TPC 
A modified $\mathrm{BFP}$ with a 1 arger $\mathrm{BF}_{3}$ detector was introduced in 1958. It had a large double cylindrical moderator weighing about $30 \mathrm{lb}$, though still portable. The $\mathrm{BF}_{3}$ detector could be slipped out of the moderator assembly, permitting use of the instrument for measuring slow neutrons. With both moderator units assembled, it could be used for fast neutron measurements. With a correction factor, the ratio of the inner moderator to that of the full assembly allowed estimation of the average neutron energy. The instrument meter had two scales, one above the other. One scale was for slow neutrons, and the other for fast neutrons. The three ranges on the slow neutron scale were $X-1(0.09 \mathrm{mrem} / \mathrm{h}), X-10(0.9 \mathrm{mrem} / \mathrm{h})$, and $X-100$ $(9 \mathrm{mrem} / \mathrm{h})$. On the fast neutron scale, the ranges were $X-1(2.5 \mathrm{mrem} / \mathrm{h})$, $X-10(25 \mathrm{mrem} / \mathrm{h})$, and $X-100(250 \mathrm{mrem} / \mathrm{h})$.

\subsubsection{Instruments Removed from Service}

The following older instruments were removed from service during this period: the Sandy, Portable Poppy, Victoreen GM, Eltronics GM, Nuclear Chicago GM, Beckman, original Hanford-designed CP, Espey Juno, and the Neut.

\subsubsection{Period from 1960 through 1969}

New developments in electronics during this period made possible additional improvements in the portable instruments. Most of the technical improvements were refinements, but the ready availability of transistors and the miniaturization of the circuits led to the development of much lighterweight instruments. The weight reduction was also attributable to the much lower power demands of the new equipment, which permitted the use of smaller batteries.

\subsubsection{Contamination Monitoring Instruments}

Three new contamination monitoring instruments were introduced during this period, the Eberline E-120 CRM in October 1968, the similar Eberline E-140 CRM in mid-1969, and the Radeco 225 CRM in mid-1969. The Eberline instruments were first purchased as GMs, but were later purchased without probes. The Eberline instruments that were procured without probes and the Radeco 225 were used as alpha survey instruments, having a Hanforddesigned and fabricated scintillator probe. These portable alpha meter 
instruments (PAMs) were transistorized, and thus smaller and lighter than their older counterparts.

The Eberline E-120 is functionally almost identical to the older HAPO GM and Nuclear Chicago GM except that it is smaller and lighter. The three ranges and degree of sensitivity are the same, and they all use the same metal-walled GM tube. The Eberline instrument has two additional features, a new "battery check" position on the combined on-off-range switch and a small self-contained amplifier-speaker that can be clipped onto the side of the instrument and plugged into the earphone socket. The Eberline E-140, still in use today, is essentially an easier-to-use model of the E-120, with the same basic features and ranges.

The Radeco-225 was very similar to the Eberline E-140, except that it had four ranges and was not equipped with a speaker-amplifier. The four ranges were $X-1(1000 \mathrm{cpm}), X-10(10,000 \mathrm{cpm}), X-100(100,000 \mathrm{cpm})$, and $\mathrm{X}-1000$ (1 million cpm).

The Hanford alpha scintillator probe, used with the Eberline E-140 and the Radeco 225, employs $\mathrm{ZnS}$ as the alpha-detecting medium with a photomultiplier tube coupled to it. The 2-in. photomultiplier tube is operated at 900 volts. The detecting surface size and shape are similar to those of the SPP. The probe has an active area of $2 \times 8 \mathrm{in}$.

\subsubsection{Exposure (Dose) Rate Monitoring Instruments}

Three new exposure and dose rate monitoring instruments were introduced during this period: the HPC, a very high-range gamma instrument, in mid-1961; and two neutron instruments, the BFQ in mid-1963, and the Snoopy in August 1969. The first two were designed and built at Hanford, and the latter was purchased offsite.

The HPC is very similar to the LPC and the TPC. However, it has a thick-walled aluminum chamber and much higher ranges: $X-1(1 \mathrm{R} / \mathrm{min}), \mathrm{X}-10$ $(10 \mathrm{R} / \mathrm{min})$, and $\mathrm{X}-100(100 \mathrm{R} / \mathrm{min})$. This instrument was designed for 
disaster-type situations, where exposure rates could be exceedingly high and personnel rescue was required. To date, it has never been used for these purposes at Hanford.

The BFQ (see Figure 3.13) was essentially a transistorized version of the BFP, with some additional modifications. Its $\mathrm{BF}_{3}$ detector tube was much smaller than that of the BFP, making the instrument less sensitive. The meter box was also smaller, about half the size and weight (15 1b versus $30 \mathrm{lb})$ of the BFP, and its double moderator was less than half the weight of the one used with the BFP. Like the BFP, the BFQ had three ranges, and the meter face had a double scale, one for slow neutrons and the other for fast neutrons. The three ranges on the slow neutron scale were $X-1(2 \mathrm{mrem} / \mathrm{h})$, $X-10(20 \mathrm{mrem} / \mathrm{h})$, and $X-100(200 \mathrm{mrem} / \mathrm{h})$. On the fast neutron scale, the three ranges were $X-1(50 \mathrm{mrem} / \mathrm{h}), X-10(500 \mathrm{mrem} / \mathrm{h})$, and $X-100(5 \mathrm{rem} / \mathrm{h})$.

The Snoopy (see Figure 3.14) is a somewhat different kind of neutron instrument from the $\mathrm{BFP}$ and $\mathrm{BF}$, though it uses a small $\mathrm{BF}_{3}$ tube similar to theirs. It has a single large, heavy, cylindrical moderator, with the $\mathrm{BF}_{3}$ tube mounted inside on the central axis of the moderator, and a small metal box containing the electronics attached to one end of the moderator. Through the use of internal filters in the moderator, it is able to provide a single

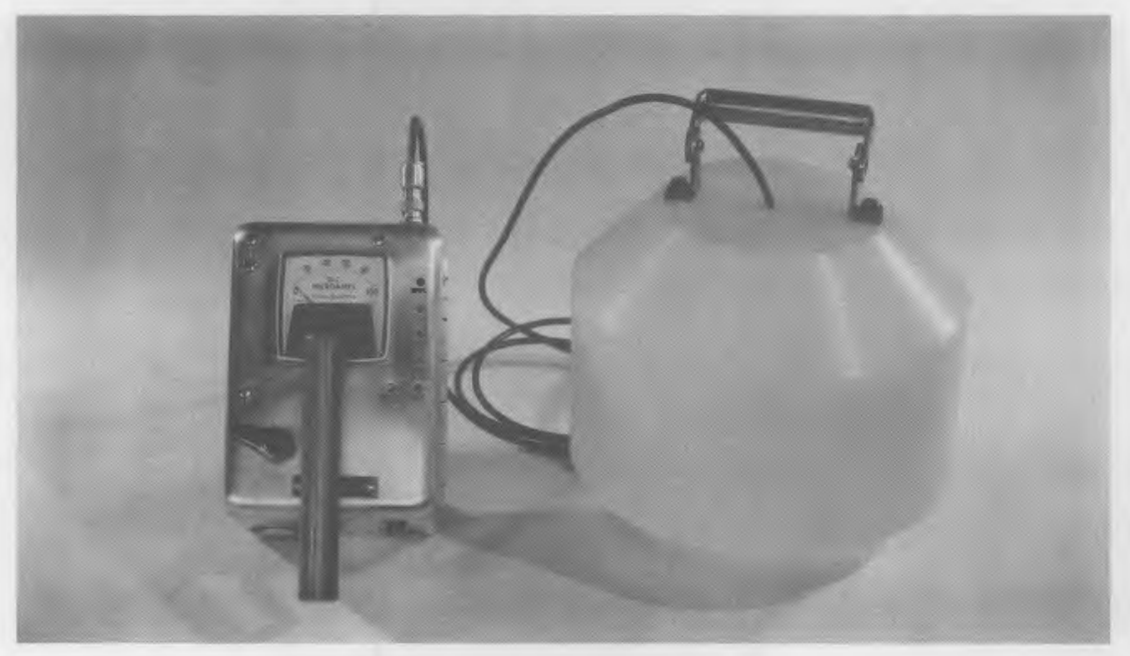

FIGURE 3.13. Double Moderated BFQ 


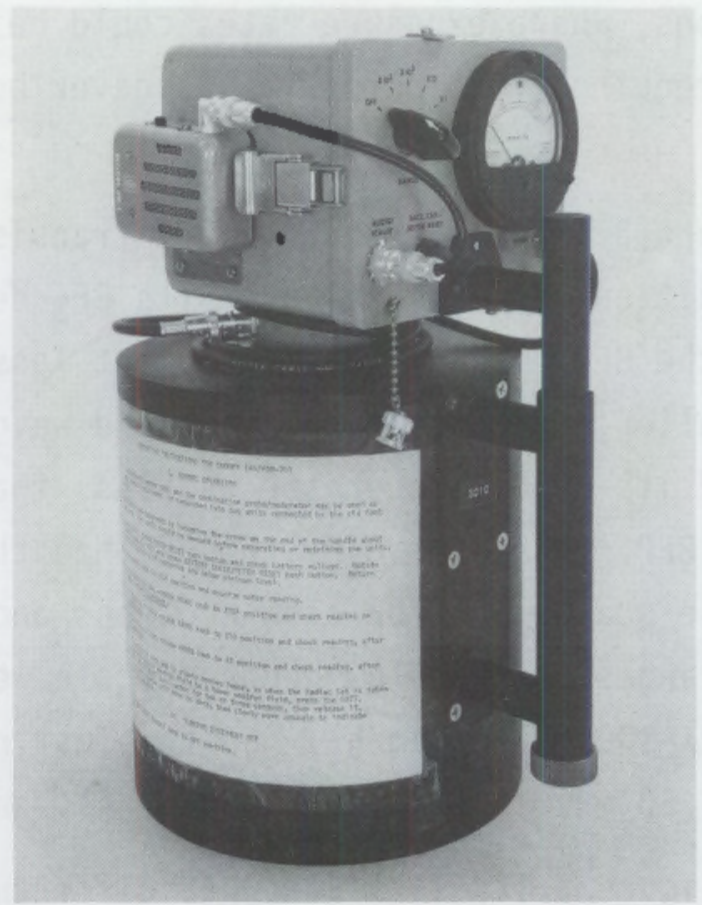

FIGURE 3.14. Snoopy Neutron Meter

composite neutron dose rate, read out directly from the meter that is installed in the upper surface of the electronics case. The Snoopy is carried horizontally by a handle mounted on the upper side of the moderator. It is $7 \mathrm{lb}$ heavier than the BFQ, and $8 \mathrm{lb}$ lighter than the BFP. Its three ranges are $X-1(2 \mathrm{mrem} / \mathrm{h}), X-10(20 \mathrm{mrem} / \mathrm{h})$, and $X-100(200 \mathrm{mrem} / \mathrm{h})$. In spite of its greater weight (22 1b), it is easier and faster to use than the $\mathrm{BFQ}$. Combining all of the equipment into a single assembly made it easier to carry, and its single composite dose rate makes it much faster to use than either the BFP or BFQ.

\subsubsection{Instruments Removed from Service}

The following older portable instruments were removed from service during this period: the Victoreen Model $389 \mathrm{CD}$ and the BFP.

\subsubsection{Period from 1970 through 1979}

Several new instruments were added during this period, some to replace older instruments, and others to extend the measurement ranges available to 
Hanford health physics personnel. These instruments contained many refinements lacking in the older instruments.

\subsubsection{Contamination Monitoring Instruments}

One new contamination monitoring instrument, the Eberline PAC- 6 , was introduced during this period in 1977. Two new GM detectors were also added in 1972.

The Eberline PAC-6 (see Figure 3.15) was designed for use with an air proportional alpha detector, similar in concept to the air proportional detector of the old SPP. However, the PAC- 6 is adaptable for use with a number of other detectors. It was purchased for use at Hanford as an alpha detector, using either a Hanford-designed scintillation probe that is very similar to the one used on the PAM, or an air proportional tube. It has a built-in speaker, as well as a meter for readout of the radiation contamination levels. It has three ranges: $X-1(1000 \mathrm{cpm}), X-10(10,000 \mathrm{cpm})$, and $X-100(100,000 \mathrm{cpm})$.

Two new GM detectors were introduced for beta contamination monitoring. One is a metal-walled cylindrical tube, similar to those previously used, but containing a halogen gas. It was intended for replacement of the older metal

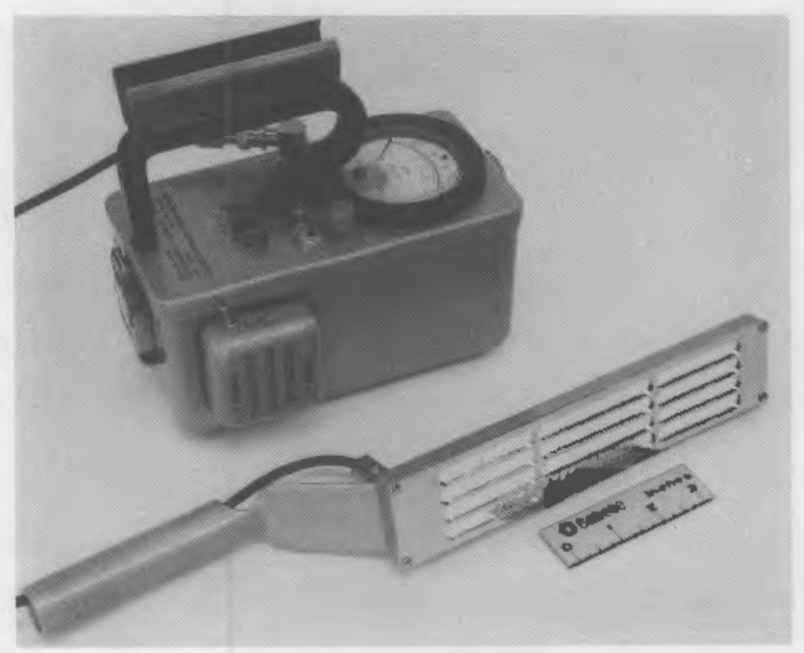

FIGURE 3.15. Eberline PAC-6 with an Air Proportional Probe 
GM tubes that would often saturate in high radiation fields, which caused the instrument meter needle to drift down-scale and produced an erroneous result. The new halogen-filled GM tube will not saturate in those circumstances, and thus the meter reading remains at full scale. The other GM tube is a short, cylindrical probe with thick metal walls and a very thin 1-3/4-in.-diameter mica window on one face. Called a pancake probe, it somewhat resembles a frying pan and has a handle on the probe. This GM probe is intended for use in detecting low-energy beta radiation, and was designed to operate at the same voltage as the cylindrical GM probe so that they could be used interchangeably on the various Hanford GM instruments.

\subsubsection{Exposure (Dose) Rate Monitoring Instruments}

Three exposure (dose) rate instruments were introduced during this period: the Eberline Teletector in 1972, the Eberline R0-3B in 1975, and a modified Eberline RO-3B (the "Bumblebee") in 1976.

The Eberline Teletector has several unique features. It uses two very small GM tubes operating in a special mode for gamma measurement, one for its high-level measurements and the other for its lower-level measurements. It also has an extendable probe, which permits moving the detectors anywhere from $20 \mathrm{in.} \mathrm{to} 13 \mathrm{ft}$ away from the main instrument. The full-scale readings of the ranges for the lower level measurements are $2 \mathrm{mR} / \mathrm{h}, 50 \mathrm{mR} / \mathrm{h}$, and $2000 \mathrm{mR} / \mathrm{h}$. Full-scale readings for the higher level measurements are $50 \mathrm{R} / \mathrm{h}$ and $1000 \mathrm{R} / \mathrm{h}$. These instruments were purchased primarily to survey for highly radioactive items of small size, such as fragments of irradiated fuel or stainless steel.

The Eberline R0-3B (see Figure 3.16) is an upgraded CP instrument. It is similar in size and shape as the earlier CPs, but slightly lighter. The ion chamber is the same diameter, but slightly shorter. It has a thin window $\left(7 \mathrm{mg} / \mathrm{cm}^{2}\right)$ and a beta shield $\left(440 \mathrm{mg} / \mathrm{cm}^{2}\right)$ identical to the other CPs. It has four ranges whose full-scale readings are $5 \mathrm{mR} / \mathrm{h}, 50 \mathrm{mR} / \mathrm{h}, 500 \mathrm{mR} / \mathrm{h}$, and $5 \mathrm{R} / \mathrm{h}$. These instruments were purchased primarily to replace the old CPs, which were becoming difficult to maintain. 


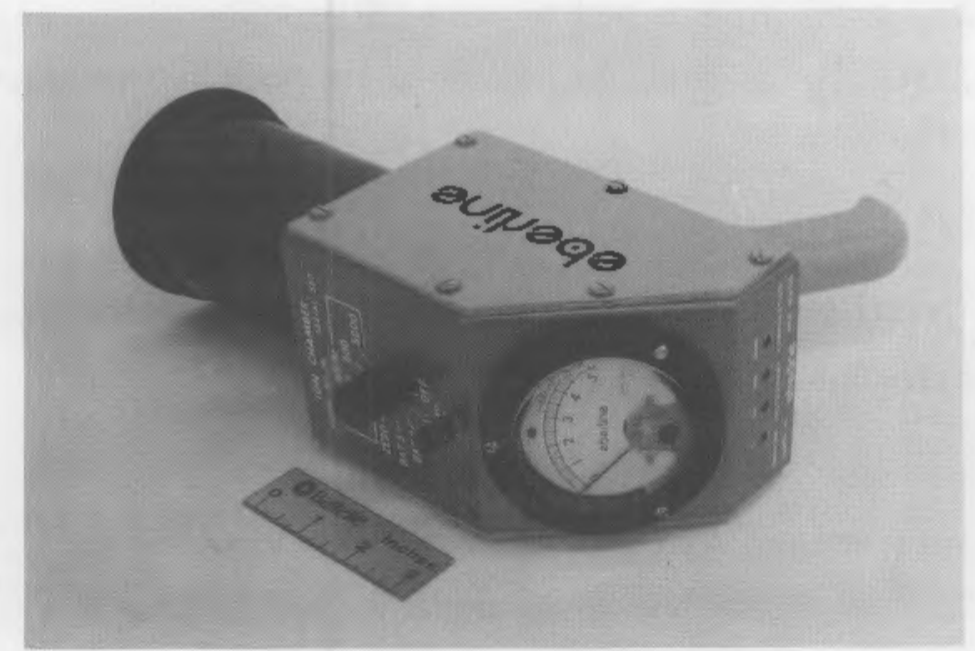

FIGURE 3.16. Eberline R0-3B

The Eberline R0-3B Bumblebee (see Figure 3.17) is exactly like the standard $\mathrm{RO}-3$, except that it has a very thin end window $\left(-2 \mathrm{mg} / \mathrm{cm}^{2}\right)$ to admit alpha radiation. It also has two shields for the window, one for alpha and the other for beta radiation. It has the same four ranges as the standard R0-3B, but is provided with calibrations for alpha, beta, and gamma radiations. The full-scale readings on the alpha ranges are $5000 \mathrm{dpm}, 50,000 \mathrm{dpm}$, $500,000 \mathrm{dpm}$, and $5 \mathrm{milli}$ ion $\mathrm{dpm}$. The full-scale readings on the beta ranges

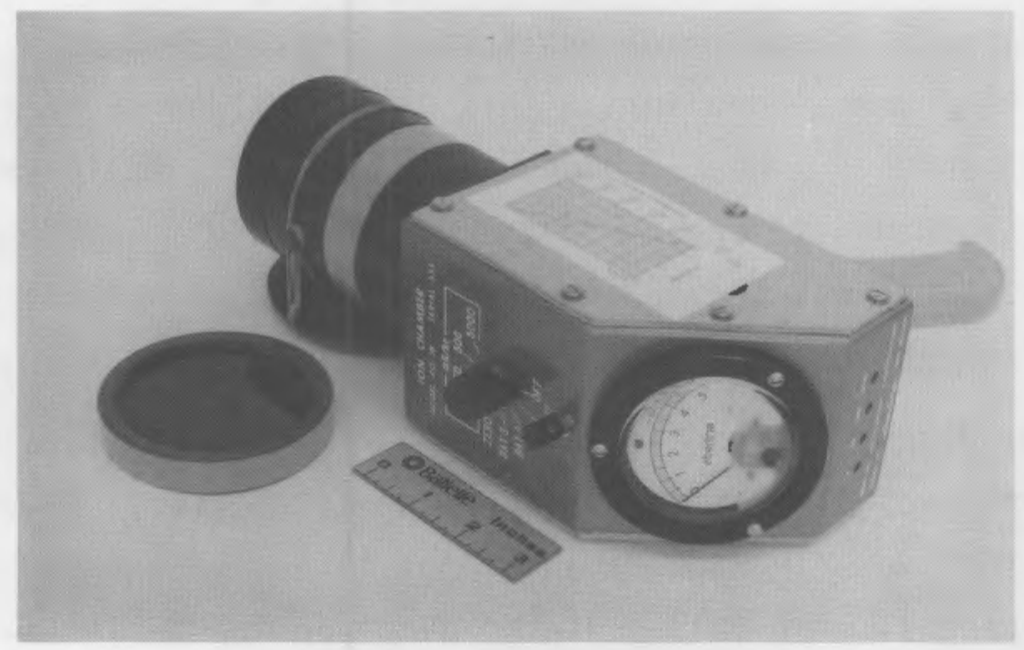

FIGURE 3.17 . Bumblebee 
are $25 \mathrm{mrad} / \mathrm{h}, 250 \mathrm{mrad} / \mathrm{h}, 2.5 \mathrm{rad} / \mathrm{h}$, and $25 \mathrm{rad} / \mathrm{h}$. These instruments were purchased to replace the old Junos, which were posing the same maintenance difficulties as the old CPs.

\subsubsection{Instruments Removed from Service}

The following older instruments were removed from service during this period: the SPP, Radeco 225, HAPO CP, and BFQ.

\subsubsection{Period from 1980 through 1988}

Three new instruments and one modified instrument were added during this period, mainly to replace older instruments. Two of the new instruments showed modest refinements over earlier instruments, but the other one contained very advanced electronics and many special features. The modified instrument provided higher dose rate measurement capabilities.

\subsubsection{Contamination Monitoring Instruments}

One new count rate meter (CRM) for contamination monitoring was introduced during this period, the Bicron "Surveyor," in 1984. It is designed to accommodate a variety of detectors, but was purchased without any. It was to be used with a Hanford-designed alpha scintillation probe. It has three ranges: $X-1(1000 \mathrm{cpm}), X-10(10,000 \mathrm{cpm})$, and $X-100(100,000 \mathrm{cpm})$.

\subsubsection{Exposure (Dose) Rate Monitoring Instruments}

Two new exposure (dose) rate monitoring instruments and a modified version of a third were added during this period. The new instruments were the Johnson "Extender," a Wm. B. Johnson high-range gamma instrument added in 1983 and 1984, and the Victoreen Model 325, developed in 1985 by Hanford personnel. The other was the "Black Widow," (see Figure 3.18) a Hanfordmodified Eberline R0-3 added in 1980.

The Wm. B. Johnson Extender, constructed in Germany, is a high-range gamma instrument very similar to the Eberline Teletector. It uses two small GM tubes, one for measuring the radiation on three low ranges, and the other for four high ranges. The full-scale readings on the three lowest ranges are $0.1 \mathrm{mR} / \mathrm{h}, 10 \mathrm{mR} / \mathrm{h}$, and $100 \mathrm{mR} / \mathrm{h}$. The full-scale readings on the four highest 


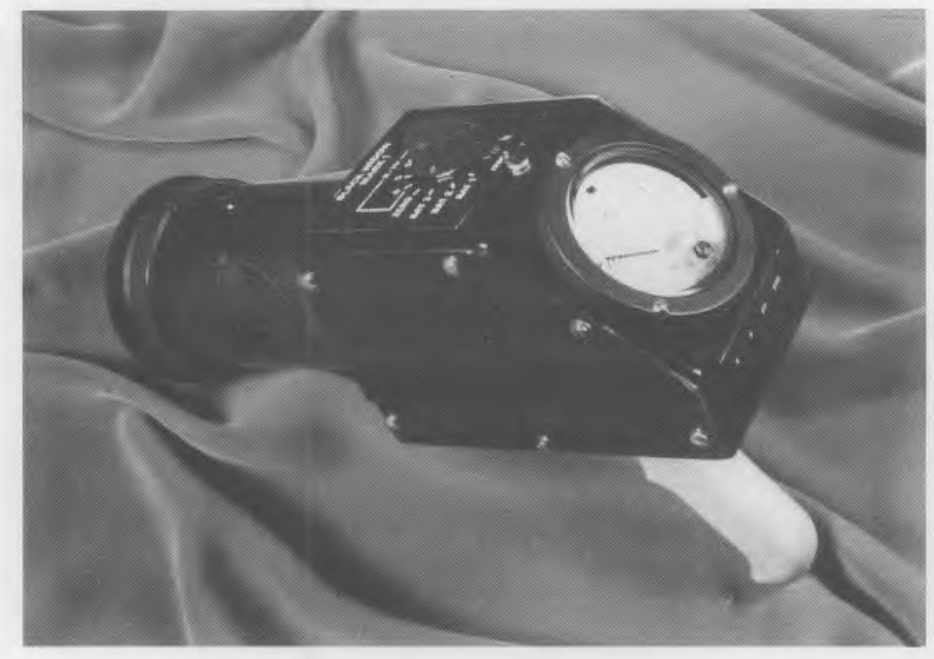

FIGURE 3.18. Black Widow

ranges are $1 \mathrm{R} / \mathrm{h}, 10 \mathrm{R} / \mathrm{h}, 100 \mathrm{R} / \mathrm{h}$, and $1000 \mathrm{R} / \mathrm{h}$. These instruments were purchased to replace similar old high-range gamma instruments.

The Victoreen Model 325 (see Figure 3.19) physically resembles the TPC class of instruments, with a CP body and a double ion chamber on an extension tube about $1 \mathrm{ft}$ long. However, it has many very advanced electronic features, including a digital liquid crystal display and a microprocessor. It has two modes of display. One mode has a series of four linear ranges that automatically change as the dose rates move above or below the range of the current scale; the other mode has a logarithmic display. The Victoreen Model 325 also has an "integrate" feature that sums and displays the accumulated dose. One unique feature, a button selector on the front of the instrument, allows the technician to select penetrating, non-penetrating, or total field dose rates. It can be provided with 1- and 2-meter extensions to permit extending the ion chamber out ahead of the main instrument body. Its five 1 inear ranges are $5 \mathrm{rem} / \mathrm{h}, 50 \mathrm{rem} / \mathrm{h}, 500 \mathrm{rem} / \mathrm{h}, 5000 \mathrm{rem} / \mathrm{h}$, and $50,000 \mathrm{rem} / \mathrm{h}$. The logarithmic scale displays dose rate ranges from 0.1 to $10,000 \mathrm{rem} / \mathrm{h}$ all on one scale. It was designed and purchased to replace the aging TPC class of instruments. 


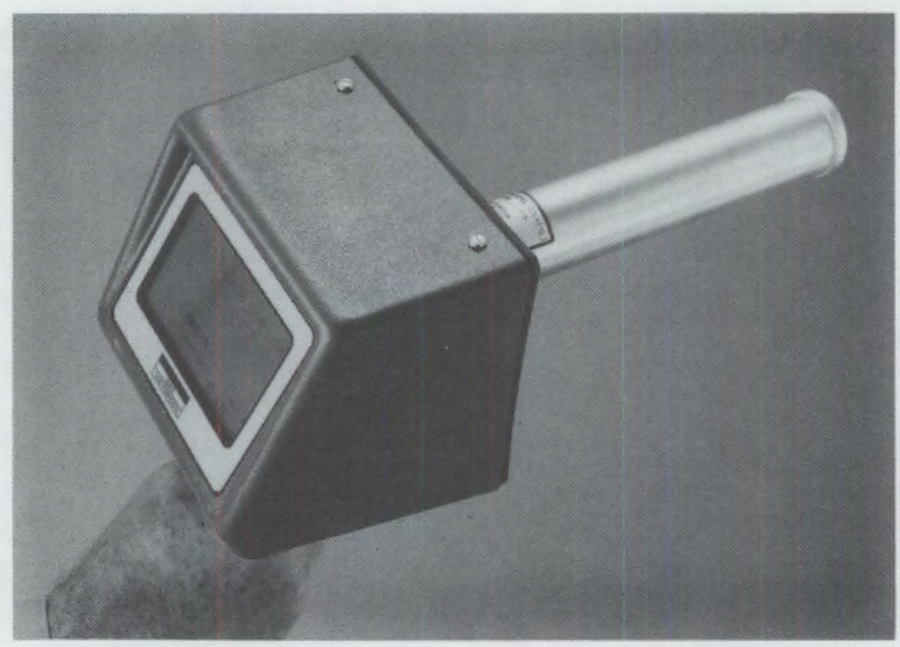

FIGURE 3.19. Victoreen Model 325

The Black Widow is a modified Eberline R0-3, similar to the Bumblebee but with higher ranges. It has four ranges and is calibrated for alpha, beta, and gamma radiation. Like the Bumblebee, it has removeable alpha and beta shields. The full-scale readings on the alpha ranges are $500,000 \mathrm{dpm}$, $5 \mathrm{million} \mathrm{dpm}, 50 \mathrm{milli}$ ion $\mathrm{dpm}$, and $500 \mathrm{million} \mathrm{dpm}$. The full-scale readings on the beta ranges are $500 \mathrm{mrad} / \mathrm{h}, 5 \mathrm{rad} / \mathrm{h}, 50 \mathrm{rad} / \mathrm{h}$, and $500 \mathrm{rad} / \mathrm{h}$. The full-scale readings on the gamma ranges are $500 \mathrm{mR} / \mathrm{h}, 5 \mathrm{R} / \mathrm{h}, 50 \mathrm{R} / \mathrm{h}$, and $500 \mathrm{R} / \mathrm{h}$. These instruments were used to replace the old high-range Junos.

\subsubsection{Instruments Removed from Service}

The following older instruments were removed from service during this period: the standard Juno, Red Face Juno, Yellow Face Juno, the two oldest Snoopys, and some LPCS, TPCS, and HPCs.

\subsection{REPLACING OR MODIFYING INSTRUMENTS}

Historically, the procurement or modification of portable health physics instruments and their accessories has been carefully maintained at Hanford. Control begins at the onset of a new idea or the identification of a need. It includes an examination of existing instrument capabilities and the possible new requirements. One or two new or changed instruments are procured or 
made and tested in the laboratory or calibration facility. If the new or changed instruments perform up to expectations, a few more instruments are procured or modified for controlled testing in Hanford facilities by the health physics technicians.

Once the new or modified instruments have completed their "field trials," procurement or change actions are initiated. Finally, tests are performed in the laboratory to ensure that the newly procured or modified instruments or accessories respond as well or better than the existing equipment. This section summarizes a few specific examples of how control has been and is exercised over procurement of new equipment and modifications to existing instruments.

\subsubsection{Procurement Control}

Perhaps the most critical control element used in procurement actions for portable health physics instruments is the development of procurement specifications. Because the use of these instruments by health physics technicians is the important factor, their operating characteristics have always been a procurement focal point. For example, in 1968 the standard portable count rate meters (without the probes) had the following operating characteristics:

\section{Characteristic}

Input Sensitivity

Battery Life

Response Time

Linearity

Temperature Dependence Operating Temperature
Specification

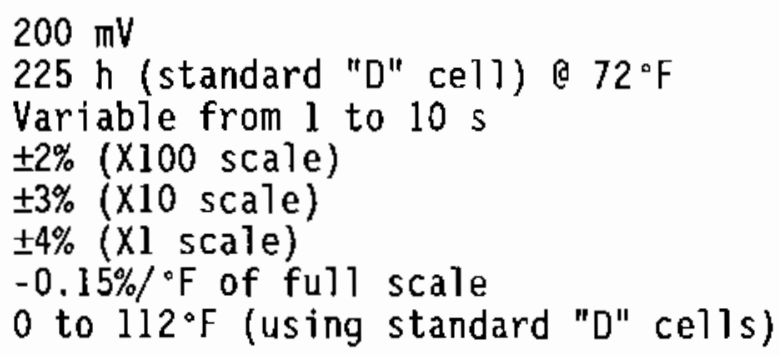

$200 \mathrm{mV}$

225 h (standard "D" cell) (a $72^{\circ} \mathrm{F}$

Variable from l to $10 \mathrm{~s}$

$\pm 2 \%(\mathrm{X} 100 \mathrm{scale})$

$\pm 3 \%$ (X10 scale)

$\pm 4 \%$ (Xl scale)

$-0.15 \% /{ }^{\circ} \mathrm{F}$ of full scale

0 to $112^{\circ} \mathrm{F}$ (using standard "D" cells)

On the other hand, if exposure (dose) rate instruments such as the $\mathrm{CP}$ are being procured, where the electronics components and the measurement chambers are all combined to one unit, the specifications have included the following: 


\section{Air Ionization Chamber}

- Chamber Wall (phenolic): 3 in. diameter $\times 511 / 16$ in. Tong $(7.62 \mathrm{~cm} \times 14.44 \mathrm{~cm})$

- Chamber Wall and Filter Thickness: $440 \mathrm{mg} / \mathrm{cm}^{2}$ (1/8 in.)

- Chamber Volume: $40.2 \mathrm{in}^{3}\left(658 \mathrm{~cm}^{3}\right)$

- Thin Window: 3 in. diameter; area $=7.16 \mathrm{in}^{2}\left(45.5 \mathrm{~cm}^{2}\right)$ Window Material: cellulose acetate, $6.2 \mathrm{mg} / \mathrm{cm}^{2}(0.002 \mathrm{in.})$

2. Useful Temperature Range: $0^{\circ} \mathrm{F}$ to $120^{\circ} \mathrm{F}$ with appropriate temperature corrections.

3. Battery Life: Approximately $300 \mathrm{~h}$ continuous operation.

4. Instrument Accuracy at Room Temperature: $+10 \%,-5 \%$; al1 ranges calibrated to radium gamma.

From issuance of the bid package, including specifications, to final acceptance testing/calibration at the Hanford Calibration Laboratory (see Section 5.0), all instrument procurements have historically been carefully controlled.

\subsubsection{Modification Control}

From time to time at Hanford, it has been necessary to modify procured instruments for special purposes or improved performance. Instrument engineers and technicians team together to make such modifications. Following completion of the modifications, the instrument would be calibrated (see Section 5.0), and, as mentioned above, field trial use initiated. All completed modifications were drawn up with a list of parts used and all the information is then documented and filed.

\subsection{COMPARATIVE INSTRUMENT CALIBRATION RESULTS}

During the development of this document, it was decided to compare three older Hanford dose rate instruments with a new Hanford dose rate instrument. It was believed that these 1 imited-scope tests would, to a reasonable degree, provide traceability of dose rate measurement precision and response times over the past 20 to 30 years. 
Three older instruments were borrowed from the Hanford Science Center. Test resuits showed that the two Hanford CPs, one from the 1950 s (routinely used for gamma surveys) and one from the 1960 s (modified for beta measurements), compared well with the new 1988 instrument used. Generally, the two older CPs averaged slightly better than the new CP in precision, were somewhat slower in response time on the 0 to $50-\mathrm{mR} / \mathrm{h}$ ranges, and had somewhat faster responses on the upper two ranges $(0$ to $500 \mathrm{mR} / \mathrm{h}$ and 0 to $5000 \mathrm{mR} / \mathrm{h}$ ). The modified Victoreen 440 (not used routinely at Hanford) was slower than all of the others on the 0 to $50 \mathrm{mR} / \mathrm{h}$ range, but the other test values were similar (see Table 3.1).

Each instrument was calibrated using the cesium-137 wells currently in operation in the 318 Building. New batteries were used in all units and measurements were taken using the same procedures for all instruments.

Precision was measured by exposing the instrument to a constant radiation field such that the mean instrument reading was near mid-scale. Readings were taken on each range. Twenty readings were obtained in each data set at 10-s intervals. The mean and standard deviation of each data set were determined, and the relative standard deviation [(SD/x)(100)] expressed in percent was calculated.

TABLE 3.1. Comparative Calibration Results

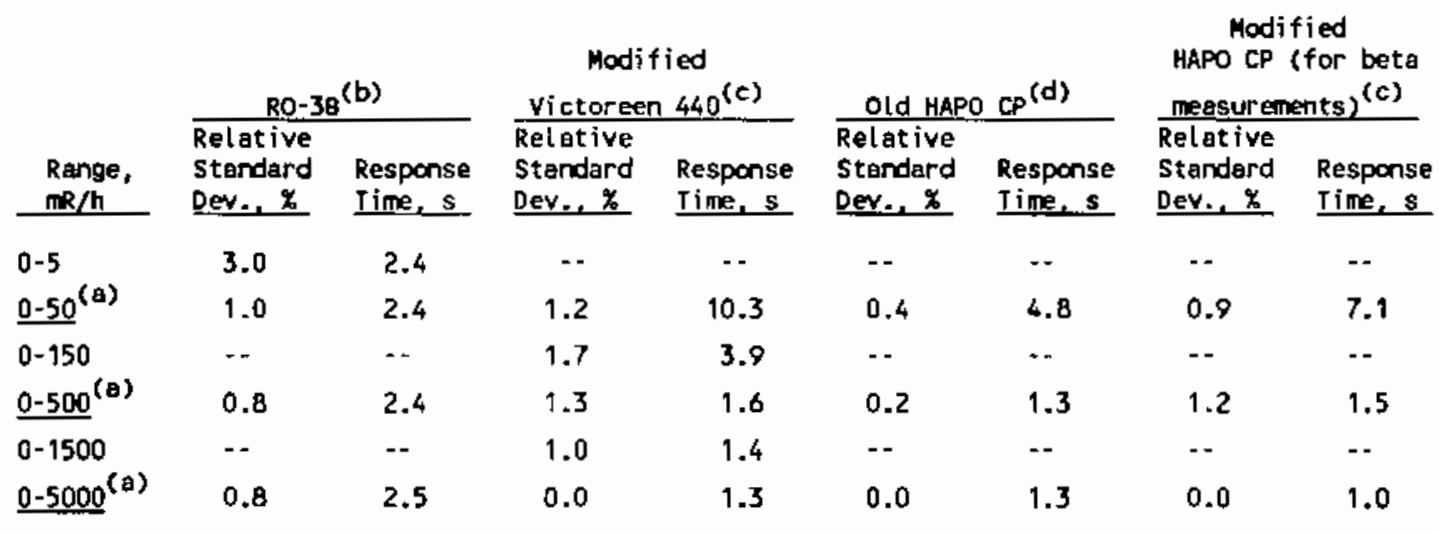

(a) Common instrument ranges available on all four instruments.

(b) Procured in 1988 .

(c) Procured in the 1960 s (not routinely used for radiation control at Hanford).

(d) Procured in the 1950 s. 
Response time for this instrument comparison is defined as the time required for the instrument reading to go from $10 \%$ to $90 \%$ of an equilibrium reading. To determine response time, the instruments were moved quickly to center the sensitive volume of the detectors over the radiation field being emitted from the calibration wells by use of a trolley mechanism. The response times were measured with a stopwatch. Data were obtained for each instrument on all scales and the equilibrium reading was chosen to be the full-scale value on each scale. Ten readings were obtained for each data set, and the mean reading is reported.

Table 3.1 shows the results of the testing. Six ranges are listed in the table; data were obtained on all the available ranges for each instrument. The RO-3B was the only instrument that had a $0-$ to $5-\mathrm{mR} / \mathrm{h}$ range. All of the instruments showed lower relative standard deviations on the highest range when compared to the lowest range. In general, the relative standard deviations decreased as the instrument was changed from the most sensitive to the least sensitive range. The response time for the R0-3B remained essentially the same on all ranges. The response times for the other three instruments were slower on ranges below 0 to $500 \mathrm{mR} / \mathrm{h}$ but were faster on ranges 0 to $500 \mathrm{mR} / \mathrm{h}$ and higher. The general trend on the three older instruments was faster response times as the ranges were changed from the most sensitive to the least sensitive range. 


\subsection{INSTRUMENT APPLICATIONS}

Because the field conditions where radiation measurements are taken differ from the conditions under which the instruments are calibrated, techniques were developed to ensure accurate field measurements. The developed techniques were based upon the identities of the radionuclides present and their characteristic emitted radiations. The radionuclide identities and radiation emissions vary among the types of operational facilities and laboratories at Hanford. After developing the field use techniques, the health physics technicians had to be trained on portable health physics instrument functions and applications and specific techniques for their use in the field. This chapter addresses the radiation monitoring field applications and the techniques and training that have typically been used at Hanford for portable health physics instruments. A general summary of the important roles played by government regulatory agencies and national and international radiation protection councils is also presented.

\subsection{RADIATION MONITORING FIELD APPLICATIONS}

To understand how portable radiation survey instruments are used in field surveillance activities, it is necessary to know some of the conditions that have existed in the operations and laboratory areas where radiation work has been performed. This section describes the general radiation measurement conditions in the various functional areas at Hanford. It begins with fuel fabrication work and ends with radioactive shipments.

\subsubsection{Fuels Fabrication}

Fuel fabrication at Hanford has involved metallic uranium that is slightly enriched in uranium-235 content for both the original production reactors and the $\mathrm{N}$ Reactor. The only remaining operating reactor, the Fast Flux Test Facility (FFTF), uses uranium oxide enriched with plutonium oxide.

The production reactor fuel emitted low levels of alpha, beta, and gamma radiation associated with uranium-238, uranium-235, and their daughter radio-

nuclides. The specific activity of the material was very low, and so was the radiotoxicity. Fabrication was carried out within controlled ventilation 
enclosures and machines, until the fuel was completely sealed within an aluminum (original reactors) or zirconium cladding (N Reactor). After that, it was handled in the open air of the fabrication area. There was some personnel exposure to both beta and gamma radiation from the bare uranium fuel material before it was enclosed within its cladding. After enclosure, the beta radiation and some of the gamma radiation was stopped by the cladding. However, personnel who handled or worked near the clad fuel were exposed to the remaining low-level gamma radiation. Portable alpha, beta, and gamma survey instruments were therefore used whenever personnel worked with this fuel.

The FFTF fuel emits the characteristic uranium and uranium daughter radiations mentioned above, and also emits the alpha, $x$-ray, and gamma radiations of plutonium-238, $-239,-240$, and -242 , and the beta radiation of plutonium-241. There are also alpha, beta, $x$-ray, and gamma radiations from the daughters of these plutonium isotopes. In addition, there is some lowlevel neutron radiation present, due to spontaneous emissions from the plutonium isotopes and interactions of the numerous alpha particles with oxygen in the fuel. Other fuel is very high in neutron emissions where, in fact, it is the predominant radiation. The specific activity of the FFTF fuel materials is much higher than that of production reactor fuel, and so is the radiotoxicity.

Fuel fabrication is carried out within totally enclosed, shielded enclosures containing inert gas atmospheres. There is no ventilation exchange between these enclosures and the atmosphere of the fabrication area. After the fuel is completely sealed within its stainless steel cladding, it is handled in the open air of the fabrication area. As was the case with the production reactor fuel, the FFTF's stainless steel fuel cladding stops much of the beta radiation, allowing most of the $x$-ray and gamma and all of the neutron radiation to pass through. Personnel who handle or work near the fuel are exposed to these low-level radiations. Portable alpha, beta, gamma, and neutron instruments are used in measuring radiation levels around the fuel and in the fabrication area. 


\subsubsection{Reactor Operations}

The radiations found in the production reactors were emitted from fissioning atoms in the fuel, and from other materials made radioactive by neutrons from the fission process. Almost all of the radiations were beta, gamma, and neutron, al though miniscule amounts of alpha radiation were present when a fuel element cladding developed a small hole in it.

During reactor operation, the reactors with their associated fuel tubes were enclosed within heavy shielding walls. A very small amount of gamma and neutron radiation leaked through the shielding, but radiation levels were normally very low in occupied areas of reactor facilities. During operation, portable gamma and neutron survey instruments were used for routine survei1lance around the reactor facilities to confirm the expected low radiation levels, and to search for unusual radiation levels that may have been due, for example, to equipment malfunctions or collection of radionuclides in valves.

When a reactor was shut down for refueling or maintenance, personnel entered the shielded areas to carry out necessary work. Radiation levels were usually low to moderate ( 2 to $100 \mathrm{mR} / \mathrm{h}$ ), with occasional localized areas of high-level radiation (200 to $1000 \mathrm{mR} / \mathrm{h}$ ). The radiations encountered were mostly gamma with some beta and, rarely, low-level alpha. There was no measurable neutron radiation when the reactor was shut down. Portable beta and gamma survey instruments were used to measure radiation fields wherever personnel were working, and to determine the radiation levels on unirradiated fuel, equipment, and tools that personnel may handle. Anything removed from the radiation control areas, including personnel, received a thorough contamination survey by the health physics technicians, who used sensitive betagamma portable instruments. Items contaminated with radioactive materials were cleaned to undetectable levels before release; if they could not be cleaned, they were kept in radioactive control areas for future use or else were packaged for disposal. Items that could have presented the possibility of measurable radiation exposure $(2 \mathrm{mR} / \mathrm{h})$ to personnel who approached or handled them were marked with warning tags that had the measured radiation 
level(s) marked on them. All materials were thoroughly surveyed with appropriate portable survey instruments.

\subsubsection{Chemical Separations}

The radiations encountered in chemical separations plants were essentially all from radioactive materials dissolved out of the irradiated fuel cladding that was processed in special facilities. Almost all of the radioactivity was from fission products. Fission product radiations were beta particles, gamma rays, and neutrons of many different energy leve1s. Some alpha radiation was also present in the uranium recovery facility because of the presence of uranium fuel that was recycled and the plutonium isotopes within the plutonium product line facilities. In the plutonium facilities, neutrons and low-energy gamma rays ( 30 to $60 \mathrm{keV}$ ) were the source of externa1 personnel exposure. Alpha particles were the source of internal exposures.

During the separation process, the head end activities were carried out remotely within very heavily shielded cells to prevent human exposure to high levels of radiation from the irradiated fuel cladding and the fission products contained therein. As in the case of the production reactors, only a small amount of gamma radiation passed through the heavily shielded facility $(<0.1 \mathrm{mR} / \mathrm{h})$. Radiation levels in occupied areas were ordinarily even lower. Portable alpha, beta, and gamma instruments were used for routine surveillance around the process areas and their associated analytical 1aboratories that contained hundreds of process samples, to ensure that radiation levels in occupied areas remained low.

Personnel very rarely entered the process cells for hands-on maintenance because of the high radiation levels. Major in situ process and maintenance activity was all carried out remotely, using specially shielded cranes equipped with a variety of tools. Because of the high radiation levels, no personnel entry was permitted to the vicinity of such work when the shielding of the process cells was open. When contact maintenance was required, the crane would be used to remove the process equipment from the cells and place the equipment on the canyon deck. Contact maintenance could then occur even though dose rates were relatively high. If cell entry was required, all 
process materials were removed and the cell was carefully cleaned and monitored. The specific protective clothing for entry to the canyon deck or cel1, and the time limits for work there were both determined from the results of radiation surveillance with portable health physics instruments.

Almost all of the residual uranium and the plutonium were extracted from the fuel. These materials were separated from each other, and the uranium was recycled for use as fuel or for other applications. The plutonium was further processed for use in weapons or advanced reactor fuels. The types of radiation around those recycling/fabrication process were essentially the same as those discussed above under fuel fabrication. However, as discussed above, neutrons, gamma rays, and alpha particles around plutonium finishing facilities were carefully monitored. Portable alpha, beta, gamma, and neutron survey instruments were used for both routine surveillance and measurement of radiation levels in areas where personnel worked with ejther uranium or plutonium materials.

The fission product residues from chemical separations were highly radioactive, and were transferred to large underground storage tanks. There were associated sampling stations and piping systems for these tanks, both of which required some operation and maintenance work by trained personnel. Samples were taken from the tanks periodically, and there were both routine and special maintenance of the sampling and piping systems. Health physics personnel performed routine surveillance of accessible areas, and measured radiation levels using portable beta and gamma survey instruments whenever personnel worked there.

\subsubsection{Laboratories}

There were three general types of laboratories at Hanford. The first type provided direct support to the various process operations; the second performed research and development for future nuclear programs; and the third performed radiation biology experiments with several species of animals. Activities in these laboratories involved essentially all of the different radionuclides found at Hanford. Radiation levels in the laboratories ranged from very low to very high. In some laboratories, much of the work was carried out within heavily shielded cells; in others, on laboratory benches. 
Work in laboratories supporting process operations most frequently involved measurement or investigation of irradiated fuels or other irradiated materials. Radiation levels were therefore often very high, and much of the work required the use of heavy shielding. It was often possible to use very small samples of the materials, reducing both the shielding requirements and the radiation levels to which personnel could have been exposed. Radiation measurements in these laboratories included both routine surveillance and measurements of radiation levels in the vicinity of personnel working there. The equipment used for these measurements includes portable alpha, beta, and gamma survey instruments.

Laboratories performing research and development for future nuclear programs worked on advanced nuclear fuels, radionuclide thermoelectric generators, radiation sources for medical applications, equipment for space applications, fundamental materials research, investigation of the properties of exotic and rare radionuclides, and many other diverse programs. Radiation levels were generaliy low to moderate ( 1 to $10 \mathrm{mR} / \mathrm{h}$ ), but some very high radiation levels were encountered. Work involving high radiation levels $(>10,000 \mathrm{R} / \mathrm{h})$ was performed behind heavy shielding. This research and development work often involved fabrication and testing of one or more full-size prototypes of the items being developed or else irradiated fuel testing. Consequently, the amounts of radioactivity involved were sometimes very large. Radiation surveillance and control activities were tailored to the specific research and development work being performed and the types and quantities of radionuclides involved. However, almost all of the available types of portable instruments were used in various aspects of this work, including alpha, beta, gamma, and neutron survey instruments.

Radiation biology research laboratories at Hanford usually worked with relatively low levels of radioactivity. Much of the biology research at Hanford involved the primarily alpha-emitting plutonium-239, so the levels of beta and gamma radiation were generally very low. The major effort usually was the control of radioactively contaminated animal wastes. Such control required meticulous procedures and very thorough surveillance. Surveillance activities included some measurements in the vicinity of personnel working in these laboratories, but the majority involved surveying for relatively low 
levels of radioactivity to ensure proper control and cleanup, as necessary. Standard beta and gamma survey instruments were used to measure personnel radiation exposure levels for this kind of surveillance and very sensitive alpha and beta-gamma detectors for facility/equipment surveys.

\subsubsection{Waste Management}

By far, the bulk of Hanford's waste management work has involved the handling and disposal of large quantities of paper, plastic, wood, clothing, liquids, and miscellaneous trash contaminated to very low levels with a variety of radionuclides. Another fairly large fraction of the work has involved the disposal of many pieces of laboratory and process equipment contaminated or activated to relatively high radiation levels. Almost all of this trash and other equipment has been buried in trenches. When appropriate, secure burial containers were provided to contain the material. Disposal of the low-level wastes involves low levels of personnel exposure. Nonetheless, each waste container was surveyed with portable instruments to determine the external radiation level. Beta and gamma instruments were used for this work. The packages of higher level wastes were usually shielded to reduce the radiation levels for personnel involved in the burial; they were ordinarily handled remotely with cranes, further reducing personnel exposures. The radiation levels to workers burying wastes and others who may have been nearby were ordinarily measured with gamma survey instruments.

The high-level liquid wastes from chemical separations processes have been stored in large underground tanks. As mentioned above, there were some personnel exposures to radiation during tank sampling and other operational and maintenance activities. In the future, it is likely that these wastes will be converted to metal-encased solid forms and transferred offsite for long-term disposal. The solidification and shipping activities will both involve some personnel exposure to radiation, and careful surveillance will be required. Considerable thought has already been given to the potential radiation exposures that are likely to be involved in high-level waste management activities. The majority of the personnel exposures will be to gamma radiation, though some of the work on solidification will also involve 
exposure to beta radiation. Therefore, both beta and gamma survey instruments will be required for this work.

\subsubsection{Radioactive Shipments}

The majority of radioactive shipments at Hanford have involved material or equipment being moved between plant areas. The shipments involving lower levels of radiation are usually made without special shielding. All shipments involving high levels of radiation have used heavily shielded containers and escort vehicles. All of these shipments were closely controlled, and close radiation surveillance was required. Surveys were made directly on the containers, at specified points on the transport vehicle, and in all locations where personnel might be exposed to measurable levels of radiation during transport. Gamma survey instruments were ordinarily used for these measurements.

Offsite shipments of radioactive materials must be performed in accordance with the regulations specified by the Department of Transportation and Department of Energy. These shipments have included highly radioactive materials such as irradiated fuel in heavily shielded containers. Personnel who approached the shipping containers closely may have been exposed to low levels of gamma radiation, but the transport vehicle drivers were ordinarily exposed to very low-level radiation fields. Radiation levels on the exterior surfaces of the containers were limited to low levels. A series of precise measurements were made on all such shipments, including the container, at specified points on the transport vehicle and at locations where personnel might be exposed during shipment. Since the shipments were heavily shielded, gamma survey instruments were used for the radiation measurements.

\subsection{TECHNIQUES AND TRAINING}

The initial radiation survey techniques used at Hanford were developed at the Metallurgical Laboratory of the University of Chicago during the early days of the Manhattan Project. Personnel assigned to Hanford attended training sessions there, and passed on that information to other early Hanford health physics personnel. Many of the early radiation survey instruments used at Hanford were also assembled at the Metallurgical Laboratory. This 
section addresses the initial techniques, changes in techniques along with their bases, records generated, radiation control applications, and training programs associated with portable health physics instruments.

\subsubsection{Initial Techniques}

Early radiation survey techniques were based upon experiences with particle accelerators, $x$-ray equipment, and sealed radium sources. Much of that experience was gleaned from the medical field, though there was some gained from industrial uses of $x$-ray, and the rest from work at universities with $x$-ray, radium, and particle accelerators. Such information was adapted for use by health physics technicians in an industrial setting, where almost all workers were completely ignorant of nuclear radiation. At that time, the only official limit for radiation exposure in the United States was the $100-\mathrm{mR} /$ day 1 imit established by the NCRP for $\mathrm{x}$-ray and gamma radiations. Health physics management at Hanford established a local 1 imit of $50 \mathrm{mR} / \mathrm{day}$. They also developed a unit for measuring beta radiation, called the "rep," with limits similar to those for gamma radiation. Very sensitive alpha and beta-gamma instruments measured radiation in cpm. Because of secrecy requirements, early health physics personnel at Hanford reported their higher-level beta and gamma measurements in "units" (actually mR/h, or $\mathrm{mrep} / \mathrm{h}$ ), with no indication of the nature of what they were measuring. The measurements of the more sensitive alpha and beta-gamma instruments were reported in $\mathrm{cpm}$, again with no indication of the relationship to the unit of radioactivity, the curie.

Early health physics personnel received the best training possible at the time, in what was admittedly a technical frontier, where much was still to be learned. They attended classes where almost everything that was known about nuclear science, radiation, and their instruments was covered. They were given thorough on-the-job instruction in performing radiation surveys under field conditions. The portable radiation survey instruments that were available to them at that time included those that measured high-level betagamma, medium-level beta-gamma, sensitive very low-level to medium-level beta-gamma, and sensitive very low-level to medium-level alpha. 


\subsubsection{Technique Changes and Bases}

The Atomic Energy Act of 1946 established the Atomic Energy Commission (AEC) and transferred almost all nuclear activities to civilian control. Although health physicists continued to depend heavily upon the NCRP and its recommendations, published in the NBS handbooks, the AEC began publishing some regulations that affected health physics activities.

In those early post-World War II years, health physics personnel and instrument development personnel pursued instrument improvements and more accurate interpretations of instrument readings. Early radiation survey instruments were very heavy and bulky, some weighing as much as $201 \mathrm{~b}$. The development of very small vacuum tubes, and later transistors, permitted major reductions in size and weight, and more convenient configurations of the instruments, making them much easier to use. Today, this would be called human factors engineering. Stability and reliability were also improved, making it possible to use instruments in the field for a longer time. Together with studies of how the instruments responded to sources of various sizes and the distances between the instrument detector and the sources, these developments provided some general improvement in the performance of radiation surveys.

The NCRP personnel dose recommendations published in 1955, with a supplement published in 1957, established new whole body limits for exposure to radiation, and limits for three other categories of tissues: skin, extremities, and all other body organs. These limits initiated a broader scope of surveys of radiation fields to which personnel could be exposed and focused efforts on improved methods of measuring exposures to the skin and localized body areas (extremities and other body organs). As would be expected, the instruments that were studied most closely were those used for measuring radiation exposures where personnel might be working. The same instruments were also used frequently in routine surveillance for radiation control purposes.

Later government regulations written by the DOE and the NRC focused on control of low-level radioactivity, especially surface contamination with various radionuclides and combinations thereof. The increased attention 
prompted examination of the very sensitive alpha and beta-gamma survey instruments to ensure that the instruments in active use were state-of-theart in both design and function.

\subsubsection{Records Generation}

The early health physics records were of two general types, those which provided for the control of radiation work activities and the movement of radioactive materials and those which recorded working conditions and the findings of routine surveillance activities.

In the former group were the Radiation Work Procedures (originally called Special Work Permits), and the Radiation Shipment Records. Health physics personnel established all of the radiation limits and radiation safety requirements on these records; the operations and maintenance personnel provided the work descriptions. The latter group of records, written by health physics personnel, included the Radiation Survey Reports and the Routine Survey Records. These records included mainly the results of instrument measurements and descriptions of conditions in the surveyed area, all provided by the health physics technicians. Portable survey instruments were used for all of that work.

The same control and surveillance records are still in use at Hanford, with slight modifications. Some of the information covered by the original system has been transferred to special forms developed later. A good example are the forms currently used to document radioactive waste burials. Still, the radiation data recorded on those forms are Iargely obtained from portable instrument measurements.

\subsubsection{Applications to Radiation Control}

The most fundamental factor in the control of personnel exposure is the establishment of radiation control zones around radioactive materials and radiation-generating machines, including the control of, entry into, and exit from those zones. Along with these factors are the three basic limiters of individual exposure: use of shielding, control of the amount of time of exposure to radiation sources, and maintenance of as much distance as practical between the radiation sources and the exposed individual. Other 
important activities that are necessary to maintain radiation control are routine surveillance of radiation conditions, direct measurement of conditions where personnel are working, continuous recording and review of accumulated radiation dose to individual radiation workers, control of the transfer of radioactive materials from one place to another, and safe disposal of radioactive wastes.

It is most important that facilities for doing radiation work provide for all of these control features. It is possible to maintain good control in a poorly designed and equipped facility, but it requires more written procedures, more administrative oversight, and more surveillance by health physics personnel. It is also most likely that there will be more total personnel exposure than in a well-designed and equipped facility.

\subsubsection{Radiation Zoning}

For adequate control, radiation zones must be enclosed within walls or barricades that do not permit casual entry. If high-level radiation is present within the zone, heavy shielding, locked access, and special restrictions on entry are usually required. Airborne radioactive material may be present, requiring special protective apparel, ventilation control, and careful surveys with sensitive radiation survey instruments when personnel or equipment leave the zone. Entries, work in the zone, and exits from the zone have strong procedural control and appropriate surveillance using portable radiation survey instruments. All of these control factors have been, and continue to be, required at Hanford.

\subsubsection{Loss of Control Investigation}

Occasionally, as a result of equipment failures, failure to follow established procedures, or inadequate attention to activity in progress, there have been cases of personnel exposures above control limits and release of radioactive materials from their designated containers. Such situations have always been investigated thoroughly to establish the cause and to apply appropriate preventive measures for the future. Some of these situations have required extensive corrective actions to restore working conditions to normal. During such restorative action, close surveillance by health physics personnel has always been required, along with many hours of use of portable 
radiation survey instruments. The data collected by the health physics technicians, and their oral and written reports, are often the major input for these investigations.

\subsubsection{As Low As Reasonably Achievable Radiation Exposures}

The principle of "as low as reasonably achievable" (ALARA) is very old. It was first published in the 1955 recommendations of the NCRP, which instructed the reader to perform his work without taking unnecessary radiation exposure. In the early 1960s, the slogan ALAP (as low as practicable) was developed. In the late $1960 \mathrm{~s}$, this slogan was modified to ALARA. The principle remains sound, and is especially important in view of the rather wide acceptance of the linear theory of biological effects of radiation on humans. However, it can carry a large economic penalty when carried to the de minimus level of no human radiation exposure. It is generally accepted that at very low levels of radiation exposure, potential risks to personnel are very low, but not necessarily zero.

Hanford limits personnel exposure to radiation through management leadership, strong control programs, and close surveillance of radiation work conditions. The latter activity has required rigorous use of many highquality portable instruments, and sophisticated surveillance techniques.

\subsubsection{Changes in Regulations}

Early government radiation control regulations provided general administrative guidelines, but contained almost no technical information. The supporting technical data were found in the handbooks of the International Commission on Radiation Protection (ICRP) and the NCRP (originally published in NBS handbooks). After the establishment of the Federal Radiation Council (FRC), there was a trend toward writing more of the technical bases and numerical control limits into the regulations of various government agencies. Following the separation of the AEC into the NRC and the Energy Research and Development Agency (ERDA), which is now the DOE, both agencies continued the process of incorporating more technical data on radiation and numerical control limits into their regulations. When the Environmental Protection Agency (EPA) was established, the functions of the old FRC were transferred to this agency, and it began to incorporate technical data on radiation and 
numerical control guidelines into its regulations. All of the government agencies with responsibilities for control of personnel and environmental exposures to radiation have continued the process of making their radiation protection regulations more detailed, and have become more administratively active in seeing that the requirements are met. This has resulted in a significant increase in workload for government contractors and other regulated organizations, principally in increased reporting on their radiation control programs. There has been some increase in actual radiation measurements, but the major effect has been a substantial increase in analytical documentation, principally periodic reports on radiation exposures and exposure levels.

\subsubsection{Trend}

Two factors have contributed about equally to a downward trend in accumulated exposures for the employees of government contractors, including those at Hanford. One is improved technology, and the other is the ALARA program.

Improved technology has permitted more accurate assessment of personnel exposures, which has significantly reduced overestimates of the radiation doses received by radiation workers in the earlier years. Technology improvements have also allowed many specific tasks to be accomplished with lower personnel exposures, often greatly improving work efficiency. The overall effect of these improvements is large, and frequently underestimated.

The ALARA program has contributed to lowering personnel exposures at Hanford in two ways, first by constantly reminding personnel to avoid unnecessary exposure, and second by ensuring that new facilities were engineered and constructed with the maintenance of low personnel exposures in mind. This has made the newer Hanford facilities significantly more costly, but has resulted in great savings in personnel exposure as they are fully utilized. Because of the objective of lower individual exposures, radiation surveillance continues to be as vigilant as ever, and the use of portable instruments in the surveillance programs remains high. 


\subsubsection{Training Programs}

Radiation protection training at Hanford has always stressed controls, procedures, limits, techniques, the use of appropriate instruments for measuring radiation, and the documentation of radiation measurements. As would be expected, the stress on these various aspects of the radiation protection training has varied from group to group, depending on their specific responsibilities. Health physics personnel have always received detailed training on radiation and radiation measurement, including the use and interpretation of the radiation survey instruments. Other personnel have received the training appropriate to their tasks.

As noted above, the early radiation survey techniques and many of the radiation survey instruments were developed at the Metallurgical Laboratory of the University of Chicago, early in the Manhattan Project. Personne 1 trained there conducted training programs for Hanford health physics personnel on radiation control and use of the radiation survey instruments. As new personnel were added, senior health physicists trained them, often on a one-to-one basis.

After World War II, as new health physics personnel were added, they were immediately provided with individual on-the-job training, and when groups of about 10 new employees had been added, they were sent to formal classroom training programs. These programs were taught by health physics supervisors and managers. Limited testing of the knowledge of the students was carried out in the classroom.

In the mid-1950s, training specialist positions were established, and more extensive classroom training was provided. There were also more formalized testing and record keeping. This kind of program continued until the early 1980s, when a formal health physics technician certification program was started.

The kinds of information imparted to students in these health physics training programs have always included radiation exposure limits, contro] techniques, current procedures, government regulations, radiobiology, the radiation protection responsibilities of the students and the people with whom they work, dosimetry devices and programs, overviews of operational 
processes, and very detailed information on the functions, appropriate use, and survey techniques for the radiation detecting and measuring instruments. As changes in any of the subject material occurred, they were incorporated into the material for future training sessions. Short refreshers were also carried out between the periodic regular training sessions whenever new practices represented a departure from past practices.

The certification programs in $\mathrm{place}$ today provide a complete retraining over all of the subject material every two years, with refreshers in between. Refreshers cover any new technical, administrative, or regulatory information that has accumulated since the last full certification/recertification program. In-depth and detailed information on the portable instrument functions, proper application, and survey techniques is provided in each of the certification/recertification programs. When new models or types of instruments are introduced between those programs, they are covered in the refresher sessions. 


\subsection{CALIBRATION EQUIPMENT AND TECHNIQUES}

When Hanford operations were initiated, a decision was made to set up an independent organization to purchase, control, calibrate, and maintain the portable health physics instruments that were used at Hanford. This organizational arrangement has been in place since that time. This section covers the work accomplished by this instrument organization. The major focus is on calibrations; details on how instruments were repaired or modified are not discussed.

Calibration of portable radiation counting and dose rate instruments at Hanford was based on techniques and recommendations of the NBS from the very beginning to the present. A number of the radiation sources used in the Calibration Facility have been calibrated by the NBS. Actual gamma dose rates at the position of the instrument detectors have always been estab7 ished through the use of the Victoreen R Meters, or precision transfer standard quality ion chamber instruments. Until 1985, each of these instruments was periodically sent to the NBS for calibration. Since 1985, traceability to NBS is maintained through the NBS measurement quality assurance (MQA) program. Neutron dose equivalent traceability is maintained by periodically sending reference standard neutron sources to NBS for calibration. Traceability for other neutron sources is accomplished by comparing them to the standard sources using a precision long counter. Different, but comparably precise methods are used in maintaining the quality of the alpha and beta measurements.

\subsection{INITIAL EQUIPMENT AND TECHNIQUES}

The 3745 Building in the 300 Area was constructed in 1943 as the original calibration laboratory, complete with a concrete-shielded storage vault for the gamma and neutron sources. The building was modified several times over the course of its use for calibration work, and an annex, the $3745 \mathrm{~A}$ Building (see Figure 5.1), was constructed in the early 1950s to accommodate equipment that could not be housed in the main building. These facilities 


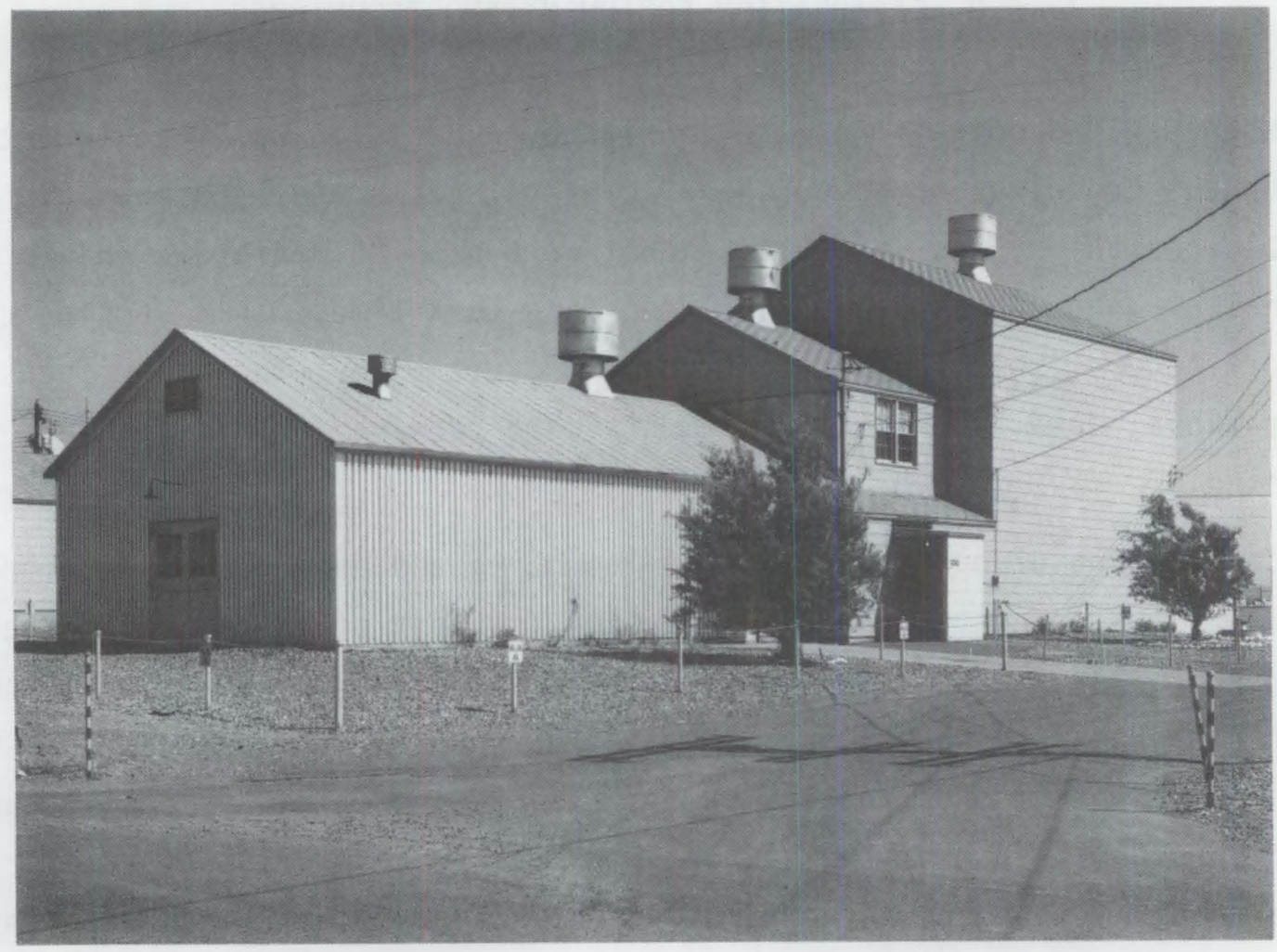

FIGURE 5.1. 3745 Calibrations Building (early 1960s photo)

continued to serve as the calibration laboratory until the early 1980s, when all of the calibration activities were removed to the 318 Building in the 300 Area.

\subsubsection{Calibration Equipment}

At the outset, radium sources were used for all of the gamma calibrations. A number of sources were available, ranging in size from 0.1 to $500 \mathrm{mg}$. Most of the sources were NBS certified with certificates provided by the manufacturers stating the mg content of radium. The radiation values of the few uncertified sources were verified with one of the NBS-calibrated Victoreen $\mathrm{R}$ Meters and compared to calçulated values.

Neutron calibrations were performed using a $500-\mathrm{mg}$ RaBe source that was NBS certified.

Slabs of pure natural uranium in equilibrium with its daughters were used in beta calibrations. The value of the beta surface dose rate on this

\section{2}


kind of radiation source had been determined by several laboratories (including Hanford) performing work for the Manhattan Project, and Hanford used the consensus value from those laboratories.

Plutonium was used as the source material for alpha calibrations. Standard solutions of plutonium salts containing known concentrations of plutonium were deposited and dried on metal disks which became the alpha sources. Since the plutonium salts were not actually electroplated onto the surfaces of the metal disks, each was stored individually to avoid rubbing off the source materials.

\subsubsection{Calibration Practices}

Initially, gamma calibrations were performed with the calibration technician across a large room from the radiation source. The instrument being calibrated was moved from the technician's position to an appropriate position near the source by means of a small cart (called a trolley) on metal rails (see Figure 5.2). The source was raised out of its shielding cask by a cable, and the instrument meter was read through a small telescope. The source was then lowered back into its cask, and the instrument moved back to the technician's position for necessary adjustment. This process was repeated until the instrument reading was a true measure of the gamma exposure rate. The same process was used in adjusting all ranges of the instrument, changing only the position of the instrument relative to the source.

Neutron calibrations were performed by placing the neutron source in its position in a Sigma $\mathrm{Pile}$, and the neutron detector (a $\mathrm{BF}_{3}$ tube) in one of several appropriate ports provided for instrument calibration. The instrument was then adjusted to provide an accurate reading of the neutron flux for that position in the Sigma Pile (Figure 5.3). The instrument was calibrated on all ranges by placing the detector in various ports where the neutron flux was appropriate to the range being calibrated.

The techniques for beta calibration of dose rate instruments and GM counters differed somewhat, though both used uranium metal as the source. Initially, both types of instruments were given gamma calibrations before doing the beta calibration. Later, the gamma calibration of the GM counters was dropped, and they were given only a beta calibration. In the case of the 


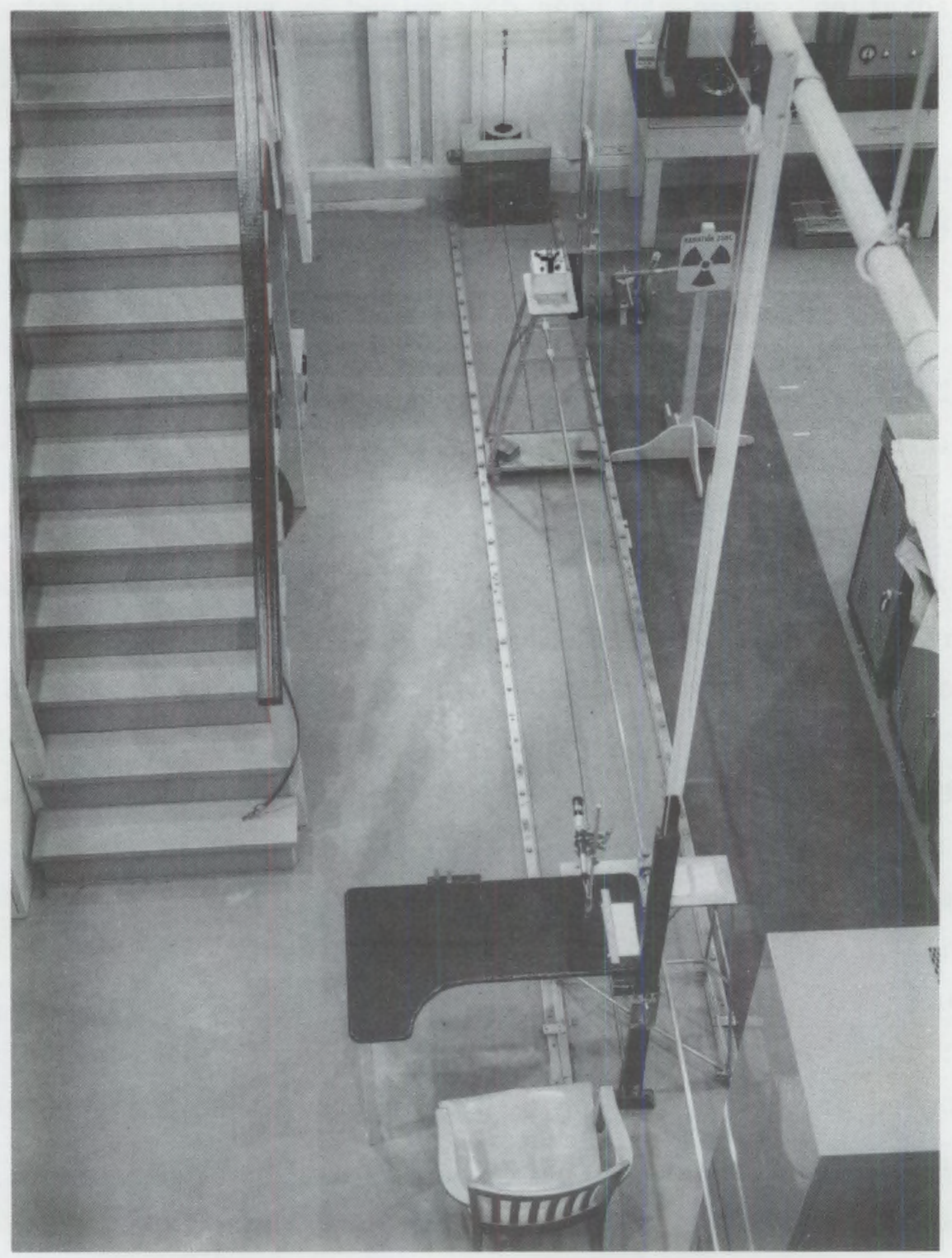

\section{FIGURE 5.2. Trolley System}

dose rate instruments, the beta window of the detector was placed directly on the uranium metal slab, and a reading was taken on one range only. A small graph was drawn up, with a line through the point and the origin to the top of the graph. The graph was then attached to the side of the instrument for use of the person using the instrument for radiation surveys. Since the instrument had been previously calibrated for gamma radiation, the instrument was not adjusted. 


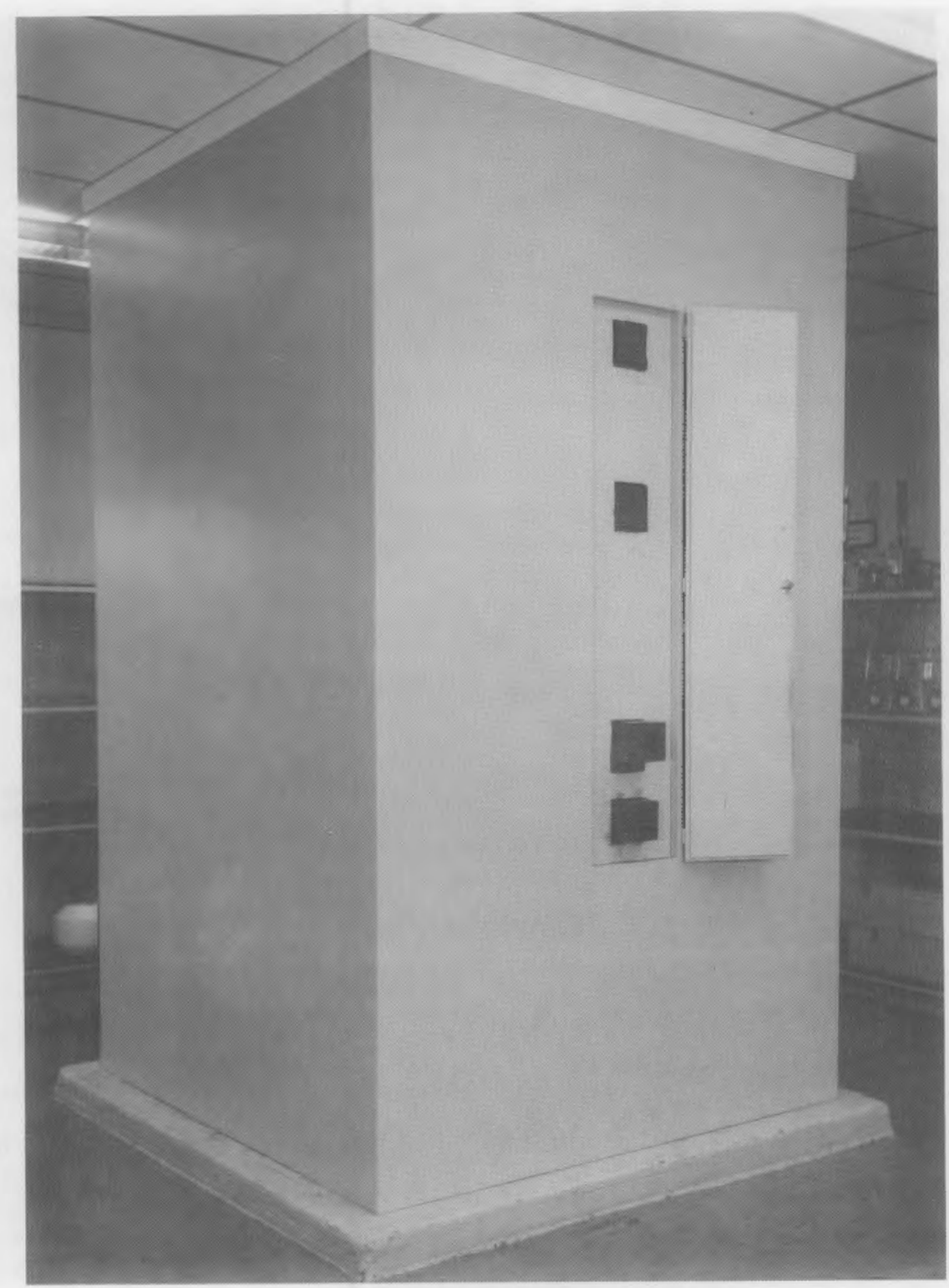

FIGURE 5.3. Sigma Pile

The technique for calibrating GM counters used a slab of uranium enclosed in a lead box (see Figure 5.4). There were three ports designed for insertion of the tubular GM detectors into one side of the box. The box was fabricated so that the detector response would be the same as its response to radium gamma rays. The beta shield of the detector was placed in the "open" position, and the detector was inserted successively into the three holes, one for each range of the instrument. 


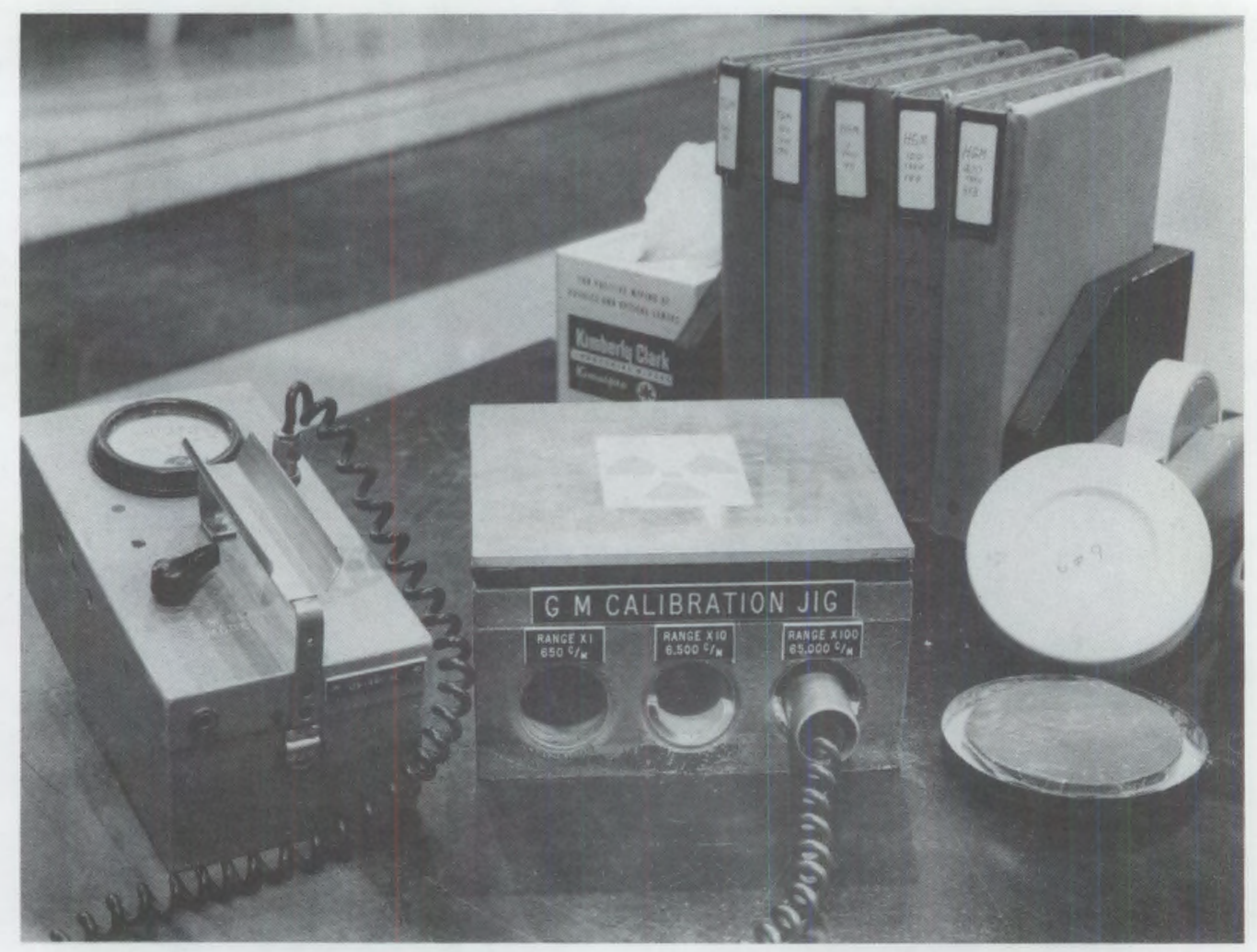

FIGURE 5.4. GM Calibration Jig with a Hanford GM

The calibration of alpha instruments was similar to that of the beta calibrations. The window of the alpha detector was placed over the alpha source, and the instrument was adjusted until its meter read the source activity accurately. Using sources of different values, the instrument was adjusted on all ranges.

\subsubsection{Instrument Control}

To ensure that each instrument received the same attention, each was provided with a unique identification number. Before the instruments were returned from the field, each was carefully surveyed to ensure that it was free of radioactive contamination, and a sticker was put on the instrument stating that it was contamination-free. Each instrument was resurveyed in the Calibrations Laboratory to ensure that it was free of contamination (see Figure 5.5). As the instrument completed the necessary steps for calibration and/or repair, the tag was checked off in the appropriate box and signed by 


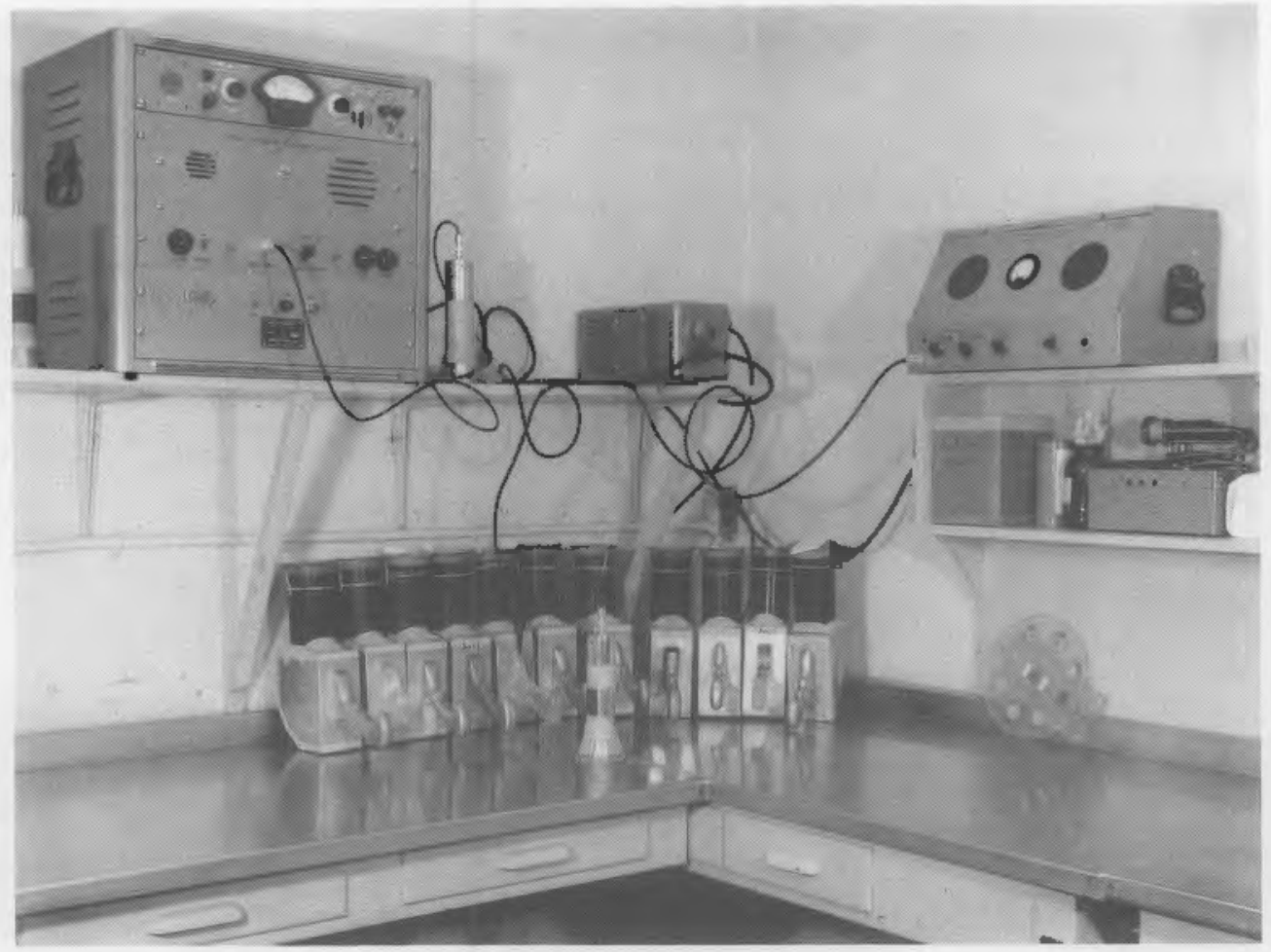

FIGURE 5.5. Instrument Survey and Decontamination Booth in the 3745 Building

the technician performing the work. Records were maintained for each instrument and included the following information: dates when an instrument was in the repair shop, any difficulties in calibration, damage, and specific repairs performed on the instrument. Those records were maintained until the instrument was permanently removed from service.

\subsubsection{Calibration Records}

The recording and maintenance of calibration records was very similar to that described above in Section 5.1.3, Instrument Control. All data generated on each instrument was recorded in the calibration log. A file was maintained for each individual instrument until it was permanently removed from service.

\subsubsection{Instrument Maintenance}

The Calibration Laboratory had its own dedicated repair shop, though some special repairs (such as GM tubes) were performed elsewhere. Senior 
technicians provided oversight of shop activities and necessary training of junior technicians. The technicians were trained on the shop procedures, repair techniques, the types of repairs, and necessary quality unti1 they were thoroughly proficient. When new instruments were introduced, senior technicians performed the initial repairs and worked out the repair procedures and techniques. The other technicians were then given the necessary training to permit them to repair the new instruments. They maintained shop records for each instrument, describing the repairs performed. As above, those records were maintained until the instrument was permanently removed from service.

\subsubsection{Site-Wide Delivery and Pickup}

Dedicated delivery vehicles and drivers did all of the delivery and pickup of the portable radiation instruments. Initially, instruments were delivered directly to all Hanford health physics offices, once a week. The delivery driver signed a receipt for those delivered and picked up. In the cases of instrument failure or damage, or the need for additional instruments, special deliveries were made outside the normal schedule. If that was not possible, health physics personnel often went directly to the Calibration Laboratory to deliver failed or damaged instruments and pick up needed replacements or additional instruments. As above, the original delivery and pickup receipts were maintained in the Calibration Laboratory for as long as they were needed.

\subsubsection{Calibration Frequencies}

Initially, portable radiation measuring and counting instruments were calibrated weekly. As the performance and reliability of certain types of instruments were improved or proven to be suitable, those instruments were calibrated every two weeks. Delivery and pickup of instruments were then staggered so that about half of the instruments in any one health physics office were exchanged each week.

\subsection{SIGNIFICANT CHANGES IN THE CALIBRATION LABORATORY}

Some major changes in facilities, equipment, and techniques have occurred over the years, some of them fairly recently. However, the basic 
calibration procedures remain much the same as they were in the beginning; they have only been refined. The changes have been brought about by various factors, including the need to reduce the radiation dose of the calibration technicians, increased workload due to larger numbers of instruments in service, the need for calibrating instruments with higher ranges, and changes in instrument technology.

\subsubsection{Changes in Facilities}

The need to calibrate instruments at higher dose rates and higher energies brought about the construction of the 3745A Building (see Figure 5.6), which was designed to accommodate a van de Graaff accelerator. This machine was installed in the 3745A Building in the early 1950s. Its maximum exposure rate was well beyond the ranges of instruments available at that time, and the maximum energy of its $x$-rays was $2 \mathrm{MeV}$. It was used extensively in the calibration of TPCs, HPCs, and other high-range instruments (see Figure 5.7). Later, a large cesium-137 source was added for special calibrations, and a

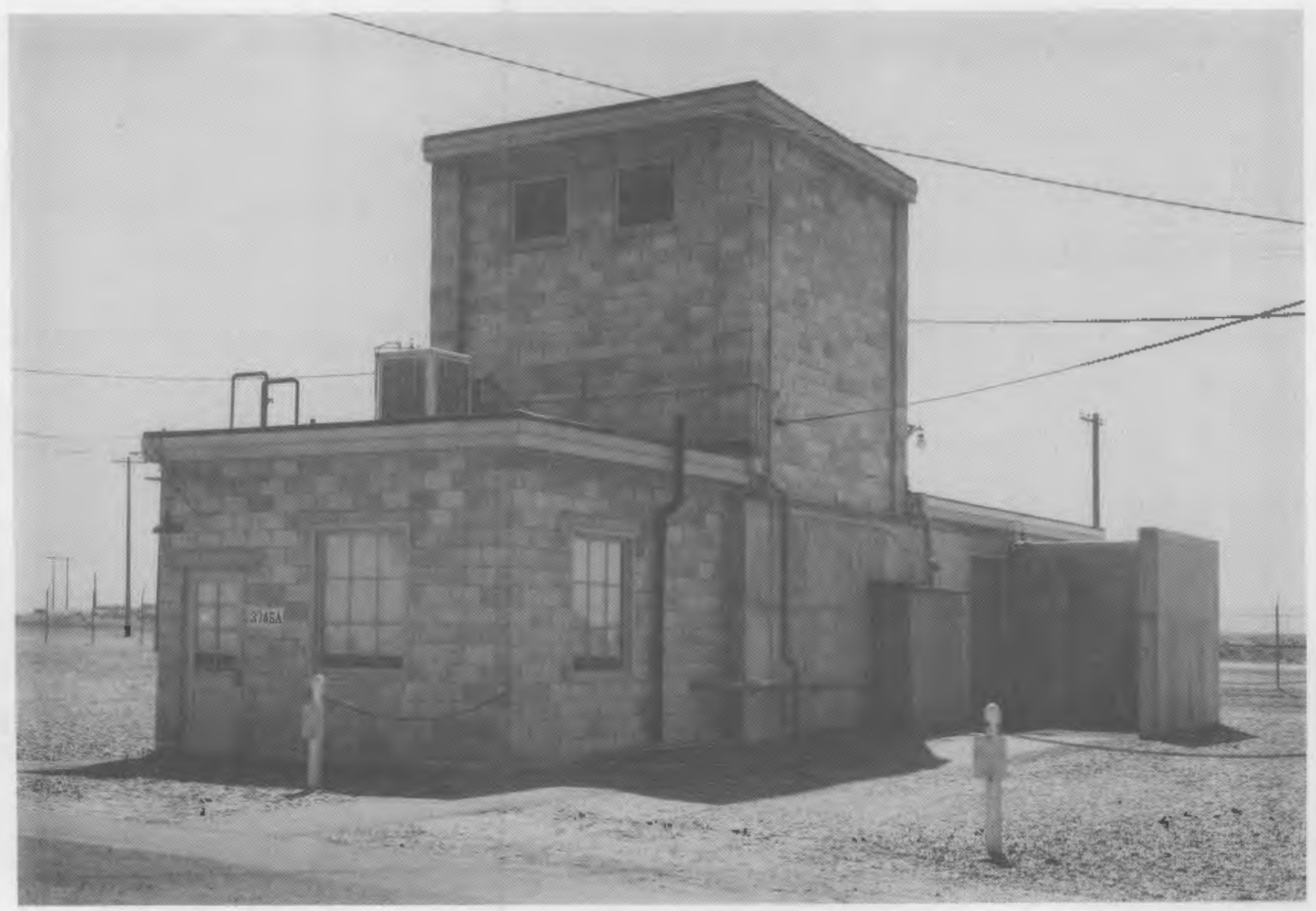

FIGURE 5.6. 3745A Calibrations Building 


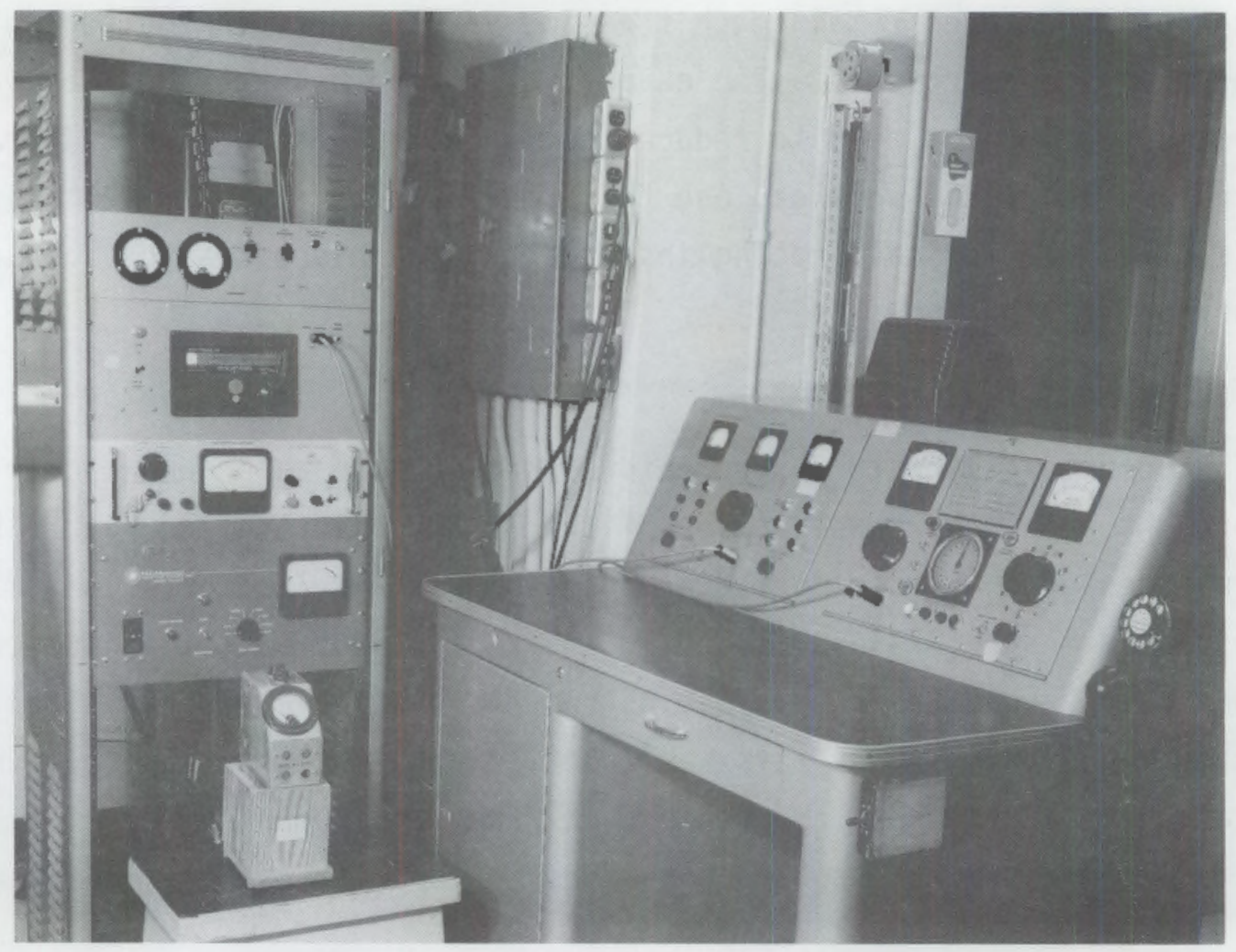

FIGURE 5.7. Van de Graff Electrostatic Accelerator Console and Related Equipment (TPC in position)

${ }^{239}$ PuBe source was added for the Snoopy neutron instrument calibrations. The facility remained in service for calibration work until late 1985.

In 1983 , all calibration activities in the 3745 Building were moved to the 318 Building. As noted above, some activities remained in the $3745 \mathrm{~A}$ Building for another two years. The move to the 318 Building was required because the Calibration Laboratory had simply outgrown the 3745 Building. The 318 Building provided much more room for regular calibration operations, instrument repair, and storage of the much 1 arger pool of portable instruments. In addition, it provided much better separation of various calibration activities, so that conflicts of both time and activities could be avoided. Finally, it provided much-needed office space for the required staff. Although annexes had to be provided for the instrument maintenance shop and some other activities, all of the major calibration work could be carried out in the main building. 


\subsubsection{Changes in Equipment}

One of the early changes in equipment was the change from plutonium solutions dried on metal disks to electroplated plutonium on stainless steel disks. This change, which occurred in the early 1950s, provided much more secure mounting of the alpha source material, since it could not be readily rubbed off the mounting material.

Another change in the early 1950 s was substitution of PoBe and PoBo sources for some uses of the RaBe source. Although this reduced the gamma radiation exposure of the calibration technicians, it was a bit more troublesome in other ways. Due to the relatively short half-life of the polonium, the sources had to be replaced fairly frequently, which was very expensive.

The construction of the gamma calibration wells occurred in 1957 (see Figure 5.8), and they were first used in 0ctober of that year. This not only reduced the gamma exposure of the calibration technicians, it also greatly accelerated the calibration operations because the instruments did not have

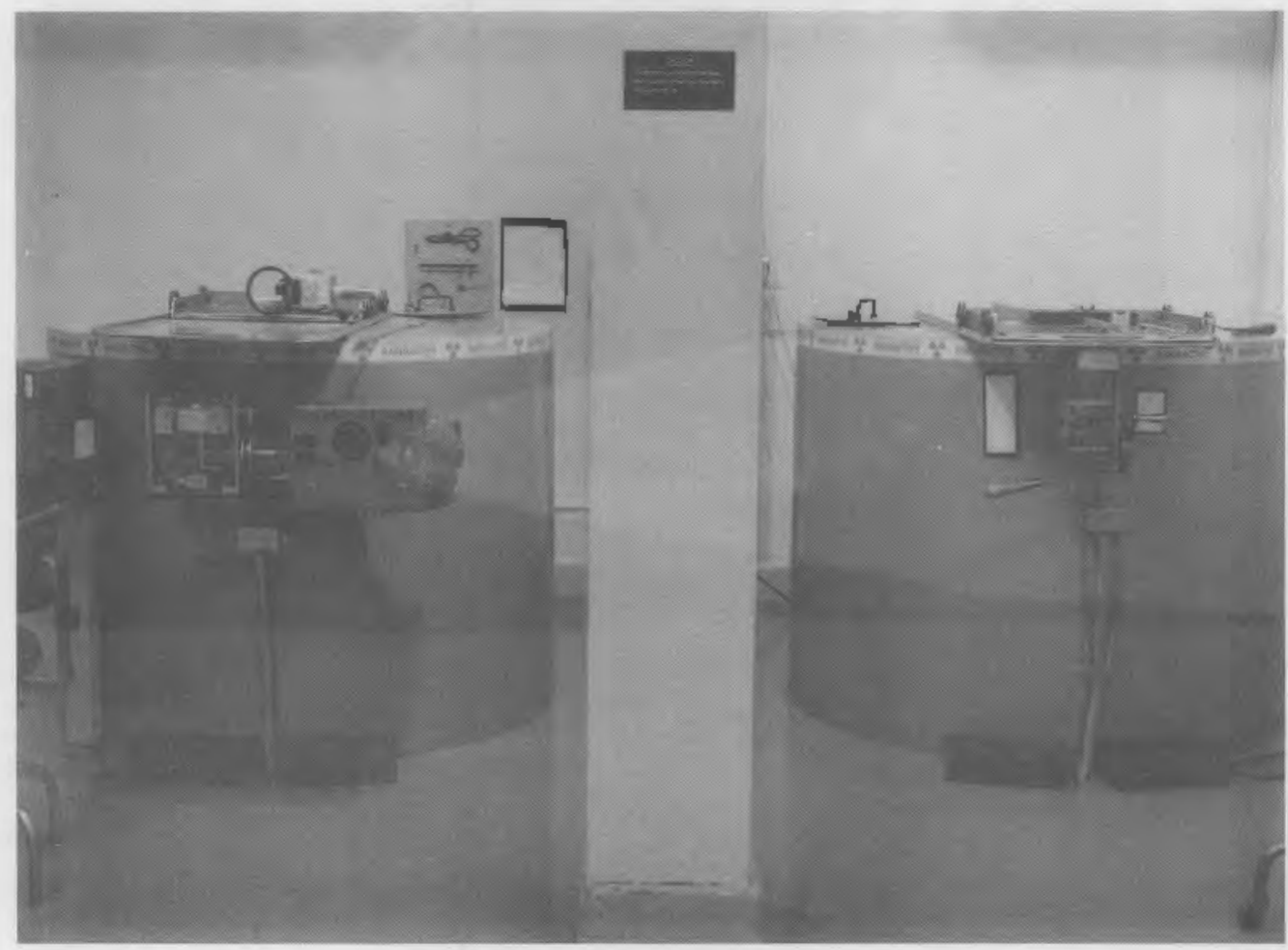

FIGURE 5.8. Gamma Wells with Cutie Pie in Position 
to be moved back and forth on the trolley and the meters could be read directly. At first, the radiation sources were raised and lowered by means of a hand crank, but in the late 1960s a power drive was installed. This al 2 sped up operations. The source movement in the wells was completely automated about 1980, when microcomputer controllers were installed on the source drives.

In the late 1950s, a large aluminum tank filled with paraffin (see Figure 5.9) replaced much of the use of the Sigma Pile in neutron calibrations. This tank was provided with a variety of holes for the neutron detectors, at various distances from the neutron sources. It also accommodated a variety of sizes of detectors more conveniently than the Sigma Pile. At the same time, a PuBe neutron source was acquired for use in calibrating neutron instruments. This source had the advantage of emitting very little gamma radiation and had a much longer half-life than the PoBe and PoBo sources. In 1958, a $\mathrm{PuF}_{4}$ source was added, providing a somewhat broader

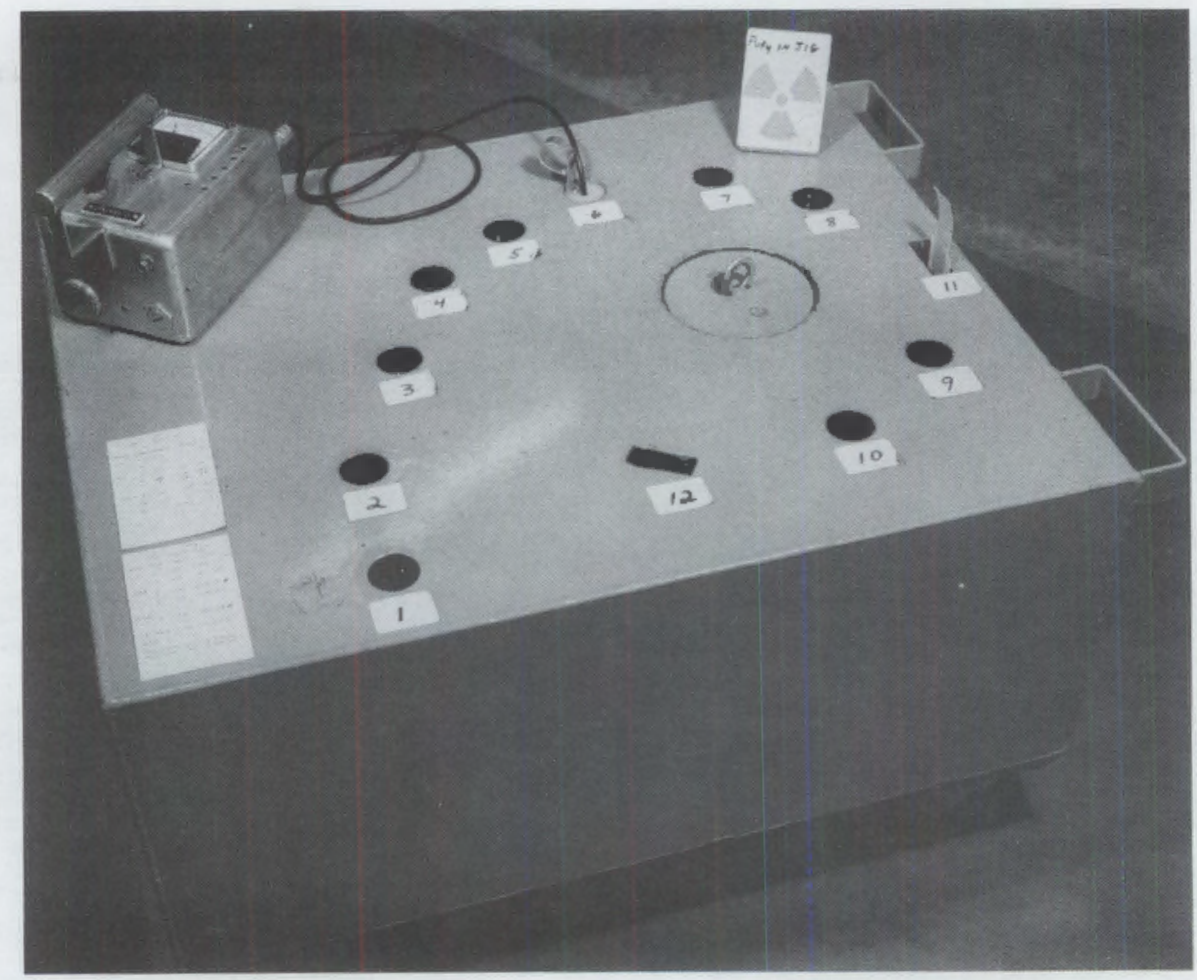

FIGURE 5.9. Paraffin-Filled Tank with BFQ Instrument Being Calibrated 
spectrum of neutron energies. The use of this paraffin tank decreased in 1970, with the introduction of the Snoopy neutron instrument. The tank was not able to accommodate such an instrument. However, the PuBe source was retained for routine calibration of the Snoopy, which was placed on top of a $1-m$ tower in open air at appropriate distances from the source for calibration on all ranges.

In the late 1970 s, there was a significant change in the method of calibrating the counting instruments, such as the GM and the alpha detectors. The main electronics were first calibrated with a signal generator (pulser) to read at 80 percent of full scale on all ranges. The detectors were then connected to the main instruments and they were calibrated. The alpha detectors were calibrated with plutonium-239 or thorium-230. The GM detectors were thin mica window pancake tubes. These were calibrated with mainly beta particles from uranium, strontium-90, technetium-99, and chlorine-36. The response to the alpha emissions from ${ }^{230}$ Th was also documented. A calibration tag attached to the probe gave the counting efficiency on the last four of the above sources. The mica window tubes were then calibrated on a Standard GM within the Calibrations Laboratory and read the same if used on any GM calibrated with a signal generator, as outlined above. In the case of alpha detectors, the probe and instrument were and still must be calibrated and kept together as a unit.

When the Calibration Laboratory was moved to the 318 Building, there were four instrument calibration wells instead of two. These were in a room on the main floor. Two of the wells contained cesium-137 sources and were intended for routine gamma calibrations. The third contained a cobalt-60 source intended for special higher energy calibrations, and the fourth contained a californium-252 source for neutron calibrations.

A high-level exposure facility was constructed in the basement; it consists of a control panel and exposure column with a rail system. The column in the basement has a carousel, accommodating four sources (two cobalt-60 sources and two cesium-137 sources), all intended for calibration 
of high-range instruments. This column was designed to allow movement of any one source into calibration position while the others remained in a shielded storage location.

The 300-keV Picker $x$-ray machine, which had been in the 3745 Building, was also installed in its own heavily shielded room in the basement of the 318 Building (see Figure 5.10). It was intended for use in calibrating instruments that measure levels of lower-energy photons and for instrument performance testing for energy dependence at lower photon energies. This unit was used up to July 1988 for some specific $x$-ray energies and techniques. A Phillips x-ray machine was purchased in 1986 and is now the only machine used.

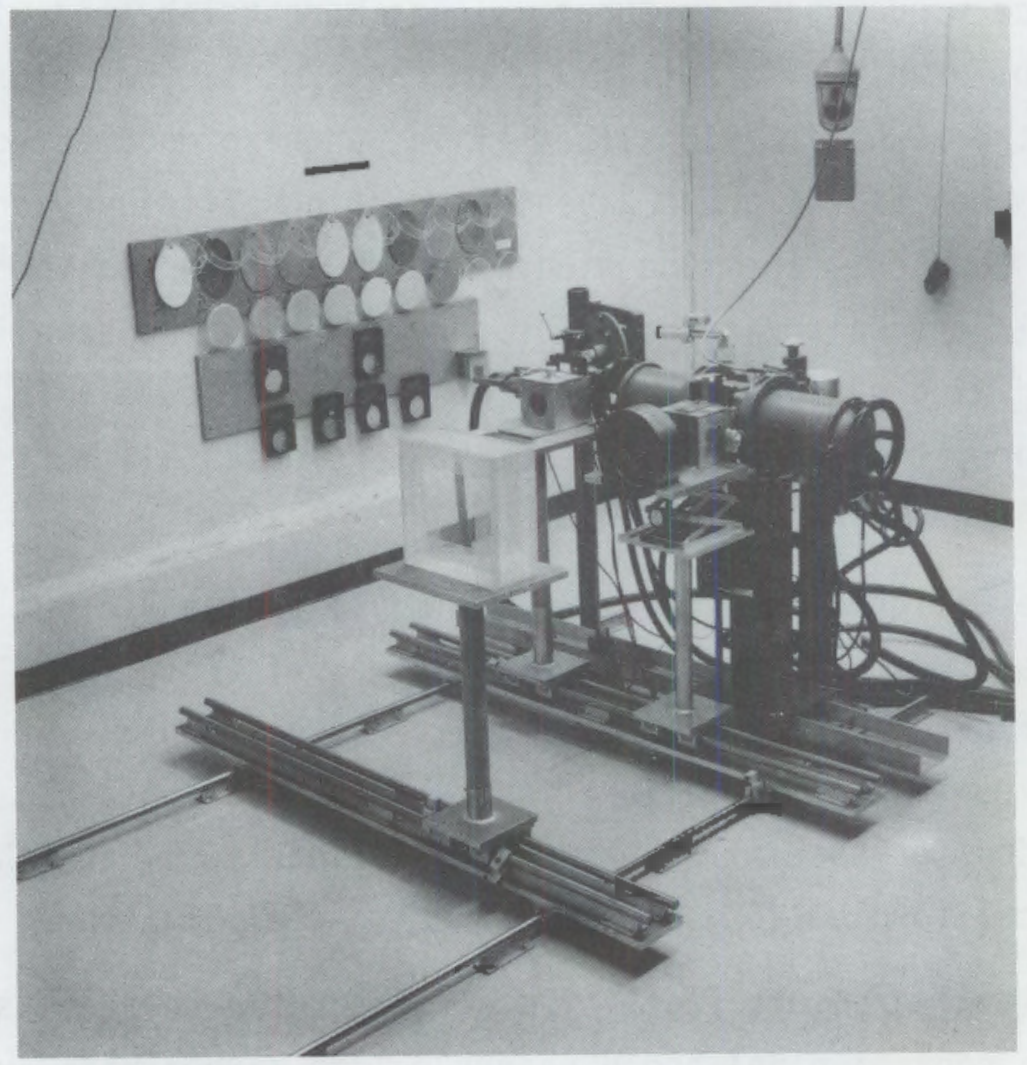

FIGURE 5.10. Picker X-Ray Machine 


\subsection{CURRENT EQUIPMENT AND TECHNIQUES}

Many of the radiation sources and much of the equipment was transferred from the 3745 Building to the 318 Building (see Figure 5.11) for continued use in calibration work. However, some of the radium sources were retired, and a substantial part of the equipment was transferred to others or disposed of. Some new radiation sources were acquired, and many new pieces of equipment were either purchased or especially constructed for use in the new facility. The record keeping has all been converted to a computer system. In addition, many procedures have been rewritten and some new ones have been written to cover work in the new facility.

\subsubsection{Calibration Equipment}

The current calibration equipment includes a large variety of radiation sources. A number of cesium-137 sources are available in various strengths, the largest of which is $100 \mathrm{Ci}$. A number of radium gamma sources are also

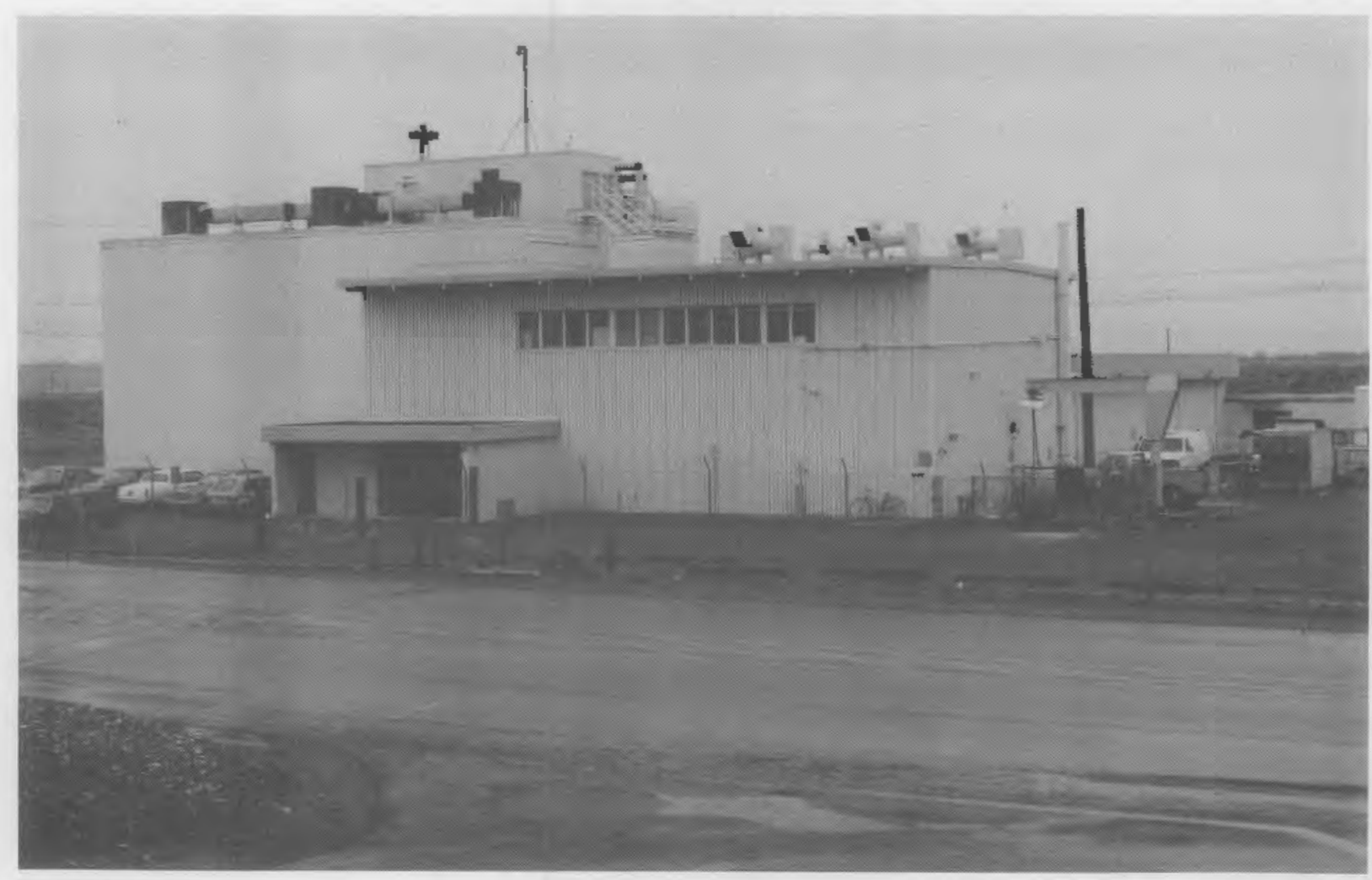

FIGURE 5.11. 318 Calibrations Building 
available in several sizes up to $0.5 \mathrm{~g}$. Three different neutron sources are in use, californium-252, PuBe, and AmBe. The alpha sources in routine use are made of thorium-230 and plutonium-239 plated on stainless stee 1 and americium-241. Uranium metal slabs are still in use for routine beta calibrations, along with plated sources of strontium-90, technetium-99, and chlorine-36. A thorium-230 source is also used to determine the pancake probe response to alpha particles.

All calibration sources have some degree of traceability to the NBS. Some are calibrated by the NBS, while others have been obtained from manufacturers who have traceability to the NBS. Those sources that do not have that kind of traceability have either been compared with radiological standard sources which have NBS certification, or have been measured with transfer standard grade equipment that has an NBS-traceable certificate. All of the certification records are kept on file indefinitely.

Devices called "calibration fixtures" are used to accurately position both radiation sources and portable instruments during routine calibrations. Each type of portable instrument has its own specific fixture that is designed to $\mathrm{place}$ the center of the detector in a precise position for each calibration.

As mentioned above, on the main floor of the 318 Building there are four calibration wells, two of which contain cesium-137 sources (nominal 0.5 and $10 \mathrm{Ci}$ ). These are used for routine gamma calibration of portable instruments. Another well contains a cobalt-60 (nominal $1 \mathrm{Ci}$ ) source used for special gamma calibrations. A fourth well contains a californium-252 source (nominal $50 \mu \mathrm{gm}$ ), used for calibrating neutron instruments (see Figure 5.12). The gamma exposure rates for these wells are all routinely calibrated with NBS-traceable transfer chambers at different positions. The data from these calibration points are then placed in an algorithm in the well control computer. Approximate exposure rate ranges for the cesium wells range from 2 to $160 \mathrm{mR} / \mathrm{h}$ for the nominal $0.5 \mathrm{Ci}$ source and from $30 \mathrm{mR} / \mathrm{h}$ to $11 \mathrm{R} / \mathrm{h}$ for the nominal $10 \mathrm{Ci}$ source. Exposure rates from approximately $8 \mathrm{mR} / \mathrm{h}$ to $2 \mathrm{R} / \mathrm{h}$ can be obtained with the nominal $1 \mathrm{Ci}{ }^{60} \mathrm{Co}$ in the well. Neutron dose equivalent 


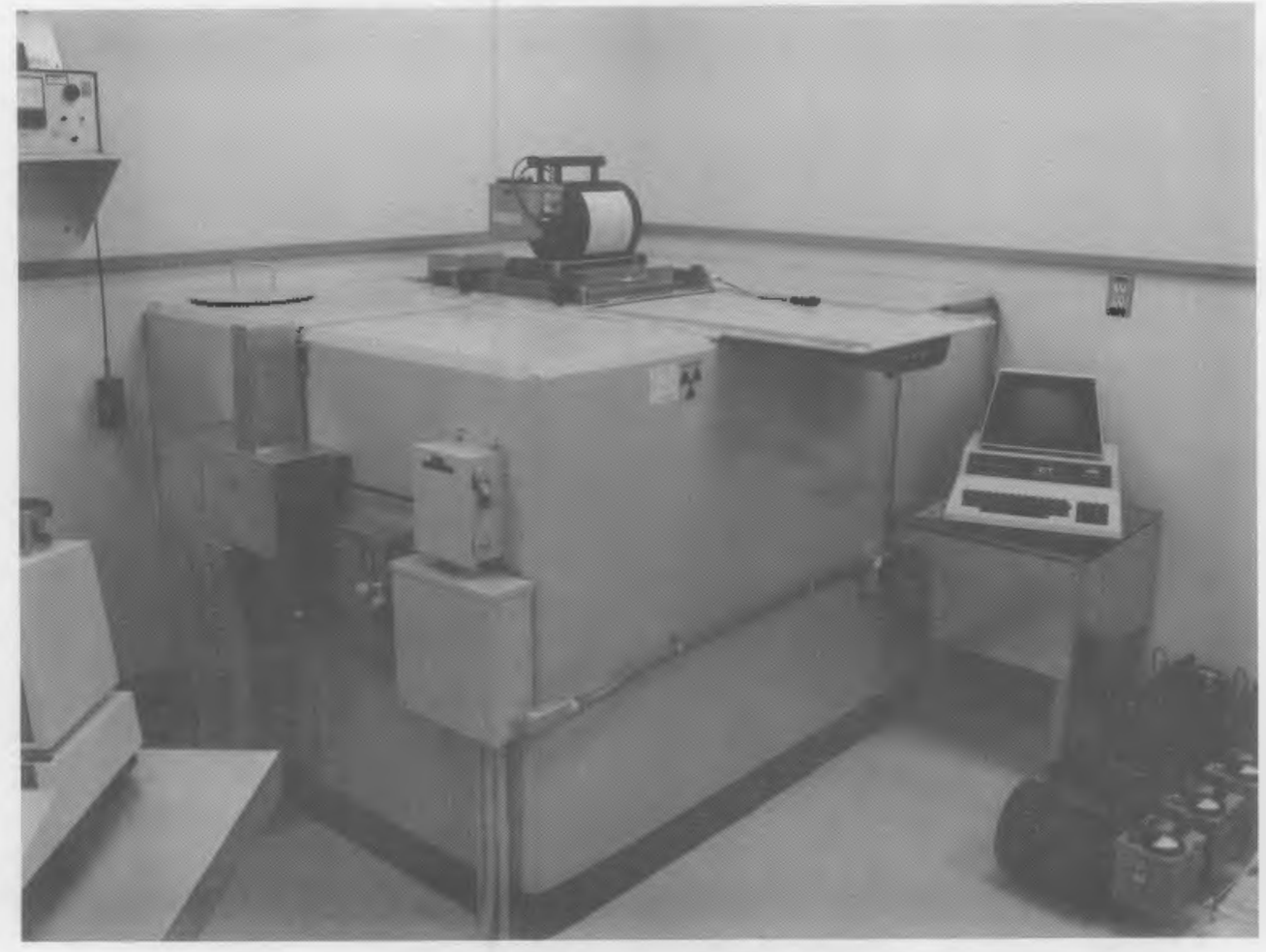

FIGURE 5.12. Neutron Calibrations Well in the 318 Building (Snoopy instrument on top)

rates from $1 \mathrm{mrem} / \mathrm{h}$ (with plastic attenuator) to $350 \mathrm{mrem} / \mathrm{h}$ can be obtained with the ${ }^{252} \mathrm{Cf}$ source. These exposure and dose equivalent rates were estimated for Apri1 1989.

The high-level exposure system in the basement contains two large cesium-137 sources, and two large cobalt-60 sources that can produce exposure rates from approximately $7 \mathrm{mR} / \mathrm{h}$ to $60,000 \mathrm{R} / \mathrm{h}$ depending on which source is used and on the distance from the source. Sources in this system include nominal activities of $10 \mathrm{Ci}, 100 \mathrm{Ci}\left({ }^{137} \mathrm{Cs}\right), 660 \mathrm{Ci}$, and $5890 \mathrm{Ci}\left({ }^{60} \mathrm{Co}\right)$. Figure 5.13 shows the control panel for the system; Figure 5.14 shows the column and the rest of the exposure system. The sources are stored in a five-position carousel located below floor level. The lead column shields and collimates the radiation. A source is pneumatically positioned in front of the 30-degree conical opening in the column, projecting a horizontal radiation field with the central axis $1.5 \mathrm{~m}$ above floor level. The beam is centered between the side walls of the $16 \times 4 \times 4 \mathrm{~m}$ room so that the primary 


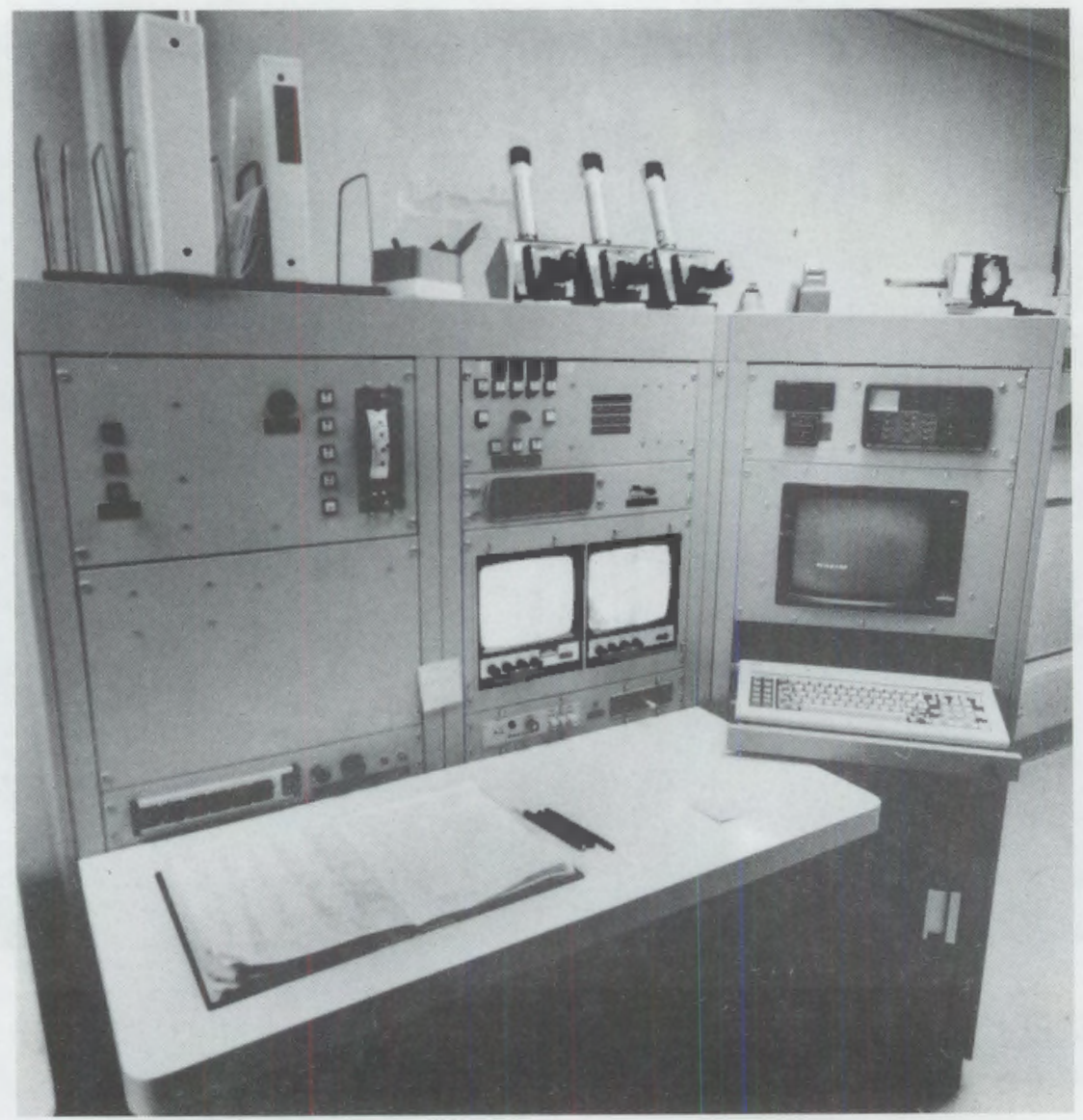

FIGURE 5.13. High-Level Exposure System Control Panel

beam strikes the back wall. The scattered radiation is relatively insignificant. Detector probes are mounted on a lightweight aluminum stand that is remotely positioned on the rail system from $25 \mathrm{~cm}$ to $6 \mathrm{~m}$ from the source. A closed-circuit television camera is used to monitor instrument readings that cannot be sent through cables to the control console.

Three other exposure systems are available for use in the 318 Calibrations Facility. These are used primarily for the exposure of film badges, thermoluminescent detectors (TLDs), pencil dosimeters, and other passive-type dosimeters. The first system contains a ${ }^{238} \mathrm{PuBe}$ (plutonium-berylium) source which can be used for exposures to fast neutrons (unmoderated) or to thermal neutrons (moderated through a tank containing $\mathrm{D}_{2} \mathrm{O}$, deuterium oxide). The second system is a beta-exposure system equipped with a beta secondary 


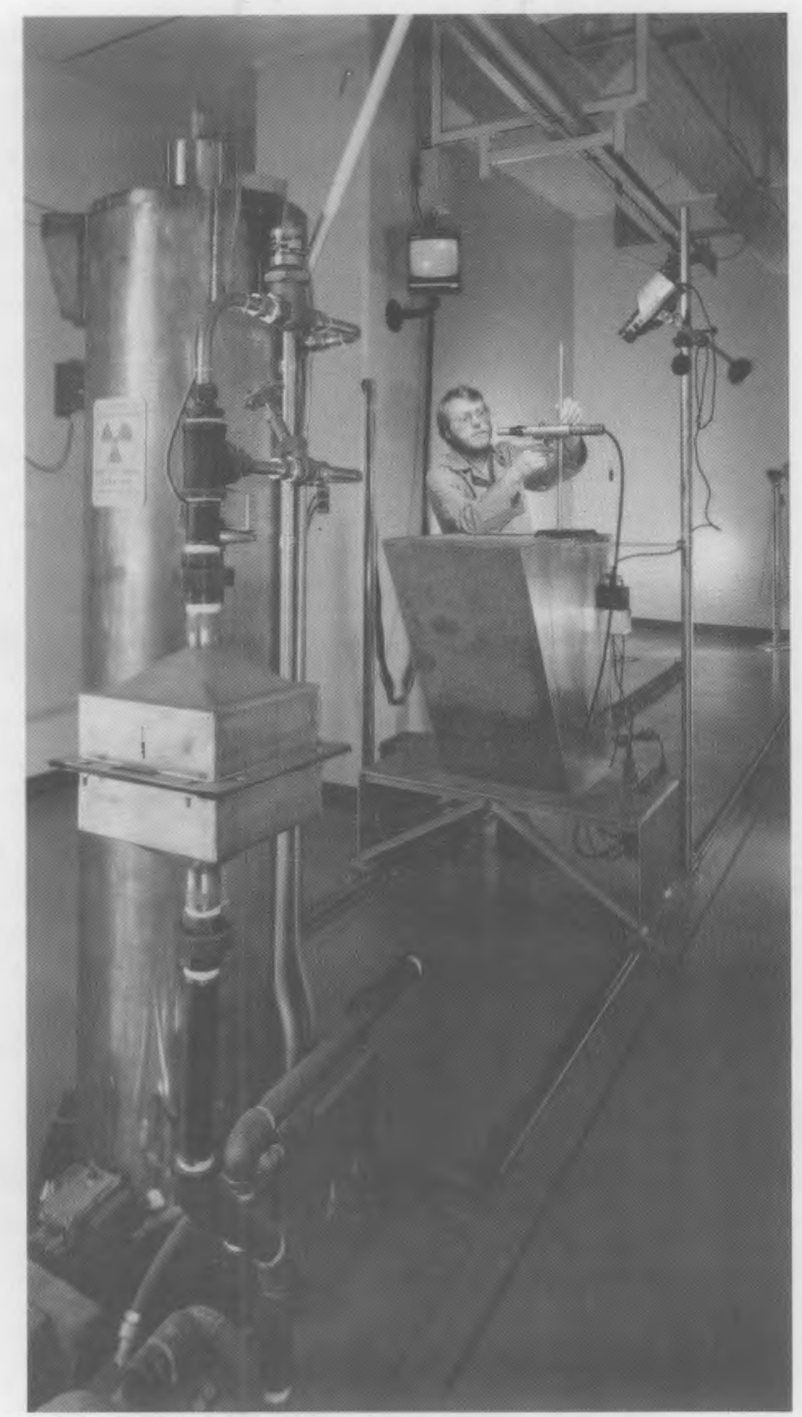

FIGURE 5.14. High-Level Exposure System

standard calibration apparatus consisting of four beta sources, an operator console, and a source $\mathrm{jig}$. The sources include two ${ }^{90} \mathrm{Sr} / \mathrm{Y}$ sources, a ${ }^{204} \mathrm{Tl}$ source, and a ${ }^{147} \mathrm{Pm}$ source. The sources were constructed and calibrated in accordance with International Standard IS0-6980. Flattening filters are used with the sources. The third system is the low-scatter room (see Figure 5.15) which provides a nearly scatter-free environment for neutron and gamma exposures. The room is approximately $10 \times 9 \times 15 \mathrm{~m}$ with concrete walls. Three fixed exposure locations are available in the room. Five radiation sources are available for pneumatic transfer from a shielded storage location to any 


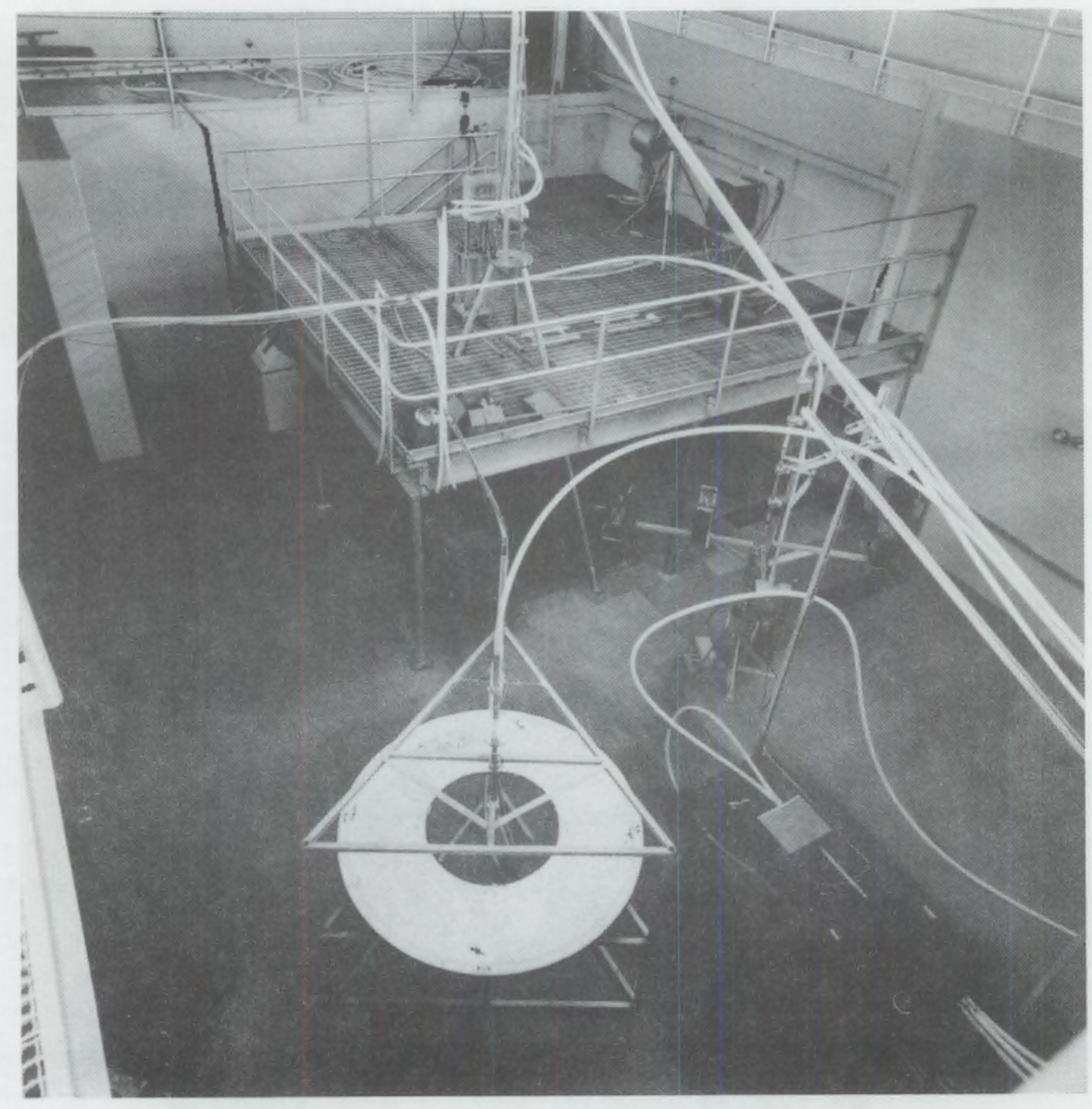

FIGURE 5.15 . Low-Scatter Room in the 318 Building

one of the exposure locations. The sources include two ${ }^{137} \mathrm{Cs}$ sources (nominal $2 \mathrm{Ci}$ and $10 \mathrm{Ci}$ ), one ${ }^{60} \mathrm{Co}$ source (nominal $2 \mathrm{Ci}$ ), and two ${ }^{252} \mathrm{Cf}$ neutron sources (nominal $80 \mu \mathrm{g}$ and $1 \mathrm{mgm}$ ). Approximate exposure rates at one meter for the ${ }^{137} \mathrm{Cs}$ sources range from $450 \mathrm{mR} / \mathrm{h}$ to $2.3 \mathrm{R} / \mathrm{h}$. For the ${ }^{60} \mathrm{Co}$ source, approximate exposure rates of $2.2 \mathrm{R} / \mathrm{h}$ at one meter are observed. Neutron dose equivalent rates at $80 \mathrm{~cm}$ of $335 \mathrm{mrem} / \mathrm{h}$ to $4 \mathrm{rem} / \mathrm{h}$ for unmoderated sources can be achieved. These exposure and dose equivalent rates were estimated for April 1989. A separate control console allows the operator to choose which source to send to which location; automatic timing of an exposure is available. 


\subsubsection{Calibration Practices}

All of the gamma instruments with maximum ranges up to $5 \mathrm{R} / \mathrm{h}$ are calibrated using the gamma wells on the main floor. During calibration work, the technician is seated beside the well in a very low radiation area. The technician moves the instrument to the exposure position over the center of the well on a small, wheeled cart, observes the instrument response remotely, and makes any necessary adjustments by using a long-handled screwdriver.

The beta calibrations are sti11 performed as described above in Section 5.1.2. Instruments which are calibrated using a uranium slab are calibrated in exactly the same way. A calibration chart is prepared from the observed instrument readings and attached to the side of the instrument. Instruments calibrated with other beta sources are calibrated in exactly the same way, and the calibration chart is also attached to the side of the instrument.

Gamma instruments with higher ranges are calibrated on the gamma wells on the main floor at exposure rates up to $5 \mathrm{R} / \mathrm{h}$, or on the basement well at higher ranges. For the higher ranges, the detector is detached from the main electronics portion of the instrument and placed in a calibration fixture near the source. It is attached to an instrument cable that runs outside the shielded room containing the source to a console used for operating the calibration equipment remotely. The console end of the instrument cable is attached to the main electronics portion of the instrument, and the detector is then exposed to the various radiation levels necessary to calibrate the instrument on its higher ranges. Since both the instrument meter and its controls are readily accessible to the calibration technician at the console, he is able to perform the necessary adjustments as easily as at the other wells on the main floor. For units that do not have external, removable probes, a closed-circuit video system is used to visually read the instruments. Adjustments are made to the instruments while the sources are in the "safe" position. 
The Snoopy neutron instruments are calibrated on the neutron well on the main floor of the building. The calibration technique is essentially the same as that described above for the calibration of gamma instruments using the gamma we11s. A californium-252 source is used for routine calibrations.

The main electronics of portable GM counters are now calibrated using an electronic pulser, which emulates the pulses coming from a GM tube. The whole instrument is calibrated by attaching the detector and exposing it to the appropriate beta source(s), as discussed above.

Portable alpha instruments are calibrated in essentially the same way as the GM instruments, except that americium-241 sources are used for the final step of the calibration.

\subsubsection{Instrument Control}

A11 instruments are provided with unique identification numbers as mentioned in Section 5.1.3, above. The processing and tracking of instruments through the Calibration facility and the repair shop are essentially the same as described there. One significant change is the transfer of the main records to the facility computer, though cards still accompany the instrument on its way, until it is ready for return to service. The records are maintained until the instrument is permanently removed from service.

\subsubsection{Calibration Records}

The calibration records are handled in essentially the same way as described in Section 5.1.4, above. The only changes are that the records are maintained on the facility computer, and they are kept indefinitely.

\subsubsection{Instrument Maintenance}

As described above in Section 5.1.5, the Calibration Laboratory still has a dedicated instrument repair shop, and it is still administered in essentially the same way. Senior technicians. still do the training of the lower level technicians, develop repair techniques, and write the repair procedures. The same repair records are maintained, as described above in Section 5.3.3, except that the records are now maintained on a computer. 


\subsubsection{Site-Wide Delivery and Pickup}

Delivery and exchange of portable instruments is carried out throughout Hanford (to about 40 different locations) in a manner similar to that discussed in Section 5.1.6, above. The instruments are delivered to a special enclosure outside the facility where they will be used, and a signed listing is left with them. Health physics personnel in the facility pick them up and check the listing to be certain it is accurate. Instruments to be returned for calibration are left in the enclosure the night before pickup; these instruments are tagged as free of contamination. As before, special deliveries and pickups are still performed. The pickup and delivery records are still maintained as long as needed.

\subsubsection{Calibration. Frequencies}

Due to increased reliability and ruggedness of the instruments, intervals between calibrations have been extended significantly in many cases. Currently, the period between calibrations ranges from three months to one year. However, if instruments fail or are damaged before their calibration is due, they are returned to the Calibration Laboratory for repair and recalibration. 


\subsection{PORTABLE INSTRUMENT RECORDS}

\subsection{CALIBRATION RECORDS}

Portable radiation monitoring instruments were all issued unique identification numbers as they were introduced into the instrument pool. In the 1940s and 1950s, Property Management issued an "assigned" (A) number as instruments were purchased. Each instrument was then given an "equipment piece" (E.P.) number. The E.P. number series usually started with the number one. For identification purposes, this number was followed by a suffix that denoted the instrument type. As an example, CPs all had the suffix 491-A. For record-keeping purposes, this number was shortened to CP \#1, CP \#2, etc.

In the late 1960s, a series of 10,000 assigned numbers was issued to the Calibrations Laboratory by Property Management. Portable instruments added to the pool after this period were issued a number from this group. The last four digits of these assigned numbers were used as the E.P. number. As an example, a CP given the assigned number 276100 used 6100 as the E.P. number. Various instrument types were kept within a given number series as another means of identification. The once-used numbers were retired when an instrument was excessed or buried as radioactive waste because of contamination.

In 1987, the effort began to get all of the instruments used on site (whether pool or contractor-owned) into the computer data base. Many instruments were given special identification numbers consisting of a 3- or 4-1etter acronym plus the unit's serial number. Tracking of all site-wide instrumentation has been improved greatly with this system.

\subsubsection{Initial Filing System}

A Kardex filing system was used to record instrument activity in the 1940 s and early 1950s. Each instrument had a card in this file. Information recorded on this card included the following: 1) date of calibration, 2) date of delivery, 3) location of delivery, and 4) date of return to Calibrations. The presence of radioactive contamination was noted along with damage or malfunction information. The pickup and delivery record provided part of this information. 
A preprinted file card was also filled out for each instrument. This card listed the instrument type and E.P. number, the type and/or the identification number of the radioactive sources used for the calibration and the instrument response to these sources. Reasons for instrument failure and repairs required were also noted. Personnel performing the work initialed this card.

These records were sent to Record Storage when they were no longer needed for reference purposes.

\subsubsection{Computerized Records}

In the mid-1950s, the Kardex record system was replaced by an IBM computer system. A set of two cards tracked each instrument's activity.

The calibration card provided spaces to record the calibration date, delivery date and location, return from field date, contamination and need of repair. Part of this information was provided by the pickup and de]ivery record.

The shop card provided spaces to record the date sent to shop, types of service requested, service provided, and the date returned from the shop. The mechanic initialed this card.

This system required the assignment of numbers to the delivery locations. Instrument types were 1 imited to a three-alphabetical-character designation. Reasons for taking instruments to and from the repair shop were limited to two alphabetical characters.

The updated instrument information was punched into the cards and a new set was returned to the files. Computer Sciences Corporation performed this service. Computer Sciences Corporation then generated instrument inventories, monthly activity reports, and cost reports using this information.

A supplemental record was maintained for each instrument. The use of the preprinted file cards described in Section 6.1.1 was continued until the late 1950s. These cards were then replaced by looseleaf preprinted forms. Each instrument was represented by a page in a notebook, with spaces for date of calibration, initials of person performing the work, and noting whether the instrument passed calibration. (There was also space to note the reason 
for failure.) Other calibration data were omitted and replaced by a calibration procedure number. This allowed a calendar year's activity to be recorded on one page.

These records were sent to Record Storage when they were no longer needed for reference purposes.

\subsubsection{Initial Computer System Cancelled}

The service provided by Computer Sciences Corporation was cancelled in 1971. Budget constraints and quality of service prompted this decision. Frequent mechanical problems delayed the daily delivery of the updated cards and slowed the turnaround time for instruments to the field.

An in-house, hand-filed record system was implemented at this time. A regulation-size IBM card was designed to accompany each instrument though the calibration and shop repair cycle. Space was provided for 12 calibration entries per card. The codings from the IBM computer system were retained for use in this system.

The Calibration Record side of the card provided spaces for the delivery date, location number, date from field, calibration date, and the initials of the person calibrating the instrument. It also provided space for information on contamination and other calibration data.

The Shop Repair Record was printed on the reverse side of the card. Spaces were provided for date to shop, user location, reasons to shop, parts and services, date returned from shop, and the mechanic's initials.

Data from the IBM card were transferred to a master card. This card file was maintained in a central location in the 3745 Building.

Information for cost reports was gathered from the daily pickup and delivery forms.

In the late 1970s, the printed inventory 1 ists for most instruments was discontinued by Property Management. This too was changed to an in-house, hand-filed record system.

All of these records were retained in the building for reference purposes. 


\subsubsection{Enhanced Computerization}

In the latter part of the 1970s, a HP1000 computer system was installed in the 318 Building, 300 Area. Communication with this computer was estab1 ished by modem and telephone lines. By 1983, when the Calibrations Laboratory was moved from the 3745 Building to the 318 Building, the instrument activities were once again tracked by computer. In 1987, a HP9000 computer system was installed to better handle this work.

The IBM card described in Section 6.1.3 has been retained. The master card has been replaced by input to the computer. A report listing instrument requirements for all locations on plant or an inventory of instruments at any location is available on demand. Reports for each location list field requirements for instruments, instruments assigned to the rocation, and those due to be returned for calibration.

Programs are now added to produce new reports as needed.

\subsection{ISSUANCE/RECEIPT RECORDS}

The pickup and delivery form has always been a vital link in the record system. This is a two-part form that is completed by the person instruments to the user groups. The heading on this form provides spaces for delivery location, name of person completing the form, and the date of delivery. The top and bottom sections are identical with instrument types preprinted. The E.P. number of each instrument is printed in by hand. The top section is identified as "instruments picked up." The bottom section is identified as "instruments delivered." The original copy is left with the instruments. A carbon copy is returned to Calibrations.

The receiving group verifies this listing with the instruments received. The IBM cards for instruments sent out on the daily load are set aside to be updated with the information from this listing. Any discrepancies are resolved by telephone conversation. 
The user groups are provided with lists of the current field requirements of instruments to be assigned to the various field locations. Computer listings are monitored to ensure that the user groups are supplied with the required instruments.

\subsection{FIELD PROBLEM IDENTIFICATION/RESPONSE}

Portable monitoring instruments that fail during use are tagged and returned to the Calibrations Laboratory for repair and replacement. Tags that 1 ist symptoms other than damage or battery failure direct attention to special problems. This reduces the chance of intermittent failure not being detected and corrected.

An instrument user's manual is provided to field health physics personnel describing the capabilities and limitations of the pool instruments. This is PNL-MA-562, "Radiation Protection Instrument Manual." Oral or written communication is often used to clarify an individual's questions on instrument functions. Knowledgeable personnel from the Calibrations Laboratory assist in training sessions when new instruments are introduced into the pool. 



\subsection{CONCLUSIONS}

Portable health physics instruments have been used as an integral part of Hanford's radiation control programs since 1944, when operations were first initiated. Although they are only a portion of the required tools for radiation control programs, they are the foundation of such programs. Without portable health physics instruments, a radiation control program cannot be properly conducted. Trained technicians have always been employed to use these instruments in making surveys of people, material, facilities, and other items used within the radiation zones at facilities containing, generating, processing or using radioactive materials. Likewise, trained technicians have always been used to maintain and calibrate the instruments.

Instrument maintenance has been carefully controlled by uniquely ident $i$ fying each instrument and maintaining records that match the instrument identification. Calibrations have been carefully controlled by using certified NBS calibration sources either directly or indirectly by making measurements with an NBS Victoreen R Meter or precision transfer standard quality ion chamber instruments.

Portable health physics instruments have been used in Hanford fuel fabrication facilities for surveillance of the uranium and plutonium materials brought into the facility, prepared for encapsulation into fuel elements, and stored in containers. They are also used when the fuel elements and waste materials are shipped out of the facility. Upon receipt at the nuclear reactor, the fuel elements are surveyed with portable health physics instruments. While such instruments are not normally used to survey irradiated fuel elements from the reactor, they are used to survey the activation and fission products in the various reactor coolant systems, the outside of shielded casks when filled with irradiated fuel for shipping, and radioactive wastes.

After the irradiated fuel is shipped to the chemical processing plant, the fuel casks are surveyed before and after the fuel is placed into the process streams. Instruments checks are made for fission product control throughout the chemical processing plant, and include the products derived 
for special nuclear materials and recycle of uranium. All visible portions of waste tanks and lines are checked, buried wastes are checked, and other support facilities and laboratories are checked with portable health physics instruments. The results are recorded in official records that are maintained for 75 years.

Laboratories have tested and conducted a wide variety of experiments with radioactive materials. Portable health physics instruments have been used to survey all such facilities, such as the facilities described above, for alpha, beta, x-ray, gamna rays, and sometimes neutrons. In addition, these instruments have been and are used on preset schedules to check facilities and vehicles that are not near facilities having radioactive materials.

Since the 1940 s, significant improvements have been made to portable health physics instruments. These improvements have resulted from technological breakthroughs in instrument components. The improvements have reduced the size and weight of the instruments, making them easier to handle and use. Early instruments in 1944 weighed up to 20 or more pounds. Most of the instruments today weigh less than 5 pounds. These changes in instruments came about when large vacuum tubes were replaced by smaller vacuum tubes, and then transistors, smaller batteries with longer life, and very small power supplies became available. Tougher Mylar films for detector windows, lighter probes, and better switches also made instruments less subject to frequent breakdown maintenance.

Vendor firms increased in numbers and size as the nuclear industry grew, providing a wider variety of portable health physics instruments. Instrument quality improved. This reduced the number of instruments that had to be fabricated and/or modified at Hanford. It also reduced maintenance frequency. Contamination monitoring instruments were designed so that they could be calibrated to use several different types of detector probes. Thus, instrument versatility has increased significantly since 1944 .

The early calibration facilities required remote calibration of dose rate instruments because of high dose rates to the calibration technicians. The technicians had to read the instruments being calibrated with a small telescope. Calibration adjustments were made with long-handled screwdrivers. 
This was time consuming, and the calibration technician received measurable (within approved administrative levels) quantities of radiation exposure. When the first calibration source wells were fabricated, the technician could read the instrument meter and adjust the calibration close to the instrument. This greatly reduced both the time required for calibrating instruments, and the amount of radiation exposure received by the technicians.

The fundamental concepts employed in developing the instrument records program in the 1940s are still used in 1988. There have been changes made to improve efficiency and use of records. Currently, the records are maintained on a computer data base.

A few older-vintage portable health physics instruments were borrowed from the Hanford Science Center to evaluate how they performed compared with today's instruments in the newest calibration laboratory. They did well on the few parameters that were checked.

It is concluded that portable health physics instruments have been successfully used at hanford as the main tools for surveillance of radioactive materials equipment, facilities, and people. Indeed, these instruments have always been the foundation of the Hanford radiation control program. 


\subsection{REFERENCES}

American National Standards Institute (ANSI). 1978. American National Standard Protection Instrumentation Test and Calibration. ANSI N323, New York.

American National Standards Institute (ANSI). 1988. Performance Specifications for Health Physics Instrumentation - Portable Instrumentation for Use in Normal Environmental Conditions. ANSI N42.17A-D9, New York.

Department of Energy. April 6, 1988 Draft, Radiation Protection for Occupational Workers. DOE 5480.1. Washington, D.C.

Evans, R. D. 1955. The Atomic Nucleus. McGraw-Hill Book Company, New York. Hughes, D. J., and R. B. Schwartz. 1958. Neutron Cross Sections. BNL-325, Brookhaven National Laboratory, Upton, New York.

International Commission on Radiation Units and Measurements (ICRU). 1980. Radiation Quantities and Units. ICRU Report 33, Washington, D.C.

International Electrotechnical Commission (IEC). 1970. Alpha, Beta and Alpha-Beta Contamination Meters and Monitors. IEC Publication 325, Geneva, Switzerland.

International Electrotechnical Commission (IEC). 1974. Portable X or Gama Radiation Exposure Rate Meters and Monitors for Use in Radiological Protection. IEC Publication 395, Geneva, Switzerland.

International Standards Office. 1983. Reference Beta Radiations for Calibrating Dosimeters and Dose Ratemeters and for Determining Their Response as a Function of Beta Radiation Energy. ISO 6980 , Geneva.

Nucleon Lectern Associates, Inc. 1970. The Radiological Health Handbook. 01 ney, Maryland.

Parker, H. M. 1950. "Tentative Dose Units for Mixed Radiations." Radiology $54(2): 257-261$. 


\section{DISTRIBUTION}

No. of

Copies

OFFSITE

2 DOE/Office of Scientific and Technical Information

H. W. DeHaven

2718 W. 7 th Street

Kennewick, WA 99336

M. L. Kress

1036 Winslow

Richland, WA 99352

L. V. Zuerner

1711 N. 16th Street

Pasco, WA 99301

\section{ONSITE}

6 DOE Richland Operations Dffice

D. L. Clark, A5-55

E. A. Erichsen, A5-55

D. T. Evans, A5-55

R. A. Holten, A5-55

J. J. Keating, A5-54

G. R. Yesberger, A5-55
No. of

Copies

6 Westinghouse Hanford Company

G. F. Boothe, R3-20

J. M. Garcia, $\times 0-04$

K. W. Gray, SO-02

R. E. Heineman, K6-31

J. B. Levine, XE-50

J. S, Patel, $\times 0-25$

29 Pacific Northwest Laboratory

C. D. Corbit (5), K3-56

D. M. Fleming, P7-01

L. G. Faust, K3-53

R. L. Kathren, $\mathrm{Hl}-01$

J. L. Kenoyer (10), P7-01

J. B. Martin, K3-56

F. E. Owen, P7-01

J. M. Selby, K3-53

K. L. Swinth, K3-55

Publishing Coordination

Technical Report Files (5) 
